\title{
Characterization of Alternative FBR Development Strategies
}

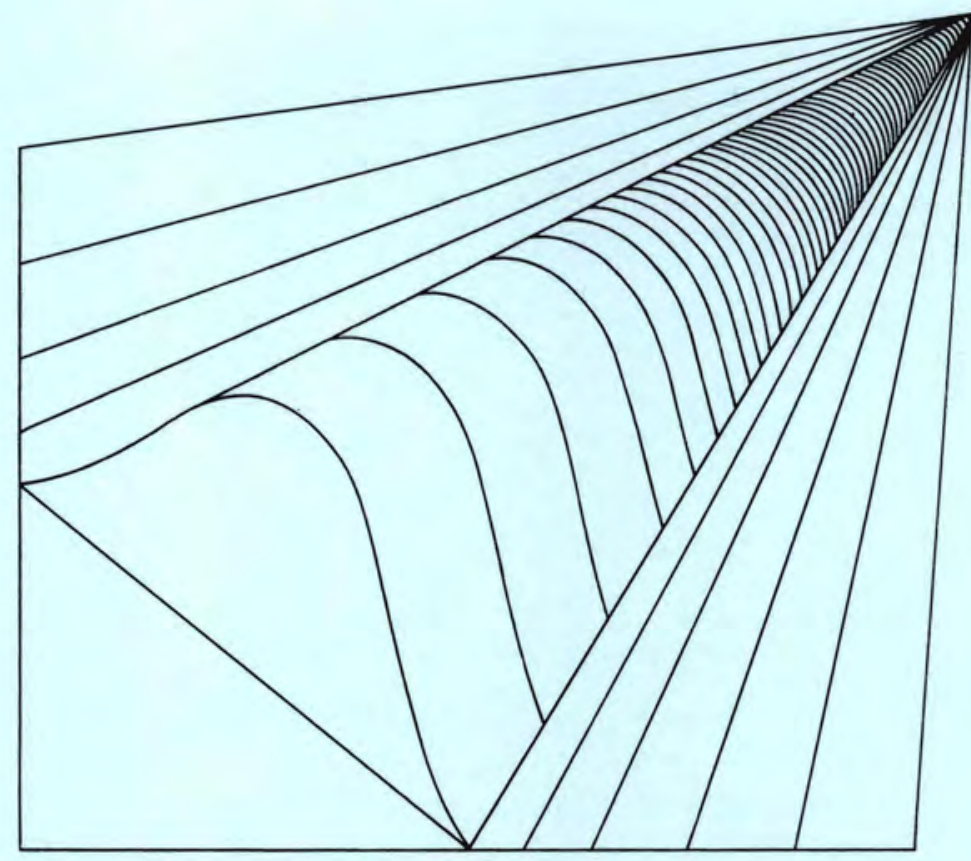

Prepared for the U.S. Department of Energy under Contract DE-AC06-76RLO 1830

Pacific Northwest Laboratory

Operated for the U.S. Department of Energy by Battelle Memorial Institute 


\title{
N O T I C E
}

This report was prepared as an account of work sponsored by the United States Government. Neither the United States nor the Department of Energy, nor any of their employees, nor any of their contractors, subcontractors, or their employees. makes any warranty. express or implied, or assumes any legal liability or responsibility for the accuracy, completeness or usefulness of any information, apparatus, product or process disclosed, or represents that its use would not infringe privately owned rights.

The views. opinions and conclusions contained in this report are those of the contractor and do not necessarily represent those of the United States Government or the United States Department of Energy.

\author{
PACIFIC NORTHWEST LABORATORY \\ operated by \\ BATTELLE \\ for the \\ UNITED STATES DEPARTMENT OF ENERGY \\ Under Contract DE-AC06-76RLO 1830
}

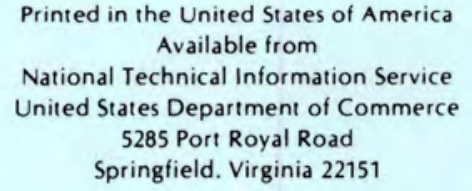

Price: Printed Copy $\$$ $\because$ Microfiche $\$ 3.00$

- Pages Selling Price

001-025 \$4.00

026-050 * \$4.50

051-075 \$5.25

076-100 \$6.00

$101-125 \quad \$ 6.50$

126-150 \$7.25

$151-175 \quad \$ 8.00$

$176-200 \quad \$ 9.00$

201-225 \$9.25

226-250 \$9.50

251-275 \$10.75

$276-300 \quad \$ 11.00$ 
PNL -3596

UC-2, 16,

51,78 ,

$79,79 i$

\section{2}

CHARACTERIZATION OF ALTERNATIVE FBR DEVELOPMENT STRATEGIES
A. J. Boege 1
M. J. Clausen

August 1981

Prepared for

the U.S. Department of Energy

under Contract DE-AC06-76RLO 1830

Pacific Northwest Laboratory

Richland, Washington 99352 


\section{CONTENTS}

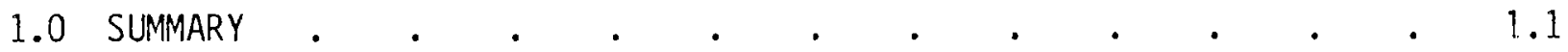

2.0 INTRODUCTION

3.0 DESCRIPTION OF ALTERNATIVE FBR DEVELOPMENT STRATEGIES $\quad$ • • $\quad 3.1$

3.1 FACTORS AFFECTING COST AND TIME UNCERTAINTIES $\quad \cdot \quad \cdot \quad \cdot \quad 3.1$

3.2 REACTOR PLANTS . . . . . . . . . . . . . . . 3.3

Developmental Plant. . . . . . . . . 3.3

Prototype Plant . . . . . . . . . . . . 3.4

Replicate Plants . . . . . . . . . . . . . 3.4

Commercial Breeder Reactor \#1 . $\quad . \quad$. $\quad . \quad$. $\quad . \quad 3.4$

3.3 STRATEGY DESCRIPTION . . . . . . . . . . . . 3.4

Strategy A: Sequential . . . . . . . . 3.5

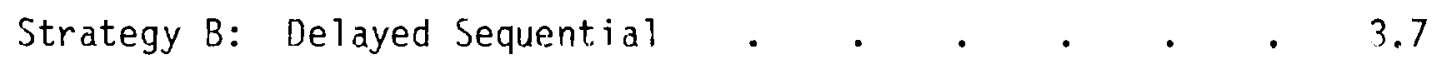

Strategy C: Compressed . . . . . . . . . . 3.8

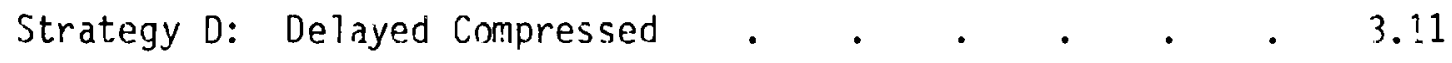

Strategy E: Component Testing . • • • • . . 3.12

Strategy F: Direct Prototype . . . . . . . 3.16

Strategy G: Direct Replicate . . . . . . . . 3.18

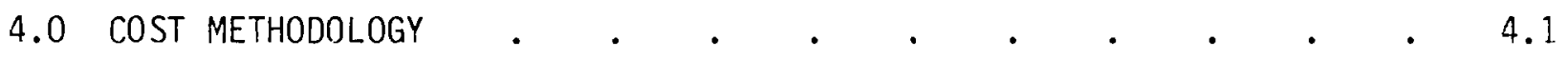

4.1 PLANT CAPITAL COSTS . $. \quad . \quad$. $\quad . \quad$. $\quad . \quad$. 4.1

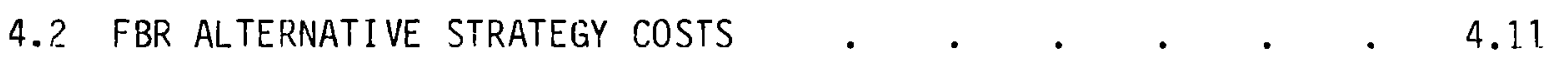

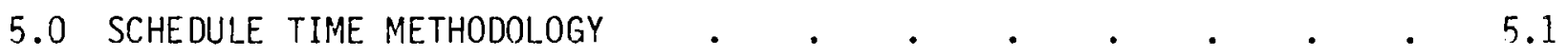

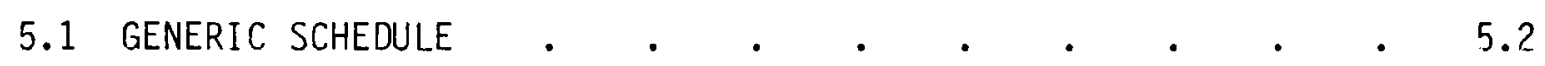

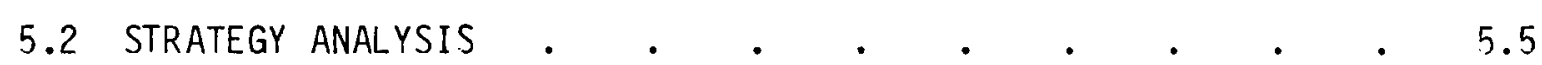


Strategy A: Sequential . . . . . . . . . 5.6

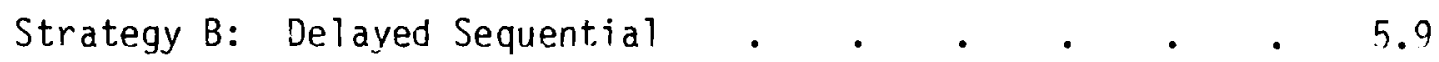

Strategy C: Compressed . . . . . . . . . 5.10

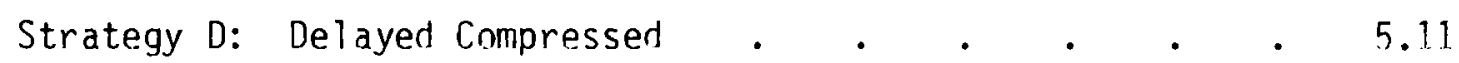

Strategy E: Component Testing . . . . . . 5.12

Strategy F: Direct Prototype . . . . . . . 5.13

Strategy $\mathfrak{F}_{\mathrm{a}}$ : Direct Replicate . . . . . . . 5.14

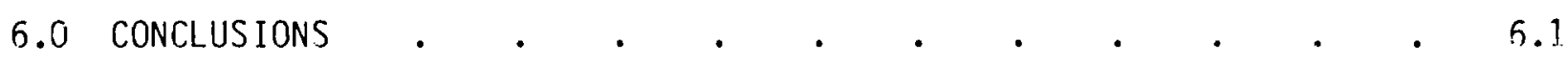

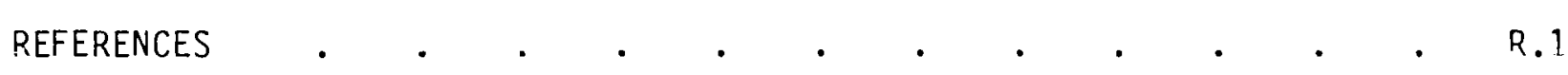

APPENDIX A - DERIVATION OF CAPITAL COST DISTRIBUTIONS $\quad$ - $\quad$ • $\quad$ • $\quad$ A.1

APPENDIX B - DEVELOPMENT OF STRATEGY TIME DISTRIBUTIONS $\quad$ • $\quad$ • $\quad$ • B.1 


\section{FIGURES}

3.1 Strategy A: Sequential .

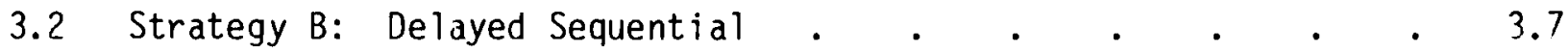

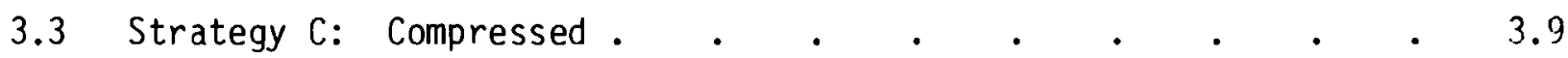

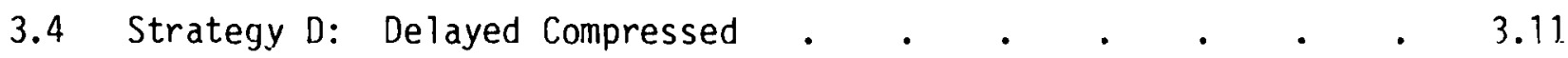

3.5 Strategy E: Component Testing . . . . . . . . . 3.13

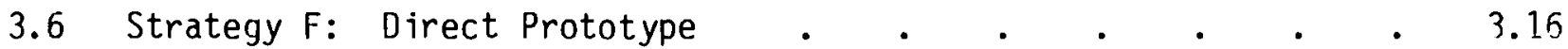

3.7 Strategy G: Direct Replicate . . . . . . . . 3.18

4.1 Capital Cost Estimates for Mature 1000-MW FBR . . . . 4.5

4.2 Capital Cost Estimates for Mature 1457-MW FBR $\quad$ • . . . . 4.7

4.3 Capital Cost Distribution for 1000-MW Commercial

4.4 Capital Cost Distribution for 1457-MW

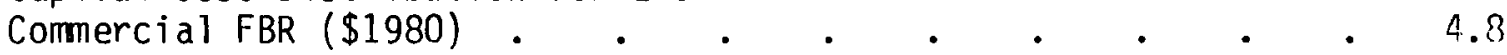

4.5 Cost Distribution for LWRs (\$1980) (Excludes Interest During Construction) $\quad . \quad . \quad . \quad . \quad . \quad . \quad . \quad . \quad . \quad 4.9$

4.6 FBR Capital Cost Reduction as a Function of Number
of Plants Built $. \quad . \quad . \quad . \quad . \quad . \quad . \quad . \quad . \quad 4.11$

4.7 Plant Capital Investment Expenditures vs. Time $\quad . \quad$. $\quad$ • 4.13

4.8 Assumed Government Support of Replicates $1-3 \quad$ • $\quad$ • $\quad$ • 4.15

4.9 Discounted Capital Cost Probability

Distribution for Sequential Strategy (A) . . . . . . 4.18

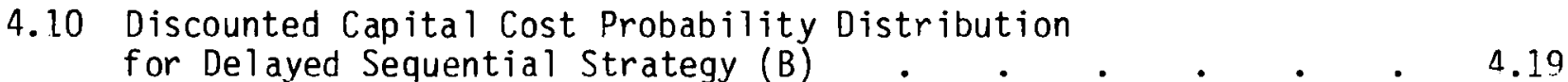

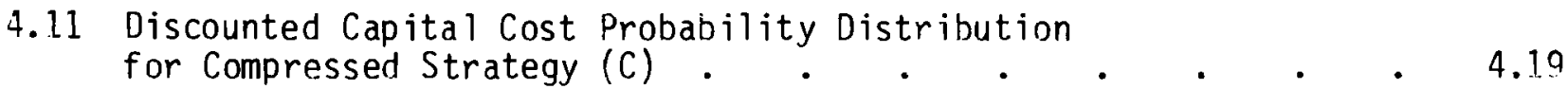

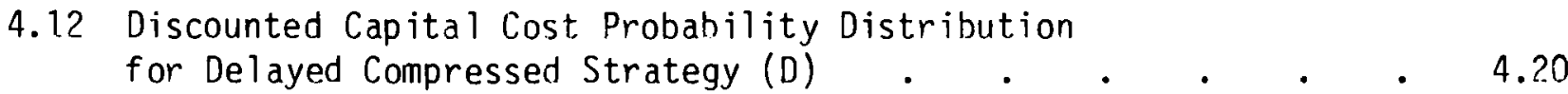

4.13 Discounted Capita] Cost Probability Distribution
for Component Testing Strategy (E) . $\quad . \quad$. . . . . 4.20 
4.14 Discounted Capital Cost Probability Distribution

for Direct Prototype Compressed Strategy (F) . . . . . 4.21

4.15 Discounted Capital Cost Probability Distribution

for Direct Replicate Strategy $(G)$. . . . . . . . 4 4.21

5.1 Generic Project Schedule . . . . . . . . . . 5.3

5.2 Primary Plant Linkage for Sequential Strategy A . . . . . $\quad 5.7$

5.3 Completion Time Probability Distribution for

Sequential Strategy A . . . . . . . . . . 5.8

5.4 Primary Plant Linkage for Delayed Sequential

5.5 Completion Time Probability Distribution for
Delayed Sequential Strategy B

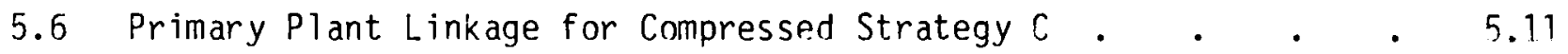

5.7 Completion Time Probability Distribution for
Compressed Strategy C . . . . . . . . . . . . . 5.1?

5.8 Primary Plant Linkage for Delayed Compressed

5.9 Completion Time Probability Distribution for

5.10 Primary Plant Linkage for Component
Testing Strategy E. . . . . . . . . . 5.15

5.11 Completion Time Probability Distribution for

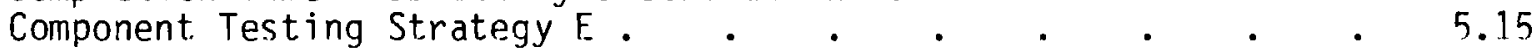

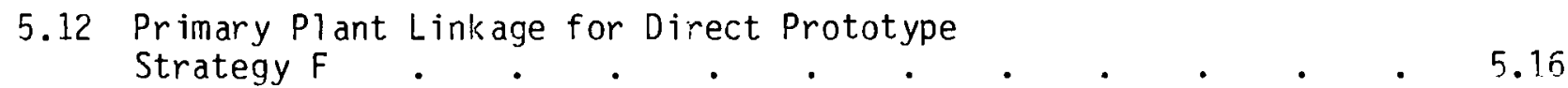

5.13 Completion Time Probability Distribution for

5.14 Primary Plant Linkage for Direct Replicate
Strategy G

5.15 Completion Time Probability Distribution for

Direct Replicate Strategy G . . . . . . . . . 5.18 


\section{TABLES}

1.1 Sumary of Alternative FBR Development Strategies . . . . 1.2

1.2 Net FBR Development Strategy Costs and Completion Times . . 1.3

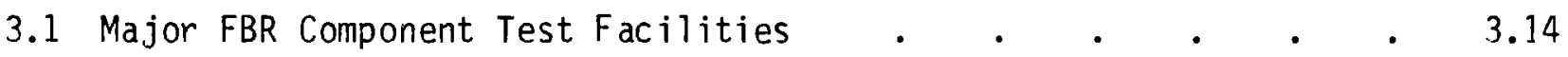

4.1 NUS-531 Cost Reporting Format . . . . . . . . . . . 4.?

4.2 Summary of Capital Cost Ranges . . . . . . . . . . . 4.3 



\subsection{SUMMARY}

A high degree of uncertainty characterizes the major factors that influence the selection of an approach and the timing for developing a fast Breeder Reactor (FBR) technology. Because an FBR development program necessarily involves the construction of a sequence of large power plants over many years, the duration and cost of the program are highly uncertain. Likewise, estimates of when FBR technology will be competitive with other central station power plant options are also uncertain. Because of these planning uncertainties, it is not possible to structure, with complete confidence, a development program that provides a mature technology exactly when economic forces establish market demand.

Despite these uncertainties, near-term decisions regarding the nature and pace of the FBR development program must be made. This study is part of a larger program designed to provide the Department of Energy (DOE) with information that can be used to make strategic programmatic decisions. The focus of this report is the description of alternative approaches for developing the FBR and the quantification of the duration and cost of each alternative. The time frames of the alternative approaches are investigated in companion reports (White 1981 and Fraley 1981). The results of these analyses will be described in a surmary report (Burnham et al. 1981). As part of this larger study, the objectives of this analysis are twofold:

1. define a comprehensive set of alternative strategies for developing and deploying FBR technology

2. quantify strategy costs, completion times, and their associated uncertainties.

Seven alternative strategies for developing the FBR have been defined to assist DOE in a selection of a preferred development strategy for the IJ.S. FBR program. Each strategy is characterized as a succession of FBRs ultimately leading to the first commercial breeder reactor (CBR-1). The selected strategies were designed to study the full range of timing, cost, and their associated uncertainties. The reference strategies, which are summarized in Table 1.1, range from a minimum completion time of 28 years (Direct Prototype 
TABLE 1.1. Sumary of Alternative FBR Deve lopment Strategies

FBR Development Strategy

Strategy A
Sequential
Strategy B
Delayed Sequential
Strategy C
Compressed
Strategy D
Delayed Compressed
Strategy E
Component Testing
Strategy F
Direct Prototype
Strategy G
Direct Rep licate

FBR Facilities Composing Each Strategy

\begin{tabular}{|c|c|c|c|}
\hline $\begin{array}{l}\text { Development } \\
\text { Plant (1000 MW })\end{array}$ & $\begin{array}{l}\text { Prototype } \\
(1457 \mathrm{MW})\end{array}$ & $\begin{array}{l}\text { Replicates } 1-3 \\
(1457 \mathrm{MW})\end{array}$ & $\begin{array}{l}\text { CBR-1 } \\
\quad(1457 \mathrm{MW})\end{array}$ \\
\hline $\begin{array}{l}\text { Deve lopment } \\
\text { Plant }(1000 \mathrm{MW})\end{array}$ & $\begin{array}{l}\text { Protoype } \\
(1457 \mathrm{MW})\end{array}$ & $\begin{array}{l}\text { Replicates } 1-3 \\
(1457 \mathrm{MW})\end{array}$ & $\begin{array}{l}\text { CBR-1 } \\
(1457 \mathrm{MW})\end{array}$ \\
\hline $\begin{array}{l}\text { Deve lopment } \\
\text { Plant }(1000 \mathrm{MW})\end{array}$ & $\begin{array}{l}\text { Prototype } \\
(1457 \mathrm{MW})\end{array}$ & $\begin{array}{l}\text { Rep } 1 \text { icates } 1-3 \\
(1457 \mathrm{MW})\end{array}$ & $\begin{array}{l}\text { CBR-1 } \\
(1457 \mathrm{MW})\end{array}$ \\
\hline $\begin{array}{l}\text { Deve lopment } \\
\text { Plant }(1000 \mathrm{MW})\end{array}$ & $\begin{array}{l}\text { Protot ype } \\
(1457 \mathrm{MW})\end{array}$ & $\begin{array}{l}\text { Rep } 1 \text { icates } 1-3 \\
(1457 \mathrm{MW})\end{array}$ & $\begin{array}{l}\text { CBR-1 } \\
(1457 \mathrm{MW})\end{array}$ \\
\hline $\begin{array}{l}\text { Component Testing } \\
\text { (10 years) }\end{array}$ & $\begin{array}{l}\text { Protot ype } \\
(1000 \mathrm{MW})\end{array}$ & $\begin{array}{l}\text { Rep licates } 1-3 \\
(1000 \mathrm{MW})\end{array}$ & $\begin{array}{l}\text { CBR-1 } \\
(1000 \mathrm{MW})\end{array}$ \\
\hline $\begin{array}{l}\text { Protot ype } \\
(1000 \mathrm{MW})\end{array}$ & $\begin{array}{l}\text { Replicates } 1-3 \\
\quad(1000 \mathrm{MW})\end{array}$ & $\begin{array}{l}\text { CBR-1 } \\
(1000 \mathrm{MW})\end{array}$ & \\
\hline $\begin{array}{c}\text { Developmental } \\
(1000 \mathrm{MW})\end{array}$ & $\begin{array}{l}\text { Replicates } 1-3 \\
(1000 \mathrm{MW})\end{array}$ & $\begin{array}{l}\text { CBR-1 } \\
(1000 \mathrm{MW})\end{array}$ & \\
\hline
\end{tabular}

Strategy) to an expected maximum completion time of 50 years (Delaved Sequential Strategy). All strategies were assumed to be ultimately successful, with the principal differentiating characteristics being cost and time.

The costs and completion times of the alternative FBR strategies were probabilistically quantified. Strategy costs include plant capital costs, fuel cycle costs, operation and maintenance costs, hase technology costs, and any government warranties that might be offered to early plants not yet at economic parity with light water reactors (LWRS). Estimates of capital costs for this analysis were provided by DOE's Reactor Research and Technology Division and reactor manufacturers and architect/ engineers of the Conceptual Design Study (CDS) team. DOE's capital cost estimates were fit to probability density functions and then combined with the other strategy costs to express the total cost probability distribution for each strategy.

As a result of interviews with nuclear plant scheduling experts, time distributions were then developed for each major activity in the construction sequence of each plant in each strategy. These activity distributions were 
then sumed with the network model QGERT to give a single completion distribution that probabilistically defines the total duration of a given strategy. Table 1.2 illustrates the total net costs (\$1980) and completion times for each strategy. Since the plants will generate power which will be sold, considerable revenues will be generated. Negative signs indicate a net revenue to the government. However, when programmatic cash flows are discounted at $5 \%$, the expected net costs of $-\$ 13$ to $-\$ 0.5$ billion become net costs of $\$ 2.5$ to $\$ 4.4$ billion, respectively; this reflects the fact that the power sales revenues substantially lag expenditures, as would be expected. Note that the strategies cover a range of 24 to 55 years with a net cost range of 0.6 to -14.8 billion dollars.

TABLE 1.2. Net FBR Deve lopment Strategy Costs and Completion Times

FBR Development Strategy$$
\text { A }
$$

B

$C$

D

E

$\mathrm{F}$

G

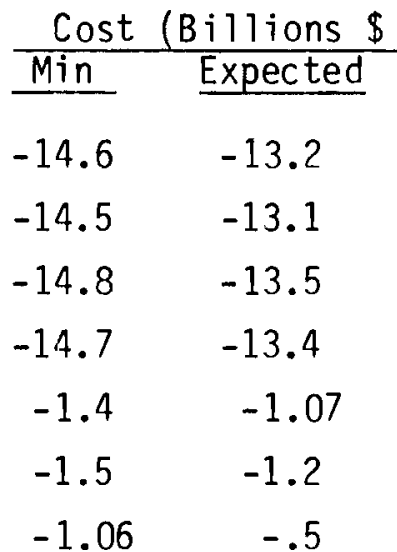

Max

Max

$-10.8$

$-10.7$

$-11.3$

$-11.134$

$-.52 \quad 34$

$-.58 \quad 24$

$.57 \quad 25.3$
Completion Time (Years) Min Expected Max

$40.8 \quad 45$

50

33

38

37

28

29
50.3

55.4

37.8

42.8

42

32

33.2 



\subsection{INTRODUCTION}

The National Energy Plan (Executive Office 1977) established the first comprehensive energy policy of the United States and provided three basic objectives:

"as an immediate objective that will become even more important in the future, to reduce dependence on foreign oil and vulnerability to supply interruptions"

"in the medium term, to keep United States imports sufficiently low to weather the period when world oil production approaches its capacity limitations"

"in the long term, to have renewable and essentially inexhaustible sources of energy for sustained economic growth."

In the near term, coal and uranium must supply the electrical needs of the United States. The NEP stresses the need for technical improvements in coal and light water reactor (LWR) technologies. In the LWR case, improved designs, advanced isotope separation technology, advanced fuel management, and other improvements are being studied.

The present fission energy policy maintains the FBR option through an integrated, cohesive research and development program. The basic objective of this program is to develop a broad technological and engineering hase with extensive utility and industrial involvement, which could be used to establish a competitive, commercial FBR industry. Development is now centered on the Conceptual Design Study (CDS), which will produce a design for a 1000-MW research and development plant. The design was completed in March 1981. This analys is focuses on identifying alternative strategies for FBR development and implementation costs to the government heginning in fiscal year 1981. The objectives of this study are twofold:

1. define a comprehensive set of alternative FBR development strategies

2. quantify strategy costs, completion times, and their associated uncertainties. 
To meet the first objective, seven alternative strategies have been defined that relate FBR commercialization to component development, testing, and plant experience. The selected list of strategies was designed to comprehensively cover the range of available options without being exhaustive.

The second objective is to quantify strategy costs to the government, strategy completion times, and their respective uncertainties. Government costs during the development phase include plant capital costs, fuel cycie costs, operation and maintenance (O\&M) costs, base technology costs, an assumed amount of government support provided to the utilities for plants not. at parity with LWRs, and credit for the sale of power.

This study is part of a larger program which is designed to provide DOE with information to formulate a rational plan for the development of the FBR. Data from this study will be combined with that of other studies (Piepel et a1. 1981; White and Merri11 1981) in a decision model (Fraley 1981). The decision model will reduce probabilistic data to metrics, which can be combined to rank strategies in several different ways.

Chapter 3 provides detailed description of the strategies. Chapter 4 describes the methodology used to develop strategy costs. Chapter 5 discusses the strategy completion time probability distributions. Chapter 6 contains the general conclusions of this analysis, followed by a detailed discussion of strategy cost and completion time in Appendices $A$ and $B$, respectively. 


\subsection{DESCRIPTION OF ALTERNATIVE FBR DEVELOPMENT STRATEGIES}

This chapter describes seven alternative strategies for commercial FBR deployment. Each strategy is characterized as a succession of FBR plants ultimately leading to the first commercial breeder reactor (CBR-1). The relative timing and in some cases the number of precommercial FBRs are varied to form seven representative strategies. To accurately quantify tradeoffs among different development strategies, an identical endpoint was selected for each. Based on a series of interviews with reactor manufacturers and architectengineers, the fifth-of-a-kind FBR (CBR-1) was selected as the endpoint for each strategy. This plant represents the point where any government financial participation in commercial FBR development ceases, and where utilities assume total financial responsibility for commercial FBR deployment. The commercial buildup of FBRs beyond CBR-1 was not considered in this analysis. Completion of CBR-1 was assumed to mark the time at which an accelerated FBR commercialization program could begin. Since electric utilities are the ultimate FBR market, they and the rest of the nuclear industry will eventually take full responsibility for commercial application, while the role of the government would decrease to that of supporting research and development for safety, advanced concepts, and design improvements. Thus, financing of FBRs will be evolutionary, progressing from near total government financing and participation in the developmental phase, to a competitive, commercial industry. It is not clear how the transition will be made between government and industry financing in the FBR's development. For calculational purposes it was necessary to make certain assumptions which are described in detail later in this chapter.

\subsection{FACTORS AFFECTING COST AND TIME UNCERTAINTIES}

This analysis attempts to quantify two key uncertainties that are associated with each development strategy: 1) uncertainty in strategy development cost, and 2) uncertainty in completion time for a given strategy. Factors related to these uncertainties are described below and each development strategy is then described in terms of these factors. 
Scale-Up. Scaling up to a commercially competitive size (1000 or 1457 MWe) contributes to cost and time uncertainties. Generally, the greater the scaling, the more the uncertainty. Primary contributors to uncertainty are additional engineering requirements to accomplish the scale-up and additional licensing requirements of larger-sized plants.

Operating Experience. Plant operating experience includes not only fabrication, and installation, but also operability, maintainability and inspectability of the plant systems and components. Incorporating this experience into a follow-on plant's design reduces the technical uncertainties of the second plant and, potentially, its costs. The uncertainties of licensing a follow-on plant are also decreased by sufficient accumulation of operating experience in the previous plant.

Personnel Retention. Too large a delay between succeeding plants may result in a possible breakdown in the infrastructure of skilled design, construction, licensing, and managerial personnel, reducing the potential for a transfer of experience from one plant to the next. The need to train new personnel for the design and licensing of follow-on plants increases cost and time and their associated uncertainties.

Licensing. The principal critical path activity for plant completion with a non-federal construction schedule is licensing. Prototype FBR licensing before commercial FBR construction reduces cost and time uncertainties. Incorporating operating experience from a preceding plant into the design of a commercial plant and maintenance of a staff of skilled licensing personnel will both decrease licensing uncertainties.

Component Testing. Components for pre-commercial FBRs will be fully tested prior to installation. Cost and time uncertainties can be reduced if sufficient time is allowed to complete the testing program and recover from any problems. This is particularly important for strategies where authorization to proceed for one plant is dependent on completion of the preceding plant's testing program.

Data Transfer. During FBR design and construction all activities leading to $\mathrm{plant}$ operation will be fully documented. These documents include Preliminary Safety Analysis Report (PSAR), Final Safety Analys is Report (FSAR), 
Environmental Impact Statement (EIS), Regulatory Guides, analytic code documentation and component operation manuals. Use of this documentation in follow-on plant design and construction can reduce cost and time uncertainties.

Vendor Commitment. An intensive FBR program provides an incentive for reactor manufacturers to staff up and commit significant resources to the design and operation of several FBRs built in rapid successinn. High personnel retention would result from this intensive program and the environment would be improved for training new personnel and reducing cost and time uncertainties. However, a large delay between design and construction of successive plants would result in attrition of skilled personnel and reactor manufacturers would not commit as much of their resources to the program. Therefore, uncertainties could increase with decreasing vendor commitment.

Utility Commitment. Before utilities commit financial resources to building commercial FBRs, they will evaluate the FBR concept technically and economically. A primary concern to utilities will be evaluation of the plant. capacity factor, which requires operation of an FBR. Without operation of an FBR and proof of licensing, the utilities' financial commitment to the FBR concept becomes very uncertain.

\subsection{REACTOR PLANTS}

To avoid unnecessary repetition a brief description of the FBR plants that comprise each strategy is given below.

Deve lopmenta l Plant

The developmental plant (CDS) will serve as the transition between base technology development, Fast Flux Test Facility (FFTF) and Clinch River Breeder Reactor (CRBR) design experience, and full-scale commercial utilization. This plant is assumed to be the first large-sized FBR in Strategies A, B, C, D, and $G$ and will be a federal project, built on a federal reservation, and totally financed by the government. Objectives of the CDS plant are to 1) incorporate FFTF and CRBR experience, 2) serve as a focus for the FBR Base Technology Program, and 3) provide a logical step toward commercial FBR deployment. The CDS will be a 4-1oop 1000-MWe plant and will operate with superheated steam conditions. The plant will be designed and built to meet or exceed ASME, IEEE, and 
ANSI requirements, NRC regulations, and other applicable codes. The plant will be licensable but not formally licensed, that is, the plant will receive a complete licensing review but no public hearings will be held.

Prototype Plant

The prototype will demonstrate the technical feasibility and economics of full-scale FBR technology. This facility will be completely licensed. It is a subject of speculation at what point industry will take over FBR development. For this study it is assumed that the prototype, like the developmental plant, is a federal project which will supply electrical energy to a utility grid.

\section{Replicate Plants}

These three plants will be of the same design as the preceding prototype plant but will be utility owned and operated. Each replicate plant, however, will be an improved version due to the knowledge gained from the prototype's design, construction and licensing. Utility financing of the replicate series is assumed in this analysis, with a warranty from the government that these plants will generate electricity at a cost no greater than an LWR built in the same year. Chapter 4 describes this in more detail.

Commercial Breeder Reactor \#1

This plant represents the first mature, commercial FBR (CBR-1) with full utility financing and no government support. As mentioned earlier, the start of operation of this facility marks the endpoint of each strategy.

\subsection{STRATEGY DESCRIPTION}

It is assumed that the development of a commercial FBR can be completed using any of the alternative strategies; each having different cost and time uncertainties.

In this section each strategy is described in terms of the factors affecting cost and time uncertainties. Plant to plant linkages within each strategy will be briefly discussed. For reference, Figures 3.1 through 3.7 graphically depict the relative timing of each strategy. 
Strategy A: Sequential

This approach to commercial FBR deployment factors a large degree of plant operating experience into the design of each succeeding plant (Figure 3.1). It is assumed that one year of developmental plant operation is required before congressional authorization will be granted for the prototype. Similarly, the NSSS for replicate 1 will not be awarded until the prototype has operated for 1 year.

\section{Discussion}

This type of plant alignment enhances transfer of design and operating experience to successive plants. The tradeoff, however, is that the lag time between plants could result in the demobilization of skilled licensing, design, and managerial personnel. Based on interviews with industry, it was learned that the average length of time that an engineer would work on a design project is roughly 3 years; the duration between design or licensing projects in this strategy would be almost 8 years.

\section{Cost and Time Uncertainties}

- scale-up - Uncertainty includes scaling a 1000-MW plant to $1457 \mathrm{MW}$.

- operating experience - The availability of operating experience for incorporation into successive plant design tends to reduce uncertainty.

- personnel retention - Attrition of skilled personnel as a result of large delays between design and construction of successive plants tends to increase uncertainty.

- licensing - Licensing uncertainties tend to be reduced as more time is available to develop criteria and operating experience. The tradeoff, however, is the potential attrition of skilled licensing personnel within NRC, which would tend to increase uncertainties.

- component testing - Sufficient time should be available to complete testing programs and resolve problems, which would tend to reduce cost and time uncertainties. 


\section{PROTOTYPE PLANT(1457 MWe)}

REPLICATE NO. 1(1457 MWe)

\section{PRINCIPAL FEATURES}

INCORPORATE DESIGN, CONSTRUCTION AND OPERATING EXPERIENCE FROM PRECEDING PLANTS INTO DESIGN OF SUCCESSIVE PLANTS

\section{REPLICATE NO. 2 (1457 MWe)}

REPLICATE NO. 3 (1457 MWe)

TIMING: ONE YEAR OF FULL POWER OPERATION BEFORE COMMITIING TO THE FOLLOWING PLANT

EXPECTED TIME FOR COMPLETION: 45 YEARS

\section{FIGURE 3.1. Strategy A: Sequential}

- data transfer - Cost and time uncertainties tend to be reduced because sufficient time is available to collect, record, and incorporate design, licensing, and operating data into future designs.

- vendor commitment - The long duration between plants forces vendors to maintain a low-level of participation, which tends to increase cost and time uncertainties.

- utility commitment - Ample time is available for a utility to technically and economically evaluate the FBR concept, which tends to reduce the uncertainty in a utilities decision to commit to FBR deployment. 
Strategy B: Delayed Sequential

This approach is the same as Strategy A except that the decision to build the developmental plant is delayed 5 years to account for a perceived lack of urgency in the demand for the FBR (Figure 3.2). Plant alignment remains the same as the Sequential Strategy.

\section{Discussion}

The 5-year delay before starting the developmental plant would increase the likelihood of losing some skilled personnel before the FBR development phase ever began. At the start of the development phase, 5 years later, retraining new personnel would be required, potentially increasing the cost and time for this plan as compared to Strategy $A$.

Cost and Time Uncertainties

- scale-up - Uncertainties are the same as the Sequential Strategy.

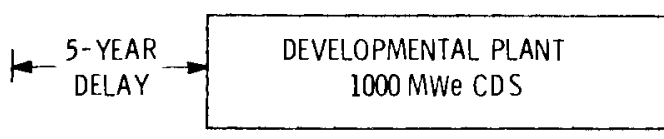

PROTOTYPE PLANT(1457 MWe)

PRINCIPAL FEATURES

SAME AS STRATEGY A WITH 5-YEAR DELAY

EXPECTED TIME FOR COMPLETION: 50 YEARS
REPLICATE NO. 1 (1457 MWe)

REPLICATE NO. 2 (1457 MWe)

REPLICATE NO. 3 (1457 MWe)

CBR- 1 (1457 MWe)

FIGURE 3.2. Strategy B: Delayed Sequential 
- operating experience - Uncertainties are the same as the Sequential Strategy.

- personnel retention - With a 5-year delay before starting the developmental plant, additional attrition of experienced reactor personnel could occur, which would increase cost and time uncertainties.

- licensing - Uncertainties are the same as the Sequential Strategy.

- component testing - If nothing were done for 5 years, the component testing industry would suffer the same attrition of experienced personnel and a possible degradation of equipment, resulting in increased cost and time uncertainties.

- data transfer - Uncertainties are the same as the Sequential Strategy.

- vendor commitment - Again, attrition of experienced personnel within the reactor manufacturer industry would increase cost and time uncertainties.

- utility commitment - Uncertainties are about the same as the Sequential Strategy.

Strategy C: Compressed

Using the same types and sizes of FBRs as the Sequential Strategy, the Compressed Strategy would accelerate commercial FBR deployment by providing an overlap in time between plants (Figure 3.3).

\section{Discussion}

Once components for the developmental plant are tested (about 4 years from authorization to proceed), the NSSS for the prototype will be awarded. The significant overlap between these two plants would help to maintain a skilled staff of licensing and design personnel. However, transfer of operating experience is minimal between these two plants since prototype design is completed at about the same time that the developmental plant is ready for ascent to power. 
DEVELOPMENTAL PLANT(1000 MWe)

PROTOTYPE PLANT(1457 MWe)

REPLICATE NO. 1(1457 MWe)

REPLICATE NO. 2 (1457 MWe)

REPLICATE N0. 3 (1457 MWe)

CBR-1 (1457 MWe)

\section{PRINCIPAL FEATURES}

ACCELERATE DEPLOYMENT OF CBR-I BY INCREASING THE SCHEDULED OVERLAP BETWEEN PLANTS

TIMING: COMPLETION OF COMPONENT TESTING FOR CDS BEFORE COMMITTING TO PROTOTYPE. COMMIT TO REPLICATE NO. I WHEN THE OPERATING LICEN SE FOR THE PROTOTYPE HAS BEEN ISSUED

EXPECTED TIME FOR COMPLETION: 33 YEARS

\section{FIGURE 3.3. Strategy C: Compressed}

Replicate 1 is committed when the prototype receives an operating license, which allows time for the utilities to observe the full licensing process on a plant similar to the one they will be commissioning.

Cost and Time Uncertainties

- scale-up - Uncertainties have the same impact as the Sequential Strategy.

- operating experierce - The lack of operating experience to factor into the design of the prototype plant increases cost and time 
uncertainties. Relative to the Sequential Strategy, less operating experience is also available to incorporate into the design of replicate 1 .

- personnel retention - The overlap between FBRs in this strategy increases the proportion of skilled personnel transferring from one plant to the next. Along with their developed skills, they would bring the experience of having worked on a similar plant, which would decrease cost and time uncertainties.

- licensing - Retention of a skilled licensing staff would decrease licensing uncertainties. However, the lack of operating experience would increase the uncertainties of licensing an FBR.

- component testing - Linking the CDS plant and the prototype plant to the completion of the CDS plant's component testing program increases cost and time uncertainties of component testing and ultimately the entire strategy. Any major problems encountered in the testing program could conceivably delay the start of the prototype plant.

- data transfer - Insufficient time to collect, record, and completely incorporate design, licensing, and operating data from the developmental plant increases cost and time uncertainties for the prototype. There is, however, sufficient time to transfer design, licensing, and construction data to replicate 1 , which tends to reduce cost and time uncertainties in that plant.

- vendor commitment - The rate at which plants are ordered increases reactor manufacturers' participation and reduces cost and time uncertainties.

- utility commitment - With this strategy utilities have less time to technically and economically evaluate the FBR concept, which increases the uncertainties associated with a utility's decision to commit to replicate 1 . 
Strategy D: Delayed Compressed

The only difference between this strategy and Strategy $C$ is the 5-year deferral of developmental plant construction. Beyond that, the relative timing of FBR plants is identical (Figure 3.4).

\section{Discussion}

The 5-year delay has the same impact on this strategy as it does on the Delayed Sequential Strategy. The attrition of skilled personnel before starting the development phase will tend to make the cost and time uncertainties larger. One advantage of this strategy is the potential of recovering from a personnel loss in the initial stages of FBR development. This results from the overlap between the developmental and prototype plants. Once the process of retraining the engineering teams for work on the developmental plant is

TIME

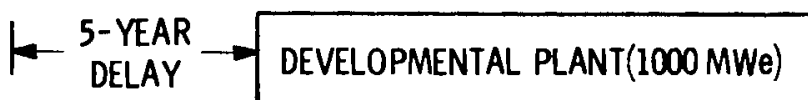

PROTOTYPE PLANT(1457 MWe)

REPLICAIE NO. l(1457 MWe)

PRINCIPAL FEATURES

SAME AS STRATEGY C WITH 5-YEAR DELAY

EXPECTED TIME FOR COMPLETION: 38 YEARS

REPLICATE NO. 2 (1457 MWe)

REPLICATE NO. 3 (1457 MWe)

CBR-1 (1457 MWe)

FIGUPE 3.4. Strategy D: Delayed Compressed 
completed, a significant proportion of those same people will be available for work on the prototype plant. This overlap would tend to reduce costs and time of completion and their respective uncertainties.

Cost and Time Uncertainties

- scale-up - Uncertainties are the same as the Compressed Strategy.

- operating experience - Uncertainties are the same as the Compressed Strategy.

- personnel retention - Delaying the start of the developmental plant 5 years could cause attrition of experienced personnel, which would make cost and time uncertainties larger.

- licensing - Attrition of licensing staff at NRC would increase cost and time uncertainties.

- component testing - If nothing is done for 5 years, the component testing industry would suffer from attrition and possible degradation of equipment, which would increase cost and time uncertainties.

- data transfer - Uncertainties are the same as the Comprissed Strategy.

- vendor commitment - Again, the personnel attrition within the FBR industry would increase cost and time uncertainties.

- utility commitment - Uncertainties are about the same as the Compressed Strategy.

\section{Strategy E: Component Testing}

As a substitute for construction and operation of the developmental plant (CDS), this strategy opts for an intensive and deliberate component testing program (Figure 3.5). The duration of component testing for this analysis was arbitrarily selected as 10 years. Durations of less or greater than 10 years are certainly plausible and within the scope of this study for quantitative analys is. 


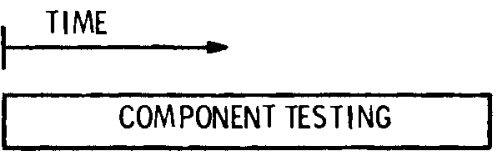

PROTOTYPE PLANT (1000 MWe)

REPLICATE NO. I (1000 MWe)

REPLICATE NO. $2(1000 \mathrm{MWe})$

REPLICATE NO. $3(1000 \mathrm{MWe})$

CBR-1 (1000 MWe)

PRINCIPAL FEATURES

SUBSTITUTE AN INTENSIVE AND DELIBERATE COMPONENT TESTING

PROGRAM FOR CONSTRUCTI ON OF DEVELOPMENTAL PLANT

TIMING: FOLLOWING 10 YEARS OF COMPONENT TESTING, AUTHORIZE START OF PROTOTYPE. COMMIT TO

REPLICATE \#I WHEN OPERATING LICENSE FOR

PROTOTYPE HAS BEEN ISSUED.

EXPECTED TIME FOR COMPLETYON: 37 YEARS

\section{FIGURE 3.5. Strategy E: Component Testing}

\section{Discussion}

The major FBR component test facilities are listed in Table 3.1. As can be seen, upgrading several of these facilities would be required to test the components for a 1000 -MWe gross $\left(2520 \mathrm{MW}_{t}\right)$ FBR. In addition to upgrading existing facilities, it would be necessary to construct a new facility that would have the capability of testing full scale integrated systems performance. A facility of this type, the plant component test facility (PCTF), has been proposed and would evaluate integrated performance of heat transfer components for the prototype plant. During the testing period, individual component as well as integrated component systems performance data would be collected to form the basis for final design of the prototype plant components. 
TABLE 3.1. Major FBR Component Test Facilities

\begin{tabular}{|c|c|c|}
\hline Test Facility & System/Component & Rating \\
\hline $\begin{array}{l}\text { Sodium Components } \\
\text { Test Installation } \\
\text { (SCTI) }\end{array}$ & $\begin{array}{l}\text { Steam Generators \& } \\
\text { Intermediate Heat } \\
\text { Exchangers }\end{array}$ & $\begin{array}{l}35 M W_{t} \\
\left(318 M W_{t}\right)(a)\end{array}$ \\
\hline $\begin{array}{l}\text { Sodium Pump } \\
\text { Test Facility } \\
\text { (SPTF) }\end{array}$ & Pumps & $\begin{array}{l}20000 \mathrm{gpm} \\
(60000 \mathrm{gpm})(\mathrm{a})\end{array}$ \\
\hline $\begin{array}{l}\text { Sodium Components } \\
\text { Test Loop } \\
\text { (SCTL) }\end{array}$ & $\begin{array}{l}\text { Instruments and } \\
\text { Values }\end{array}$ & $3500 \mathrm{gpm}$ \\
\hline $\begin{array}{l}\text { Stearn Generator } \\
\text { Test Rig } \\
\text { (SGTR) }\end{array}$ & Steam Generators & $\left.{ }_{(318}^{2 M W_{t}} M W_{t}\right)(a)$ \\
\hline $\begin{array}{l}\text { High Temperature } \\
\text { Sodium Facility }\end{array}$ & Core Internals & Static \\
\hline
\end{tabular}

(a) Values for 1000 MWe FBR

An intensive component testing program would be required to prevent demobilization of FBR personnel and abandonment of fabrication facilities.

Plant scaling uncertainties are reduced with this strategy. The expeditious route to commercial FBR deployment with the 10-year "delay" is by direct replication. The basic 1000-MWe CDS design, without the testing and diagnostic equipment necessary for a developmental plant, would be used for the prototype plant. The prototype plant will be completely licensed and will then be replicated through CBR-1. The NSSS for replicate 1 will be awarded when the prototype's operating license has been granted. This assures the utilities that the replicate plants are licensable and that the regulatory system is firmly established to license additional FBRs.

Cost and Time Uncertainties

- scale-up - Minimal scale-up is performed with this strategy. 
- operating experience - This strategy affords no operating experience to factor into the design of replicate 1, which increases cost and time uncertainties.

- personnel retention - During the 10 years of component testing, a sma 11 number of FBR design personnel, predominantly those familiar with the individual components, will be retained. As a result, more uncertainty will be associated with having enough design and licensing personnel available to begin work on the prototype and complete it in 12 years. From the prototype to replicate 1, cost and time uncertainties will be reduced since the overlap enhances retention of skilled personnel.

- licensing - During the 10-year component testing program, a larger uncertainty will be associated with licensing the prototype plant due to attrition of licensing personnel, lack of licensing activities, and no plant design, construction, and testing prior to the prototype.

- component testing - Intensive component testing for the prototype plant reduces performance uncertainties and since replicate 1 is the same size as the prototype, the components will be similar.

- data transfer - No large plant design and operating data would be accumulated during the 10-year testing program. This lack of data available for incorporation into the prototype design increases its cost and time uncertainties. However, the extensive amount of data collected during component testing will be factored into the prototype design, which reduces component performance uncertainties.

- vendor commitment - The intensive component testing program will keep reactor manufacturers at a modest participation level in FBR design. This low participation level without the opportunity to work on a large FBR increases cost and time uncertainties.

- utility commitment - The lack of operating experience will increase uncertainties associated with a utility's decision to commit to replicate 1 . 
Strategy F: Direct Prototype

Neither integrated plant demonstration nor extended component testing (Strategy E) are assumed for this strategy (Figure 3.6). The technology for immediate prototype plant design and construction is assumed to be already in place. The prototype is of the same design as the prototype in Strategy E.

\section{Discussion}

As in Strategy $E$, the prototype plant will be completely licensed. The NSSS for replicate 1 is awarded after the prototype receives its operating license. Here again, the entire sequence of FBR licensing is demonstrated to TIME

$$
\text { PROTOTYPE PLANT (1000 MWe) }
$$

REPLICATE NO. 1 (1000 MWe)

REPLICATE NO. $2(1000 \mathrm{MWe})$

REPLICATE NO. $3(1000 \mathrm{MWe})$

CBR-1 (1000 MWe)

PRINCIPAL FEATURES

INTEGRATED PLANT DEMONSTRATION IS NOT REQUIRED ASSUMING

THAT THE TECHNOLOGY FOR THE PROTOTYPE PLANT IS ALREADY IN

PLACE

TIMING: COMMIT TO REPLICATE II WHEN OPERATING LICENSE FOR THE PROTOTYPE HAS BEEN ISSUED

EXPECTED TIME FOR COMPLETION: 28 YEARS

FIGURE 3.6. Strategy F: Direct Prototype 
the utilities before they commit to replicate 1. However, no large plant. operating experience will be available to be factored into the prototype's design, and a minimal amount of operating experience available for the design of replicate 1, which would tend to increase strategy cost and time uncertainties to the point. where utilities would not commit until the prototype has operated for one year.

Cost and Time Uncertainties

- scale-up - Minimal scale-up is associated with this strategy.

- operating experience - With a minimal amount of operating experience available to be factored into the design of replicate 1 and no large plant operating experience to be factored into the design of the prototype, the cost and time uncertainties are increased.

- personnel retention - With a firm commitment to develop a commercial FBR at an accelerated rate and with the overlap of the prototype and replicate 1 somewhat compressed, personnel retention will be higher, thereby reducing cost and time uncertainties.

- licensing - With no licensing experience to draw upon, and a lack of fully developed licensing criteria, the uncertainties of prototype licensing will be increased.

- component testing - Sufficient time is available for correction of any delays or problems in testing prototype components. Once tested and verified, these components will be similar to components used in replicate 1 . This has the overall effect of showing equivalent cost and time uncertainties as the Sequential Strategy.

- data transfer - Enough time is available to collect and record design, licensing, and construction data from the prototype and incorporate these data into design of replicate 1 . This has little effect on cost and time uncertainties.

- vendor commitment - A firm commitment to accelerate FBR commercialization will entail heavy industry involvement, which has the effect of reducing cost and time uncertainties. 
- utility commitment - Little time is available for the utilities to technically and economically evaluate the FBR concept (due to minimum operating experience). This will increase the uncertainties associated with a utility's decision to commit financial resources to replicate 1 .

Strategy G: Direct Replicate

This strategy calls for achieving operation with the developmental plant as soon as possible with the intent of utilizing operating experience from the developmental plant as a basis for licensing replicate 1 (Figure 3.7).

\section{TIME}

DEVELOPMENTAL PLANT (1000 MWe CDS)

REPLICATE NO. I (1000 MWe)

REPLICATE NO. $2(1000 \mathrm{MWe})$

REPLICATE NO. 3 (1000 MWe)

CBR-1 (1000 MWe)

\section{PRINCIPAL FEATURES}

ACHIEVE OPERATION WITH THE DEVELOPMENTAL PLANT AS SOON AS POSSIIBLE WITH THE INTENT OF UTILIZING OPERATING EXPERIENCE

FROM DEVELOPMENTAL PLANT AS A BASIS FOR DESIGN AND LICENSING OF REPLICATE \#1.

TIMING: 1 YEAR OF FULL POWER OPERATI ON WITH DEVELOPMENTAL PLANT BEFORE COMMITTING TO REPLICATE \#I

EXPECTED TIME FOR COMPLETION: 29 YEARS

\section{FIGURE 3.7. Strategy G: Direct Replicate}




\section{Discussion}

After 1 year of developmental plant operation, the NSSS for replicate 1 will be awarded. By the time the final prototype design is completed, the developmental plant will have operated for 7 to 8 years. Because of the significant amount of developmental plant operating experience, and since there is minimal plant scale-up, the timely deployment of a commercial FBR can be achieved by bypassing prototype design and construction and going directly to replicate 1. This strategy places more importance on the demonstration of FBR techrology prior to utility comnitment, whereas the Direct Prototoype Strategy (Strategy F) assumes that the technology is already in place and demonstration is unnecessary.

\section{Cost and Time Uncertainties}

- scale-up - Little scale-up is required, thus scale-up uncertainties are minimized.

- operating experience - Because less operating experience is available for incorporation into the Jesign of replicate 1 than in the Sequential Strategy, cost and time uncertainties are increased.

- personnel retention - As a result of the large delay between design and construction of the developmental and replicate 1 plants an attrition of skilled personnel will occur and result in increased cost and time uncertainties for replicate $l$ but to a lesser degree than the Sequential Strategy. Replicate 1 is affected less because the Sequential Strategy has long durations between the developmental, prototype, and replicate 1 plants, whereas this strategy has only one large separation between the developmental plant and replicate 1.

- licensing - With developmental plant construction and operation preceding construction of replicate 1, there is time to develop licensing critieria that is tempered by operating experience. This will reduce licensing uncertainties associated with replicate 1.

- component testing - Sufficient time is available to complete testing programs and resolve problems, which tends to reduce cost and time uncertainties. 
- data transfer - Sufficient time to collect, record, and incorporate design, licensing, and operating data into future designs has an impact on cost and time uncertainties similar to the Sequential Strategy.

- vendor commitment - The duration between the developmental plant and replicate 1 would force vendors to maintain a low level of participation, which would introduce cost and time uncertainties similar to those in the Sequential Strategy.

- utility comitment - With operating experience from the developmental plant factored into the design of replicate 1, the uncertainties associated with the utilities decision to commit will be reduced. Lack of demonstrated licensing, however, will increase the uncertainty of that decision. 


\subsection{COST METHODOLOGY}

Capital cost estimates for a commercial sized (1000 to 1457 MW) FBR have considerable uncertainty. A large FBR has never been built in the United States and licensing procedures have not been firmly established. Large size components such as steam generators and intermediate heat exchangers have not. been fabricated or tested. Quantifying the decrease in capital costs to he expected when several FBRs are built in succession involves further uncertainty. Therefore, deterministic methods for evaluating FBR capital costs and strategy costs were inadequate and a probabilistic approach was taken.

First, the probabilistic cost distributions of the individual plants are evaluated. These are then combined with plant life-cycle fuel costs, 0\&M costs, base technology costs, the government support that is assumed would be provided to utilities for early plants not yet at economic parity with LWRs, and credit for power sales. The resultant is the total net cost to the government for implementation of a particular strategy. The following is an explanation of how individual components of total government cost were deriver.

\subsection{PLANT CAPITAL COSTS}

Capital cost estimates for this analysis were provided by DOE's Reactor Research and Technology Division and reactor manufacturers and architect/ engineers of the Conceptual Design Study (CDS). Plant capital costs were estimated explicitly as a function of each strategy and were received in NUS-531 Code of Accounts format at the two-digit level of detai1. This format can be seen in Table 4.1. Table 4.2 presents the strategy specific FBR plant. capital costs and their respective ranges. Capital costs for a generic LWR were also estimated and fit to a probability distribution. These costs are based on the historical data presented in "Power Plant. Capital Cost Analysis" by Ramesh Budwani (1980) of Burns \& Roe. The specific set of data used is for a LWR scheduled for operation in 1992 and has a range of $650 \$ / \mathrm{kW}$ to $1550 \$ / \mathrm{kW}$ with an expected value of $1100 \$ / \mathrm{kW}$, excluding interest during construction (IDC). This estimate includes the impact of TMI to make it consistent with 


\section{TABLE 4.1. NUS-531 Cost Reporting Format.}

\begin{tabular}{ll} 
Account & \multicolumn{1}{c}{ Account Title } \\
\hline 20 & Land \& Land Rights \\
21 & Structures \& Improvements \\
22 & Reactor Plant Equipment \\
23 & Turbine Plant Equipment \\
24 & Electric Plant Equipment \\
25 & Misc. Plant Equipment \\
26 & Heat Rejection Systems \\
91 & Construcion Services \\
92 & Home Office Engineering \& Services \\
93 & Field Office Engineering \& Services \\
94 & Other Cost \\
& Subtotal \\
& Contingency \\
Grand Total & Not Included: \\
& $1)$ Escalation \\
& 2) Interest during construction
\end{tabular}

the FBR capital cost estimates. This LWR capital cost estimate is used in a related analysis Evaluation of the Commercial FBR Introduction Date (White and Merrill 1981): The following assumptions were used to estimate the FBR and LWR capital costs:

- For the developmental (CDS) and prototype plants (government managed and funded), it is assumed that the participating contractors will perform the same technical scope as that on CRBR Project. Further, the reference design excludes "innovative" designs that are not proven by prior similar components and/or extensive technical design and analysis documentation.

- Only state of the art technology that is achievable within 5 years has been considered. Therefore, long-range and highly possible technological breakthroughs such as a primary steam generator have not been considered. 
TABLE 4.2. Summary of Capital Cost Ranges (Billions \$1980)

\begin{tabular}{|c|c|c|c|c|c|c|c|}
\hline \multirow[b]{2}{*}{ Plant Type } & \multicolumn{7}{|c|}{ Capital $\operatorname{Costs}(a, b)$} \\
\hline & $\begin{array}{c}\text { Strategy } \\
\text { A }\end{array}$ & $\begin{array}{c}\text { Strategy } \\
\text { B }\end{array}$ & $\begin{array}{c}\text { Strategy } \\
\mathrm{C} \\
\end{array}$ & $\begin{array}{c}\text { Strategy } \\
D \\
\end{array}$ & $\begin{array}{c}\text { Strategy } \\
E\end{array}$ & $\begin{array}{c}\text { Strategy } \\
F\end{array}$ & $\begin{array}{c}\text { Strategy } \\
G\end{array}$ \\
\hline $\begin{array}{l}\text { DEVELOPMENTAL CDS } \\
(1000 \mathrm{MW})\end{array}$ & $\$ 2.920(c)$ & $\$ 3.020(\mathrm{c})$ & $\$ 2.920(c)$ & $\$ 3.020(c)$ & & & $\$ 2.920^{(c)}$ \\
\hline $\begin{array}{l}\text { PROTOTYPE } \\
\text { (Improved CDS) } \\
(1000 \mathrm{MW})\end{array}$ & & & & & $\$ 2.750^{(d)}$ & $\$ ? .6 ? 0(d)$ & \\
\hline $\begin{array}{l}\text { PROTOTYPE } \\
(1457 \mathrm{MW})\end{array}$ & $\$ 2.564(d)$ & $\$ 2.564(d)$ & $\$ 2.424(d)$ & $\$ 2.424(d)$ & & & \\
\hline $\begin{array}{l}\text { REPLICATE \#1 } \\
(1000 \mathrm{MW})\end{array}$ & & & & & $\$ 1.740(e)$ & $\$ 1.740(\mathrm{e})$ & $\$ 1.987(e)$ \\
\hline $\begin{array}{l}\text { REPLICATE \#1 } \\
(1457 \mathrm{MW})\end{array}$ & $\$ 2.127(\mathrm{e})$ & $\$ 2.127(\mathrm{e})$ & $\$ 2.056(\mathrm{e})$ & $\$ 2.056(\mathrm{e})$ & & & \\
\hline $\begin{array}{l}\text { CBR-1 } \\
\quad(1000 \mathrm{MW})\end{array}$ & & & & & $\$ 1.582(\mathrm{e})$ & $\$ 1.582(\mathrm{e})$ & $\$ 1.582(\mathrm{e})$ \\
\hline $\begin{array}{l}\text { CBR-1 } \\
\qquad(1457 \mathrm{MW})\end{array}$ & $\$ 1.870(\mathrm{e})$ & $\$ 1.870$ (e) & $\$ 1.870(\mathrm{e})$ & $\$ 1.870(\mathrm{e})$ & & & \\
\hline $\begin{array}{l}\text { (a) Excluding inte } \\
\text { (b) Including Impa } \\
\text { (c) }-9 \% \text { to }+20 \%(n \\
\text { (d) }-7 \% \text { to }+12 \%(n \\
\text { (e) }-5 \% \text { to }+10 \%(n\end{array}$ & $\begin{array}{l}\text { rest during } \\
\text { ct of Three } \\
\text { inimum to } \mathrm{m} \\
\text { in imum to } \mathrm{m} \\
\text { inimum to } \mathrm{m}\end{array}$ & $\begin{array}{l}\text { construction } \\
\text { Mile Island. } \\
\text { aximum) } \\
\text { aximum) } \\
\text { aximum) }\end{array}$ & & & & & \\
\hline
\end{tabular}


- For the utility-managed plants (replicates 1 through 3, and CBR-1), it is assumed that conventional utility practices and performing organizations (i.e., one reactor manufacturer, one architect/ engineer) will be used.

- The LWR plant cost estimate is based on historical information presented in "Power Plant Capital Cost Analysis," R. Budwani (1980).

- In all FBR plant estimates, the "expected" cost incorporates the added uncertainties in each 2-digit account. Therefore, "expected" costs for the LWR and FBR plants will have an equivalent "expected" confidence level and thus, the same percentage contingency.

- An attempt was made to quantify the cost impact of the "Delay Start" and "Sequential" strategies. The approach was to estimate the attrition factor of key RM/AE personnel and the temporary loss in productivity by their replacements.

- Finally, for certain plants, estimates were made for "minimum" and "maximum" cost within the framework of no technology breakthrough being reflected in the "minimum" cost and no insurmountable technical problem being reflected in the "maximum" cost.

Confidence levels were requested for the capital cost estimates so that a probability density function could be calculated for each specific plant. For the maximum, there is a $90 \%$ confidence or probability that the estimate will not be greater than the quoted maximum cost, for the minimum, there is a $10 \%$ probability that the estimate will be less than the quoted minimum cost.

From data presented in Table 4.2 and confidence levels mentioned above for the minimum and maximum costs, a probability density function was derived for the developmental plant. The function that provided the best representation of the developmental plant cost data was the beta $(\beta)$ distribution. This distribution is a useful model for variates whose values are limited to a finite interval. For a mathematical treatment of the derivation of capital cost distributions see Appendix A. 
There are different capital costs for the developmental plant depending on the strategy. These differences are due to the attrition of skilled personnel as a result of delaying the construction of the developmental plant by 5 years in Strategies $B$ and $D$. The prototype plant in Strategy $E$ has a higher capital cost than in Strategy $F$ as a result of the 10-year delay in its construction.

Because the capital costs associated with the developmental plant are strategy specific, four different probability distributions had to be calculated. These distributions and their respective cost transformations are presented in Appendix A, Table A.1.

A sampling of capital cost estimates from industry was provided by DOE for the 1000 MWe and 1457 MWe mature FBRs as illustrated in Figures 4.1 and 4.2 respectively. These estimates represent the individual viewpoints of the contributing reactor manufacturers and architect/engineers of the CDS project, and do not include interest during construction.

The individual cost estimates shown in Figures 4.1 and 4.2 were found to fit a Weibull probability density function. The results are shown in Appen$\operatorname{dix} A$. To collapse these individual estimates into a single distribution, the Weibul1 functions were summed and averaged for each set of FBR estimates. The resultant set of points yielded the two distributions shown in Figures 4.3 and 4.4. These distributions probabilistically represent the range of estimates for the 1000-MWe and 1457-MWe mature FBRs, with expected capital costs of $1582 \$ / \mathrm{kW}$ and $1285 \$ / \mathrm{kW}$, respectively. Figure 4.5 illustrates the capital cost probability distribution that was calculated for the LWR, and has an expected value of $1100 \$ / \mathrm{kW}$.

These functions in the above form are used in other related studies to calculate the commercially competitive cost dates (White and Merrill 1981) and various decision metrics (Fraley 1981).

Strategy specific capital cost estimates for the prototype and replicate 1 plants were also received from DOE. However, to calculate the net strategy cost to the government, the capital costs for replicates 2 and 3 had to be estimated. This was done using traditional learning curve methodology. 


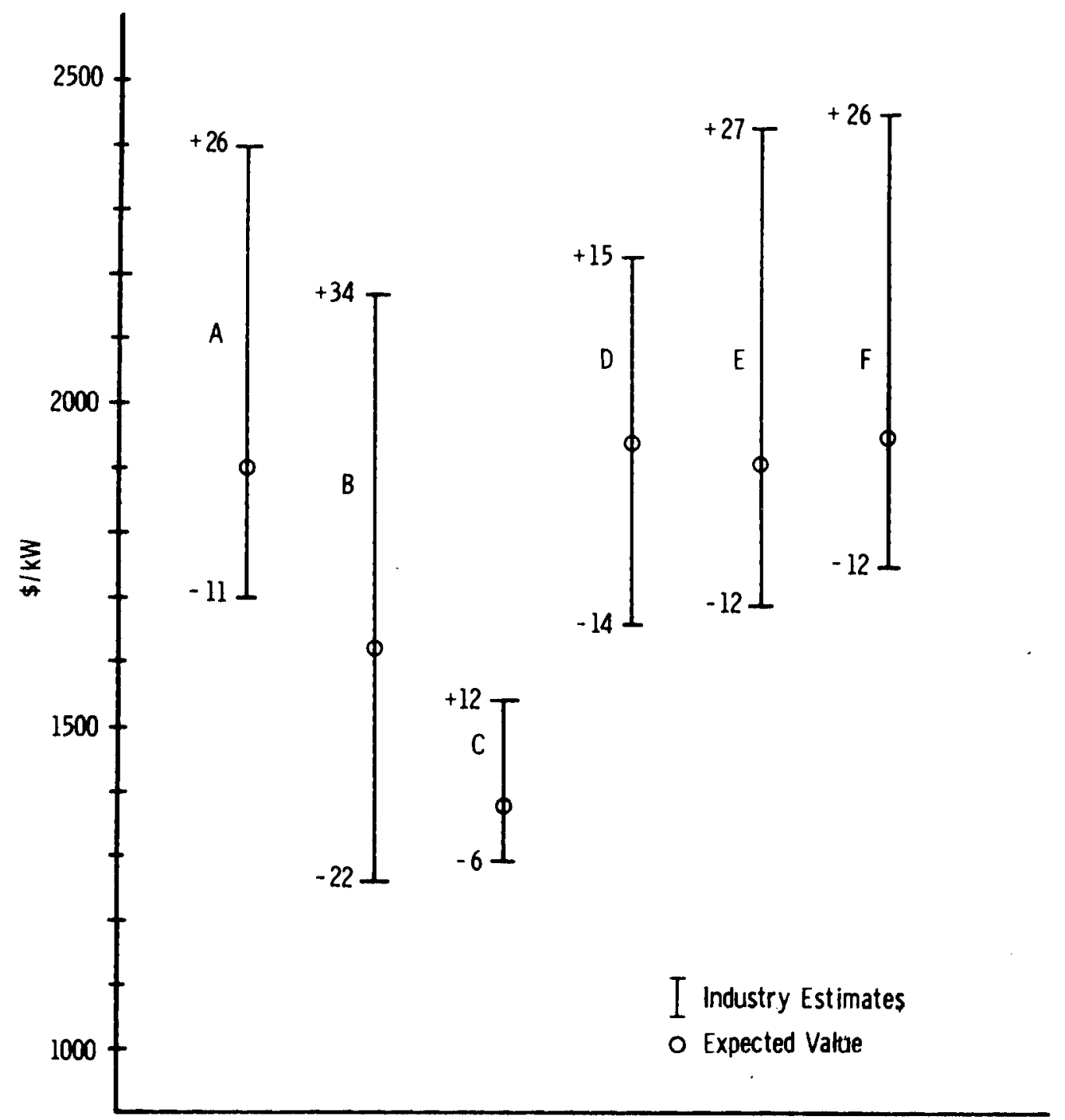

FIGURE 4.1. Capital Cost Estimates for Mature 1000-MW FBR

It was assumed for all strategies that as additional plants beyond the prototype were built, the capital cost per unit would decrease. However, for capital costs to decrease, certain conditions must be met. Successive plants must have the same basic design; hence, the term replicate for those plants between the prototype and CBR-1. Technological improvements such as those found in tooling, fabrication of components, procurement, and improved construction techniques must be transferable to successive plants. For a commercial FBR industry, there must also be a stable licensing environment. 


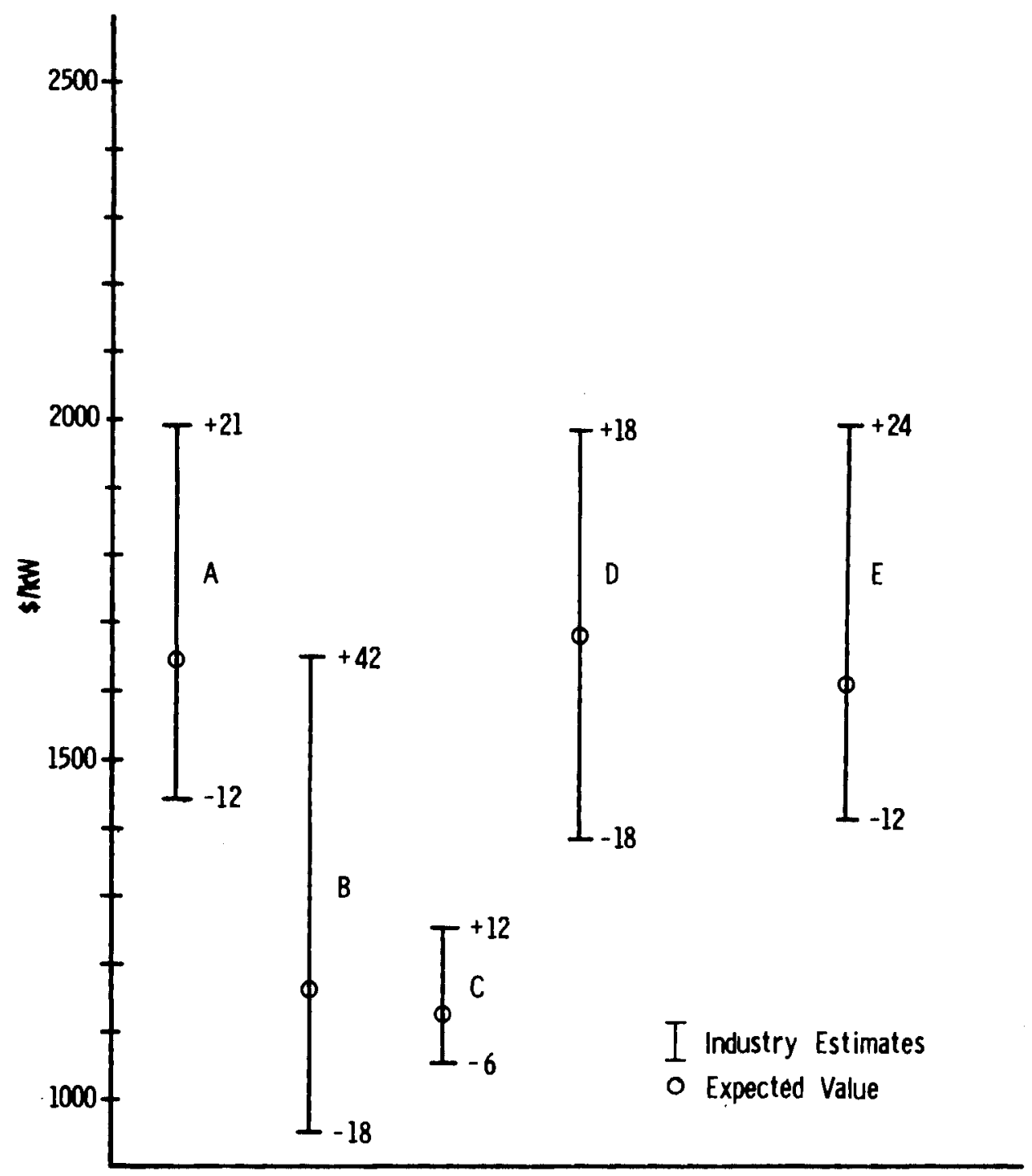

FIGURE 4.2. Capital Cost Estimates for Mature 1457-MW FBR

In all strategies, the prototype design is assumed to be replicated through CBR-1 to take advantage of the learning effects mentioned above. Thus, with the capital costs for the prototype plant, replicate 1 and CBR-1 provided by $D O E$, a learning or cost maturation function was fit to these costs of the form:

$$
y_{n}=A m^{b}
$$




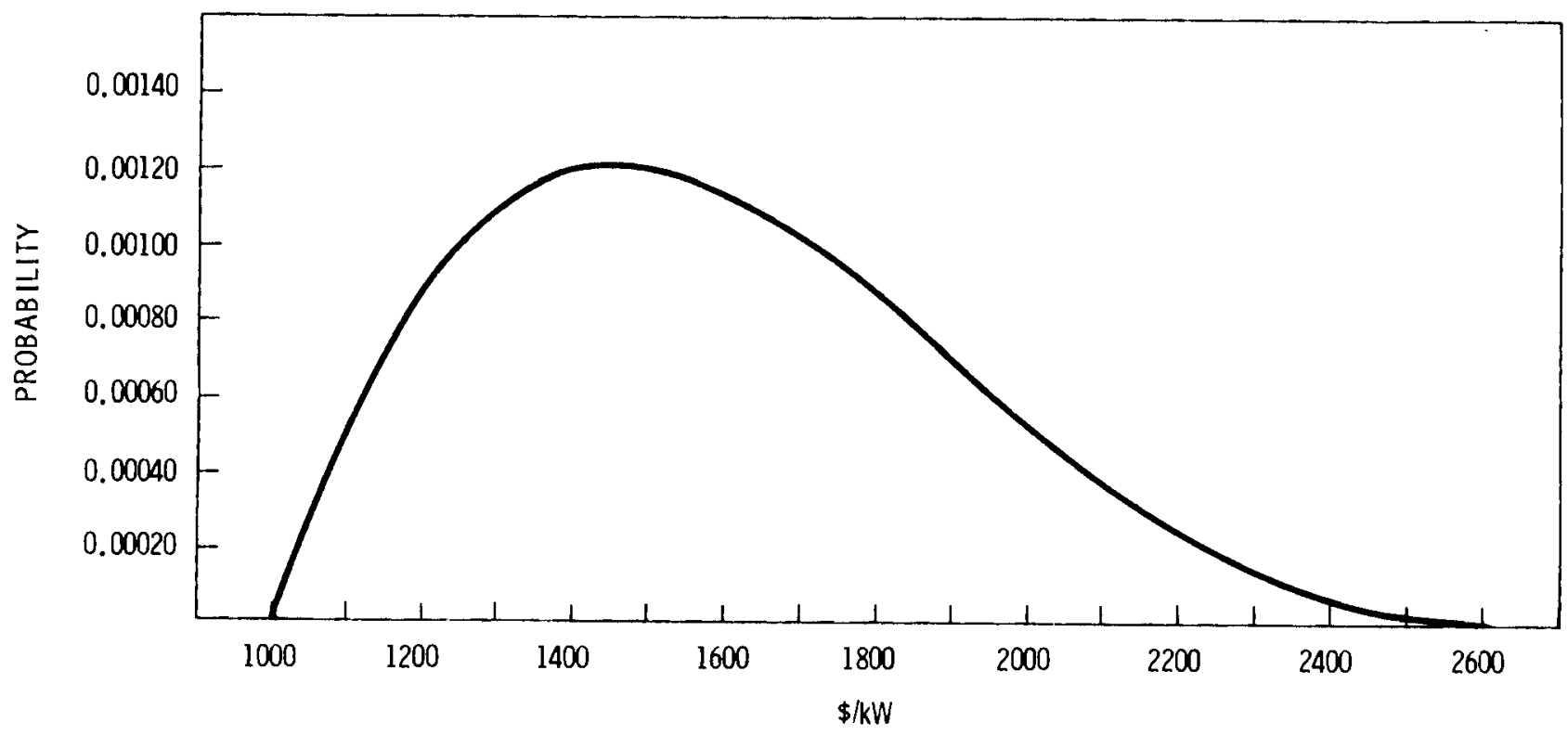

FIGURE 4.3. Capital Cost Distribution for 1000-MWe Commercial FBR (\$1980)

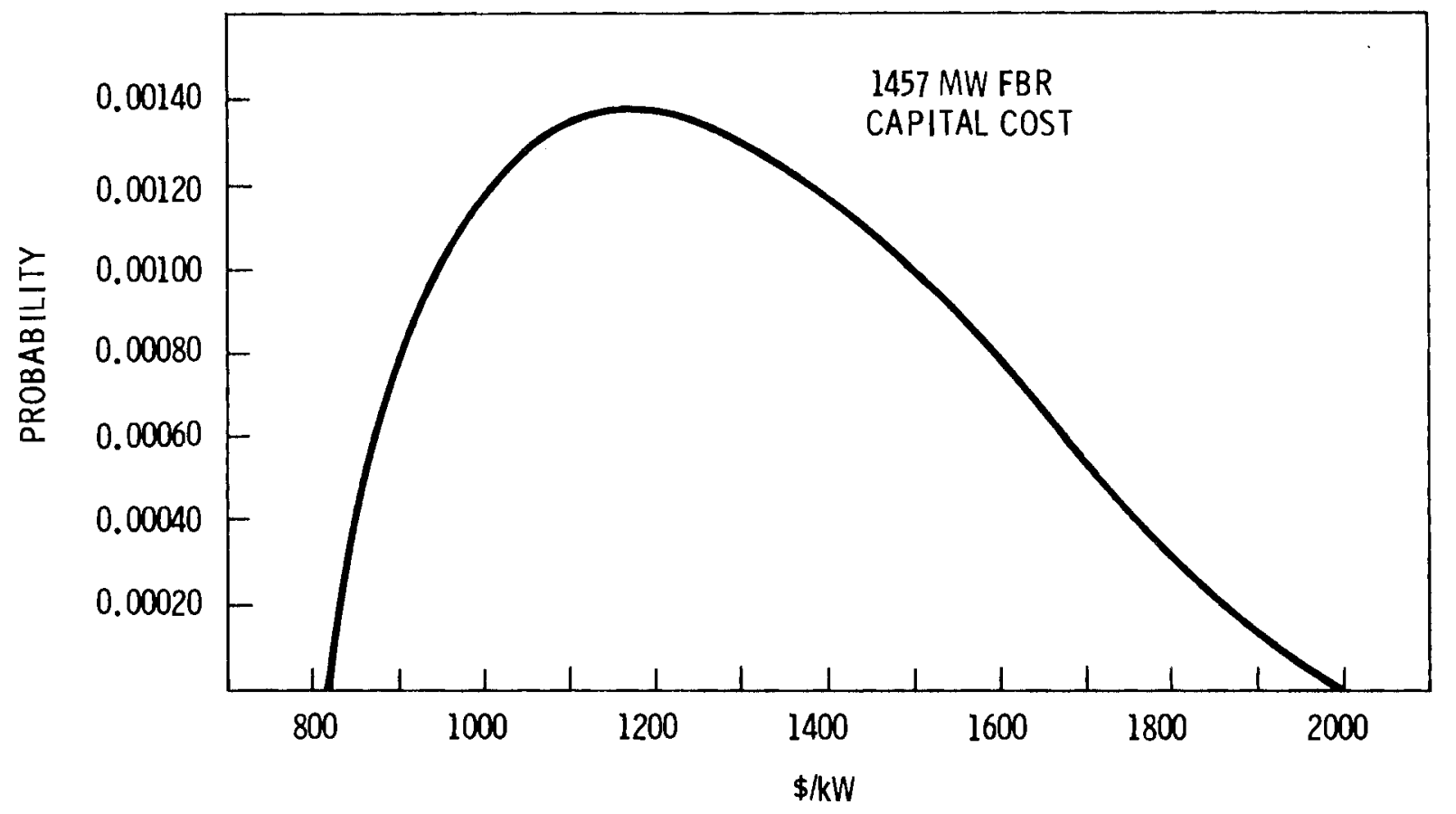

FIGURE 4.4. Capital Cost Distribution for 1457-MWe Commercial FBR (\$1980) 


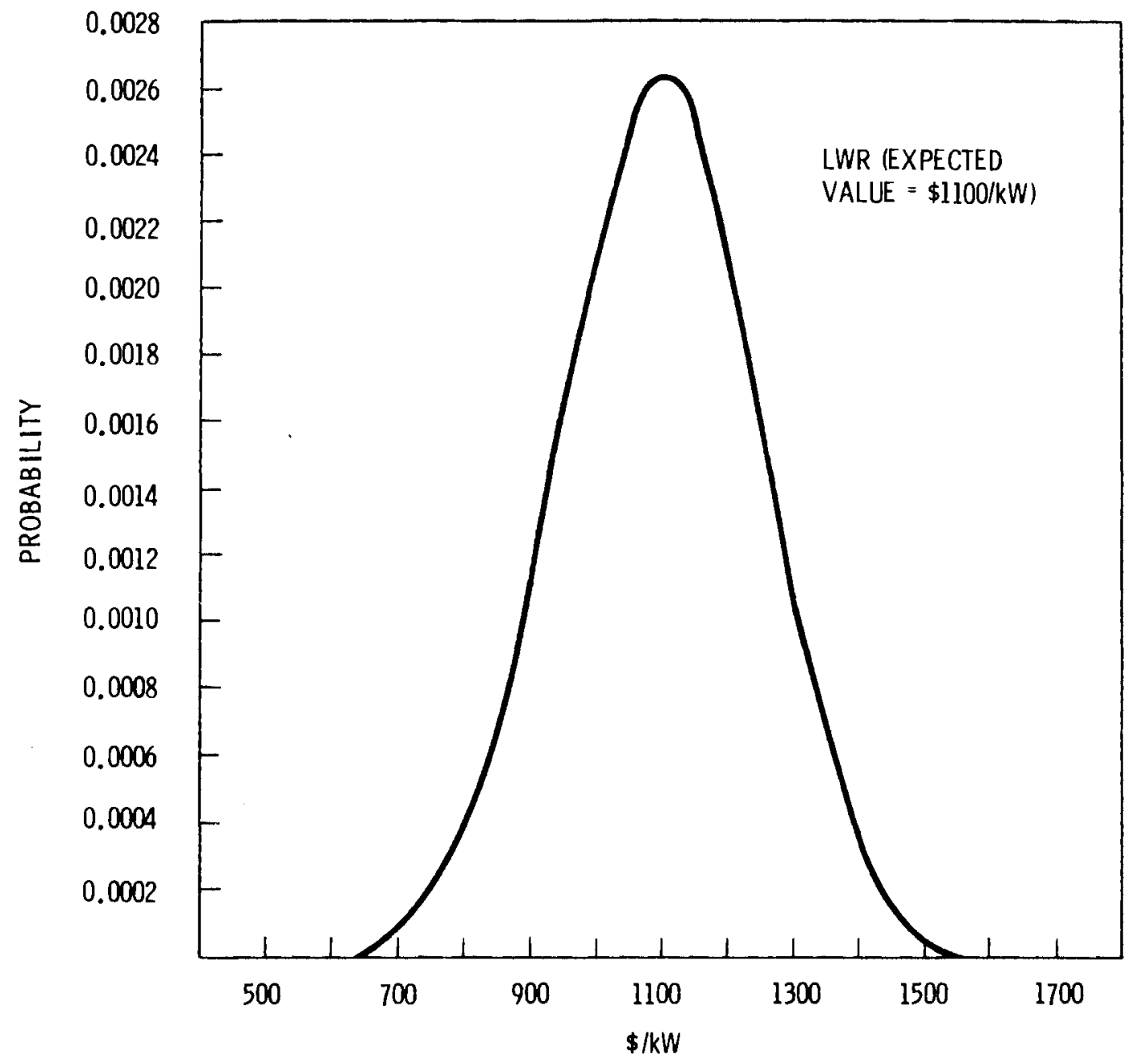

FIGURE 4.5. Cost Distribution for LWRs (\$1980)

(Excludes Interest During Construction)

where

$$
\begin{aligned}
y_{n} & =\text { capital cost of the nth plant }\left(\$ 10^{5}\right) \\
A & =\text { capital cost of the prototype } \\
m & =\text { number of plants built } \\
b & =\text { constant. }
\end{aligned}
$$

The capital costs for replicates 2 and 3 can be estimated with this relationship. A similar relationship for estimating future FBR capital costs was used in the Report of the Nonproliferation Alternative Systems Assessment Program 
(NASAP). The NASAP report uses an $80 \%$ cost maturation curve for estimating the costs which is very similar to the strategy specific capital cost maturation functions calculated for this analysis. The determination of these plant. capital costs is necessary in order to assess the amount of government support that might be required for the replicate plants not yet at economic parity with LWRs. This is discussed further in Section 4.?, FBR Alternative Strategy Costs.

Furthermore, this analysis assumed that the distributions of capital costs for the prototype through replicate 3 plants possess the same shape as that of CBR-1. That is, had individual estimates been received from industry, as was the case with CBR-1, for the prototype through replicate 3 plants, the results would have followed a consistent pattern. The implicit assumption here is that the uncertainty in the capital costs for these plants is similar to the uncertainty in the CBR-1 capital cost estinates.

As mentioned earlier, when CBR-1 is completed, it is assumed that the FBR is economically competitive with the LWR, a competitive market exists, and utilities will begin placing multiple orders. CBR-1 is not, however, the minimum cost FBR. Most of the capital cost reductions will occur in the first five plants. During this phase it is assumed that a single industry team builds these plants with no competition and that the maximum learning occurs due to the accumulation of licensing and construction experience and plant replication. As multiple FBR orders are placed, more competition is assumed. Each reactor manufacturer and architect/engineer who enters the FBR market will experience different rates of learning. These different rates could be combined to form a composite learning or cost reduction rate that would represent the industry as a whole. A straight line was assumed to represent the composite industry's cost reduction rate from CBR-1 to the twentieth plant. A reduction of approximately $12 \%$ in FBR capital costs was assumed over this period. This is similar to the results reported in NASAP. Estimating this point was necessary in order to calculate the benefits of having the breeder.

This information is presented in more detail in the decision model (Fraley 1981) where the results of the benefit calculations are reported. Therefore, two cost maturation curves exist, one, which is strategy specific (Proto to 
CBR-1) and the other which depicts the learning that occurs in the competitive FBR market (CBR-1 to plant \#20). This is illustrated qualitatively in

Figure 4.6 .

The manner in which the capital cost distributions discussed in this section are used to calculate the net strategy cost to the government is discussed in the following section.

\subsection{FBR ALTERNATIVE STRATEGY COSTS}

The net cost to the government for implementation of a particular strategy is the sum of a number of components, the most important being the individual plant costs discussed above. This section explains how stratequ costs were derived for this analysis.

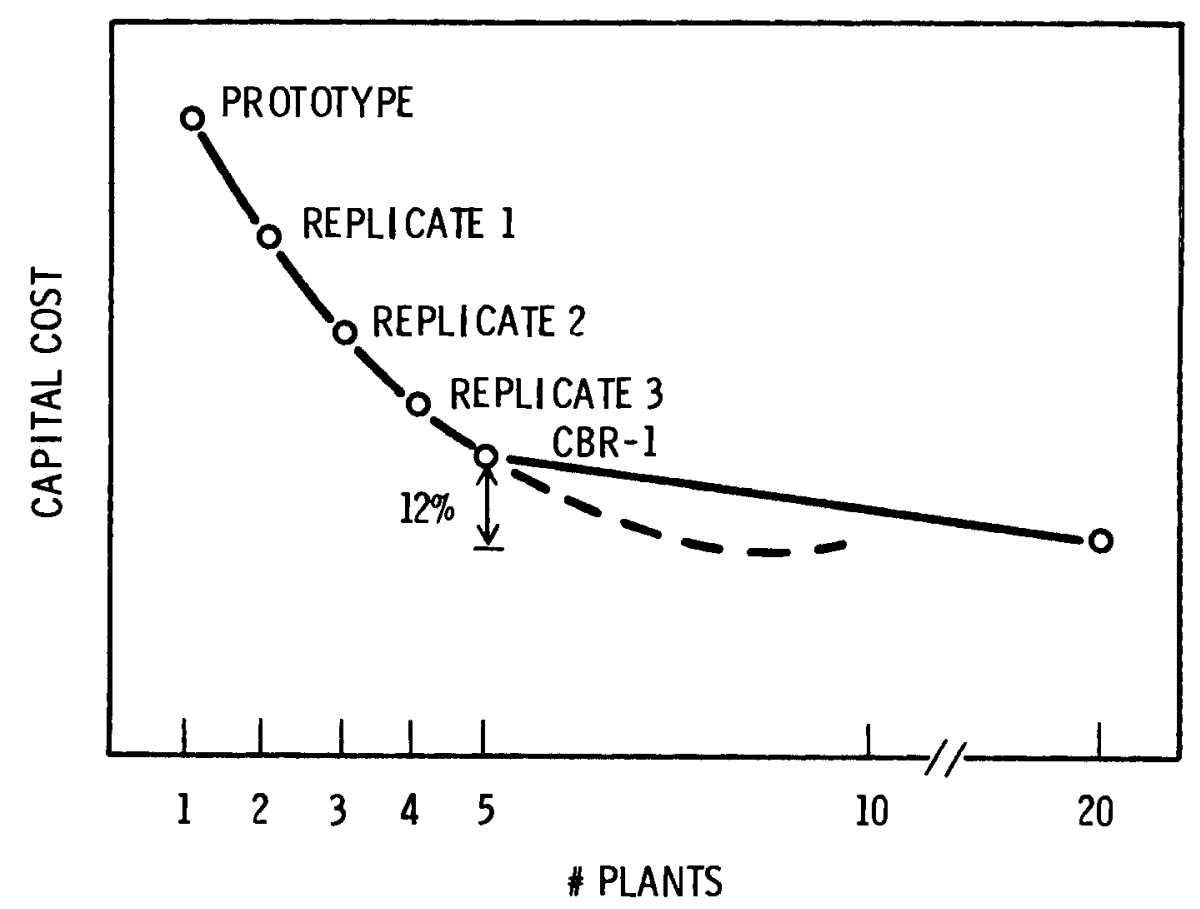

FIGURE 4.6. FBR Capital Cost Reduction as a Function of Number of Plants Built 
FBR strategy costs include the following components:

- all plant capital costs

- fuel cycle costs

- operation and maintenance costs

- base technology cost

- credit for the sale of power generated from a government facility.

- a warranty for replicate plants 1 through 3.

For government financed facilities (developmental and prototype plants), these components are calculated on an annual basis over their operational life, which was assumed to be 40 years. For replicates 1 through 3 a capital cost differential is calculated between the replicate series and CBR-1; for calculational purposes it is assumed that this differential is assessed to the government in the year a specific plant is ready for full power operation. One could view this as a warranty to the utilities that replicates 1 through 3 will cost no more over their lifetime than an LWR built in the same year. This is intended to simulate a program similar to the old AEC Reactor Development Program during the time between the full scale prototype and commercialization. The strategy cost components are summed annually and the total amount is then reported in constant $\$ 1980$. The total net undiscounted cost streams for each strategy are summarized in Appendix A.

Plant Capital Cost

Derivation of plant capital cost distributions was discussed in the previous section. These costs are spread over the duration from beginning of plant design to full power operation. This duration will vary as a function of the number of plants already built and the relative timing of the plants. For this analysis the duration from start of plant design to commercial operation was estimated for the developmental and prototype plants using the network model QGERT. This procedure is briefly discussed in Chapter 5.

Once the construction duration for a given government facility is estimated, the capital expenditure pattern over this period is computed with the aid of Figure 4.7 . 


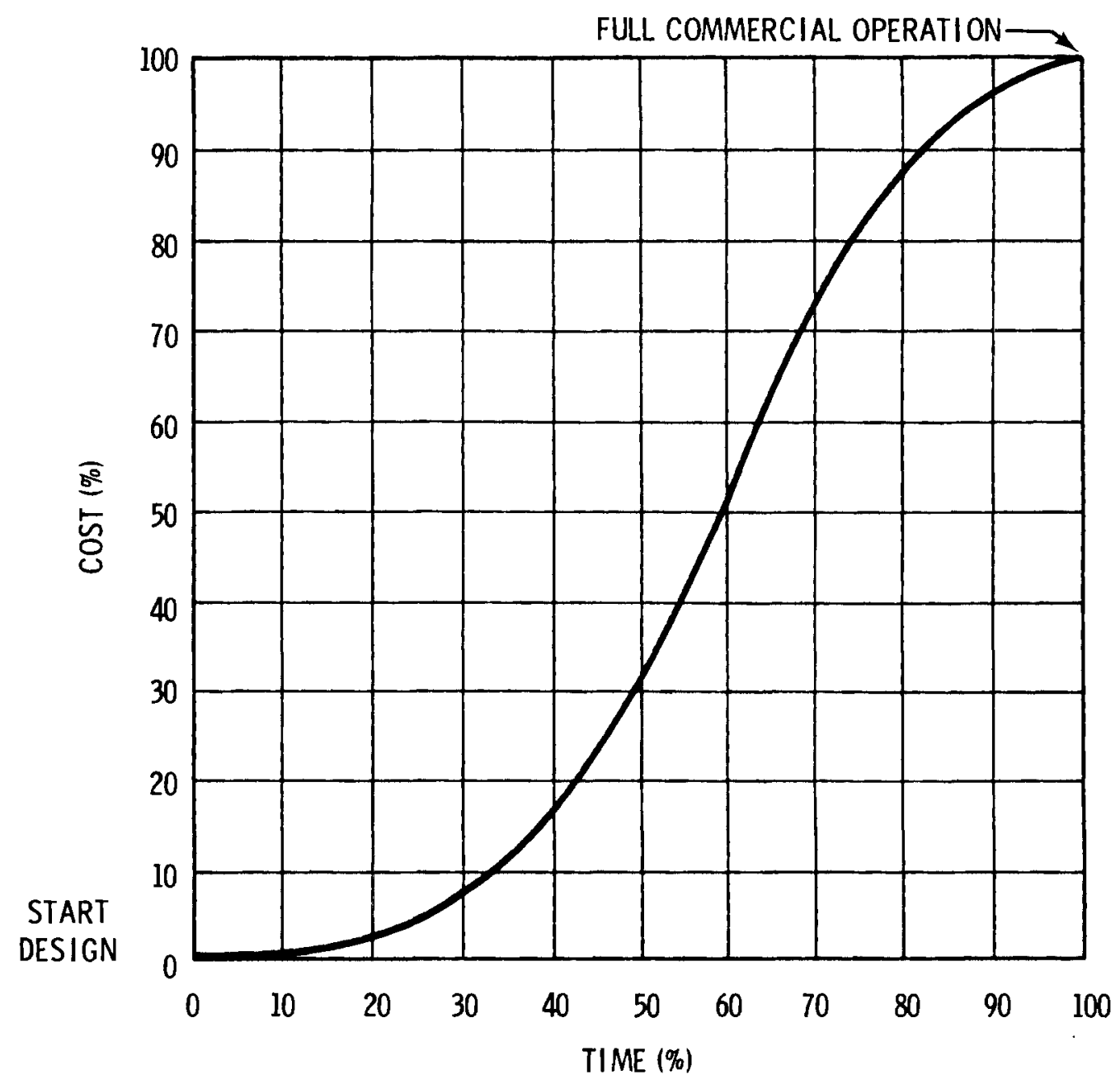

FIGURE 4.7. Plant Capital Investment Expenditures vs. Time

\section{Fuel Cycle Cost}

Appendix A, Table A.4 shows the unit costs used in this analysis for the calculation of fuel cycle costs. These costs, from Evaluation of the Commercial FBR Introduction Date (White and Merrill 1981), are for a developed industry, and may therefore, underestimate the early portion of fuel cycle costs. The details of the fuel cycle cost calculations can be seen in Appendix A. 
Operation and Maintenance Costs

Annual operation and maintenance expenses are primarily a function of plant staffing requirements, supplies and expenses, insurance, and maintenance material. For this analysis, these were assumed to be constant at $\$ 21.3 \times$ $10^{6} / \mathrm{yr}$ for both the 1000-MWe developmental plant and the 1457-MWe prototype plant. A detailed breakdown of these expenses can be seen in Appendix $A$.

\section{Base Technology Program}

This program consists of six primary research and development areas: physics, safety, fuels, components, materials, and chemistry. The principal thrust of this research program is to develop the technology required for full-scale FBR demonstration. This analysis assumed that the duration of this program would be from the present to the start of replicate 1 design. The total cost to the government was assumed to be strategy independent and a constant $\$ 6.0 \times 10^{9}$ spread equally over the time duration mentioned above. Credit for Sale of Power

Since utilities are the ultimate FBR market, developmental plants will have to demonstrate operation on an electrical grid to assess their behavior under all system conditions. Since they will be producing power, credit to the government for the sale of this power was included in the strategy cost calculations. A similar agreement exists in the CRBR contract. It is to be connected to the electrical grid of a consortium of utilities including TVA and Commonwealth Edision. Power generated by this government facility is to be sold at the highest incremental cost of replacement power on the grid computed on an hourly basis. Determination of this incremental rate, which is regionally dependent, is beyond the scope of this analysis. The CDS program addressed the question of credits for power sales. The estimated plant capacity factors and gross revenue rate ( $48 \mathrm{mil1s} / \mathrm{kWh}$ ) from CDS were used here. Government Support

The commercial nuclear industry has indicated that there will be no turnkey projects associated with commercial FBR development as there were in LWR development. As a result, the government may have to provide an economic incentive for participating utilities. This analysis assumes that there will 
be a government energy warranty for replicates 1,2, and 3. For the government, this financial committment is approximated by the capital cost differential between the three replicate plants and CBR-1, since CBR-1 is considered commercially competitive. This concept is illustrated qualitatively in

Figure 4.8. The shaded region illustrates the assumed government support for the replicate plant series.

\section{Total Strategy Cost}

To probabilistically assess the costs of a particular development strategy to the government, the total strategy cost had to be put in the form of a probability density distribution. This was done by breaking down the total strategy cost into four components as follows:

$$
S_{t}=A+B+C M+D
$$

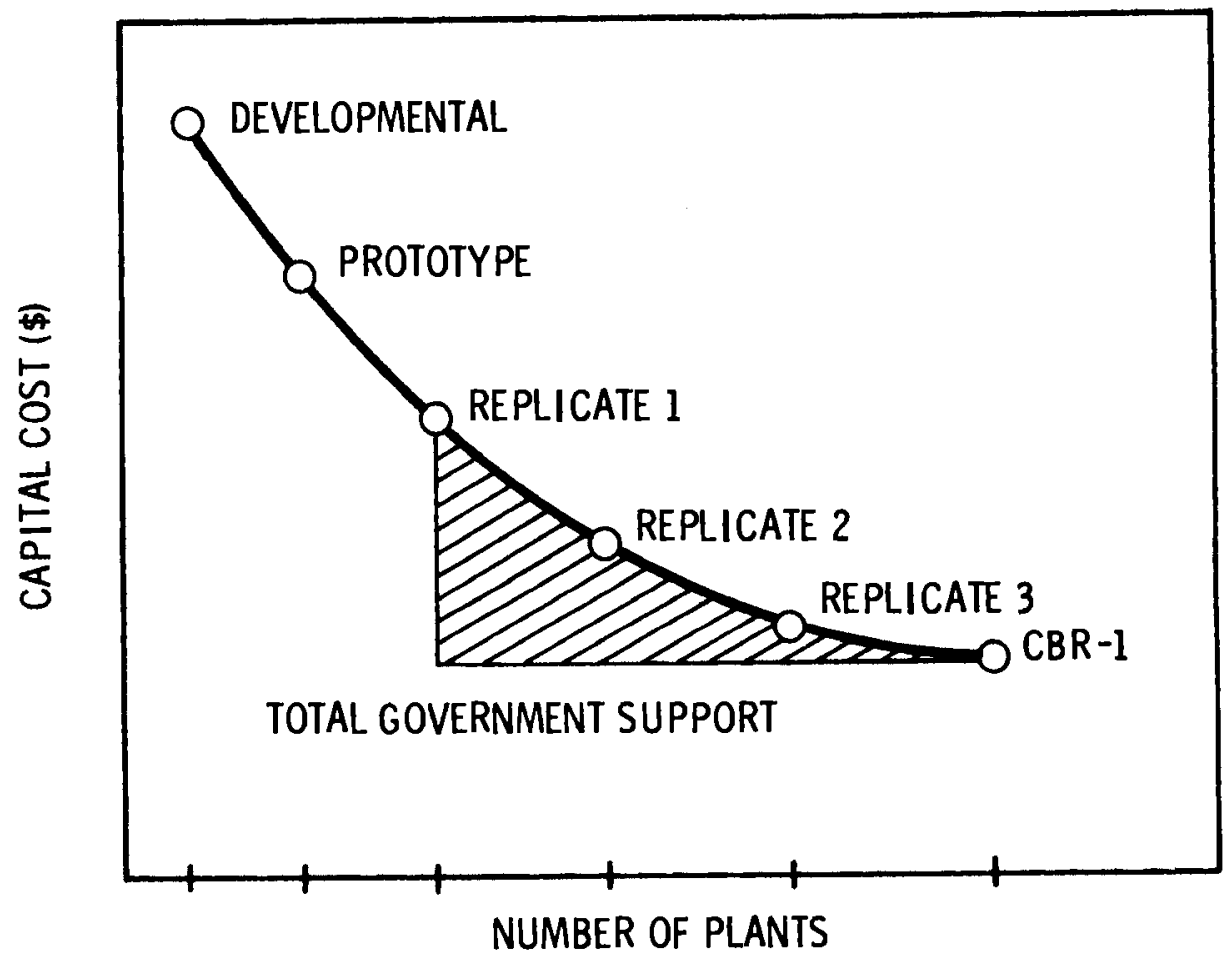

FIGURE 4.8. Assumed Government Support of Replicates 1-3 
where

$$
\begin{aligned}
S_{t} & =\text { total strategy cost } \\
A & =\text { fuel cycle cost component } \\
B & =\text { developmental plant cost component } \\
C & =\text { constant } \\
M & =\text { CBR-1 capital cost component } \\
D & =\text { base technology cost component. }
\end{aligned}
$$

Calculation of the first term, $A$, was discussed in the previous section. For the Sequential Strategy the second term, $B$, is a distribution of costs represented by the probability density function:

$$
f(x) \operatorname{CDS}=2.47(x)^{\gamma-1}(1-x)^{n-1} \quad(0 \leq x \leq 1)
$$

where

$$
\begin{aligned}
& r=1.29 \\
& \eta=2.58
\end{aligned}
$$

and

$$
\text { Capital Cost }\left(\$ \times 10^{6}\right)=960(x)+2600
$$

The third term, $C$, represents the amount of government support to the pre-commercial FBRs.

To calculate $C$, the prototype and replicates 1 through $3 \mathrm{plant}$ capital costs are put in terms of the capital cost of CBR-1 since these plants have the same basic design and their respective capital costs are assumed to have the same uncertainties as the cost of CBR-1. With the cost of CBR-1 set at unity, the capital costs of the prototype through replicate 3 are assessed as multiples of the CBR-1 cost. For example, for the Sequential Strategy: 


$$
\begin{aligned}
\text { CBR-1 } & =1 \\
\text { Rep-3 } & =1.034 \\
\text { Rep-2 } & =1.094 \\
\text { Rep-1 } & =1.137 \\
\text { Prototype } & =1.371
\end{aligned}
$$

The difference between the normalized costs of the prototype through replicate 3 plants and CBR-1 is then calculated. These differences are then summed to determine the constant $C$.

The term $M$ is the capital cost of CBR-1 which is represented by the probability density function:

$$
f(x)_{1457}=5.707(x)^{\gamma-1}(1-x)^{\eta-1} \quad\left(0^{\prime} \leq x \leq 1\right)
$$

where

$$
\begin{aligned}
& \gamma=1.61 \\
& \eta=2.47
\end{aligned}
$$

and

$$
\text { Capital Cost }(\$ / k W)=1180(x)+820
$$

The term $D$ is the sum of the base technology costs over the duration of their application.

The terms $A$ and $D$ when added, equal a constant such that equation 4.2 reduces to

$$
S_{t}=K+B+C M
$$

The capital cost distributions $B$ and $C M$ are then statistically added to form a strategy probability density function. This convolution technique is discussed in detail in Fraley 1981. Thus, for any capital cost of the 
developmental plant and CBR-1, and any fuel cycle and base technology cost, the cost probability distribution for each strategy can be computed.

The strategy-specific cost probability distributions are illustrated in Figures 4.9 through 4.15. These distributions are used in the decision model discussed in Fraley (1981) to probabilistically assess the risks and benefits of each development strategy. The strategy costs represented by these distributions are discounted by $5 \%$ to 1980 dollars. The purpose of discounting is to reflect the time value of money.

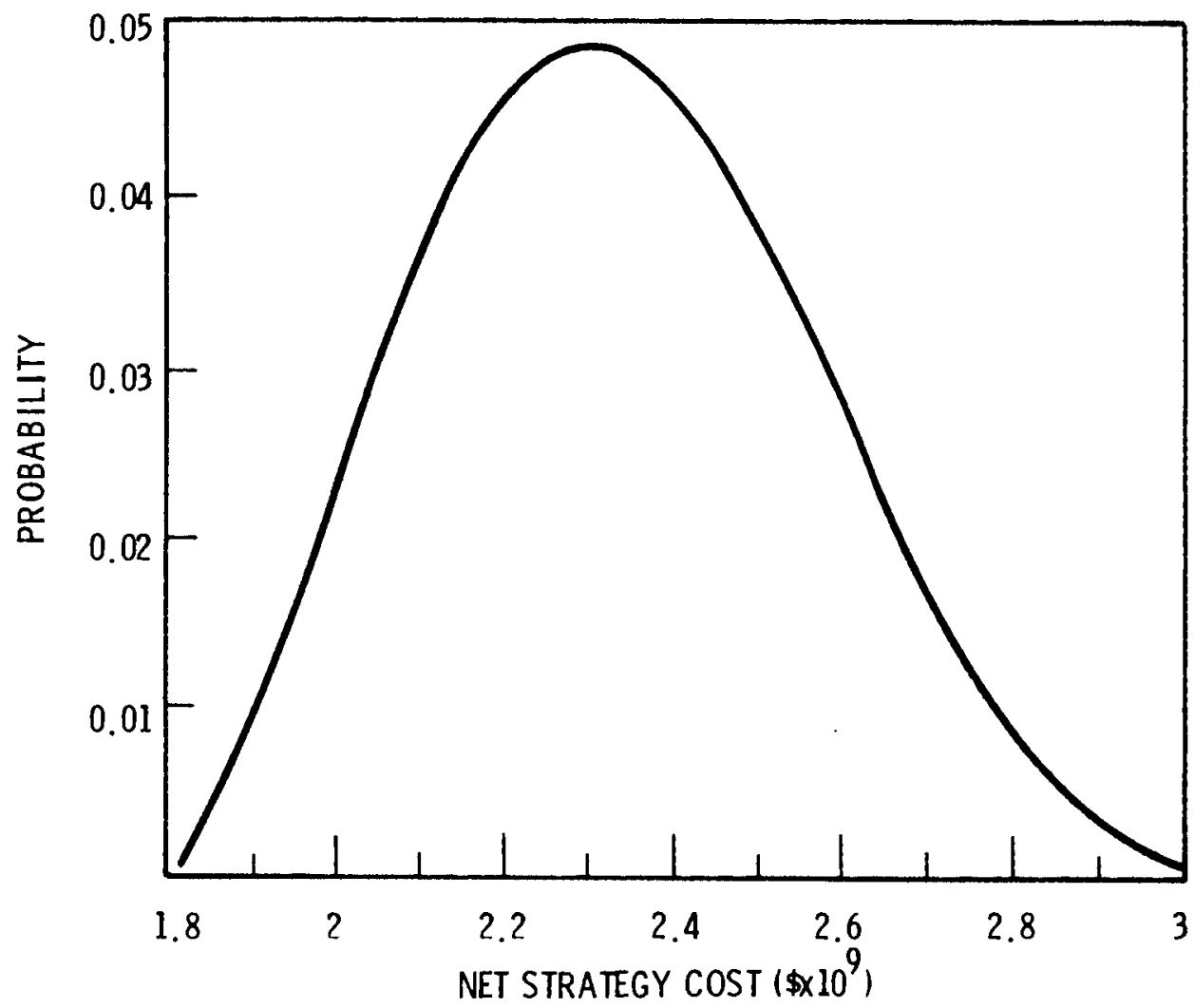

FIGURE 4.9. Discounted Capital Cost Probability Distribution for Sequential Strategy (A) 


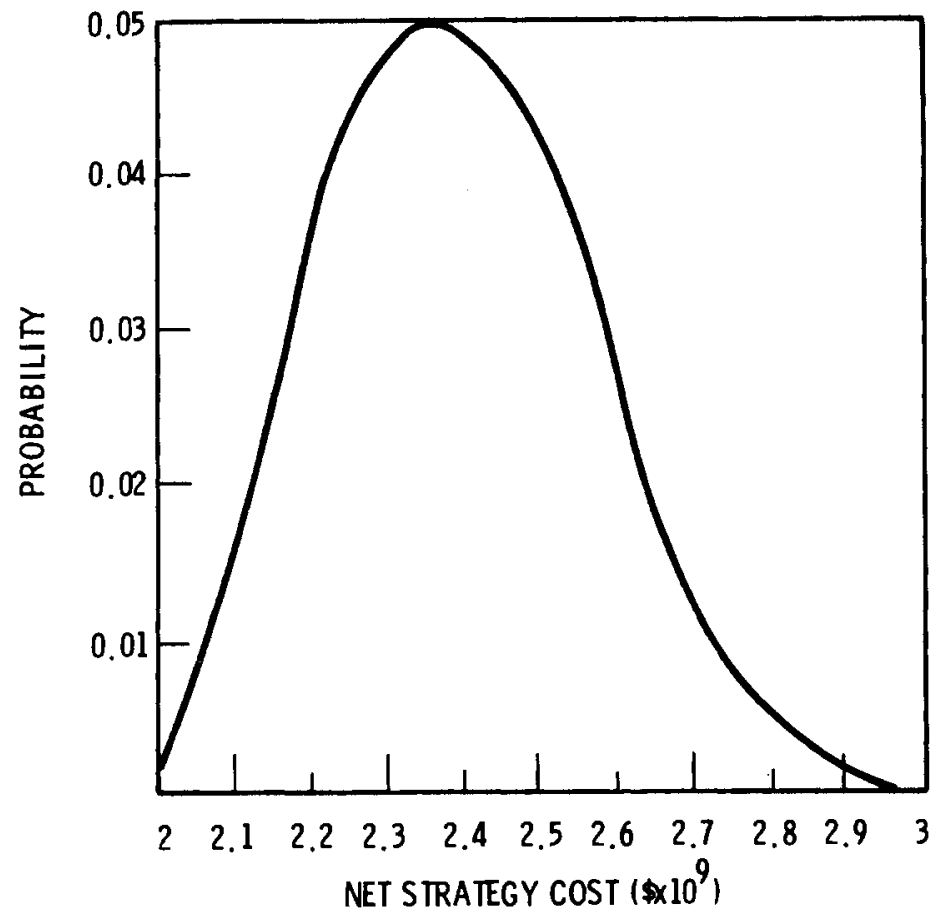

FIGURE 4.10. Discounted Capital Cost Probability Distribution for Delayed Sequential Strategy (B)

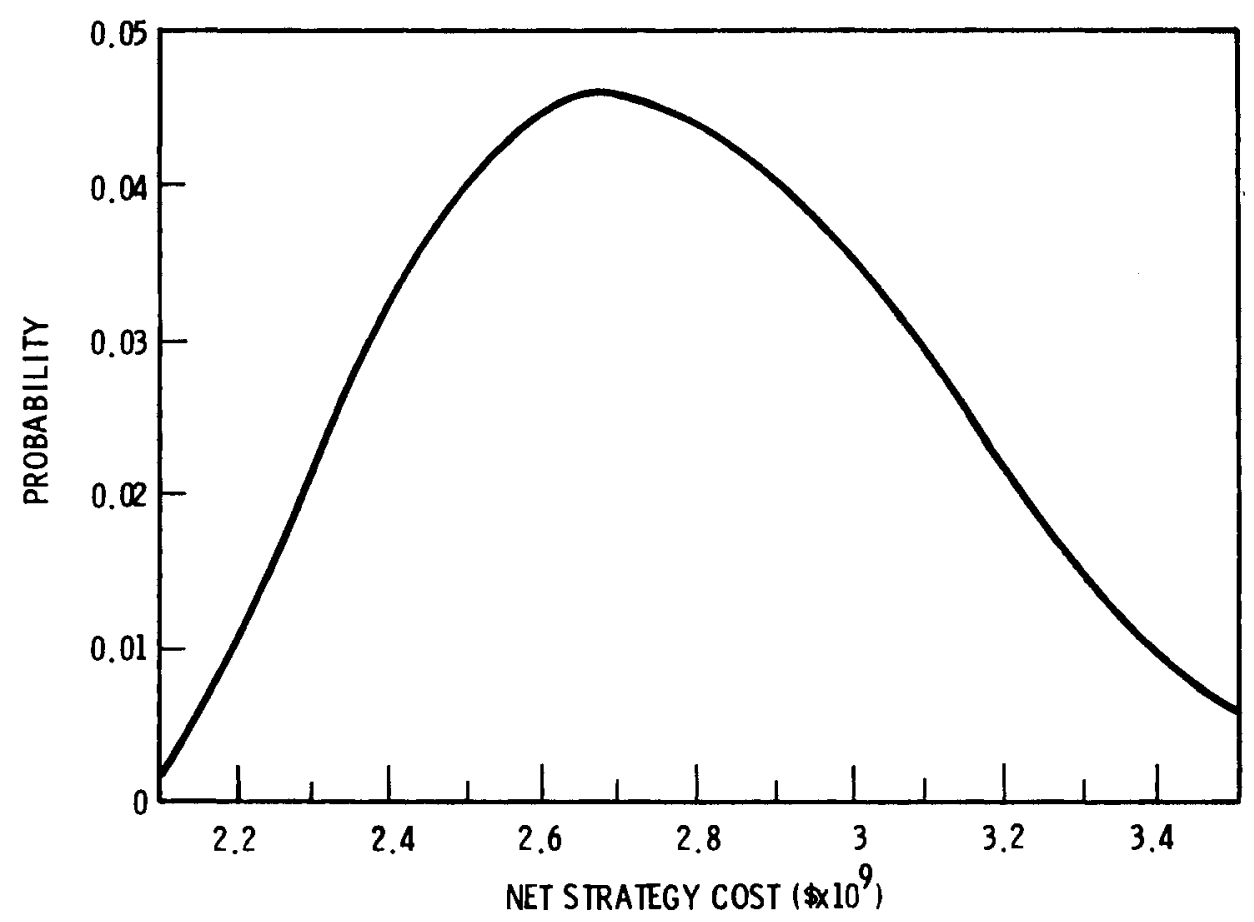

FIGURE 4.11. Discounted Capital Cost Probability Distribution for Compressed Strategy (C) 


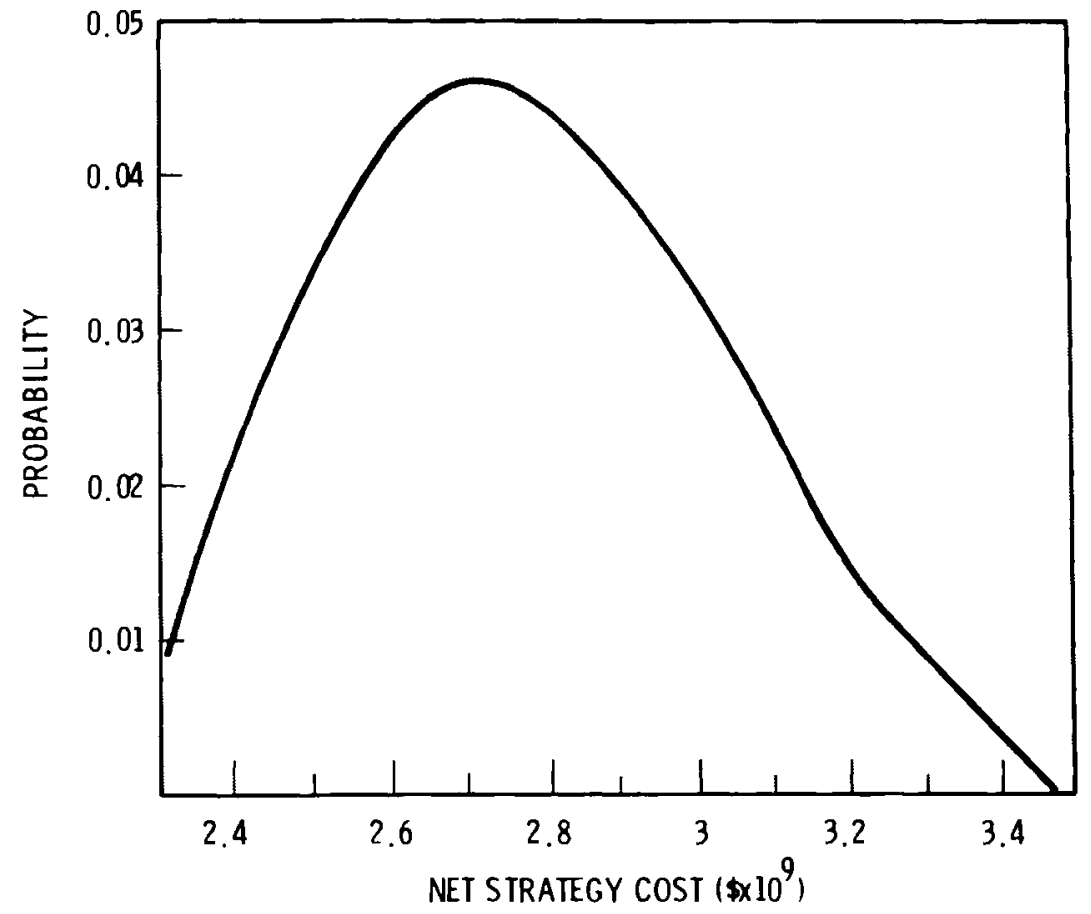

FIGURE 4.12. Discounted Capital Cost Probability Distribution for Delayed Compressed Strategy (D)

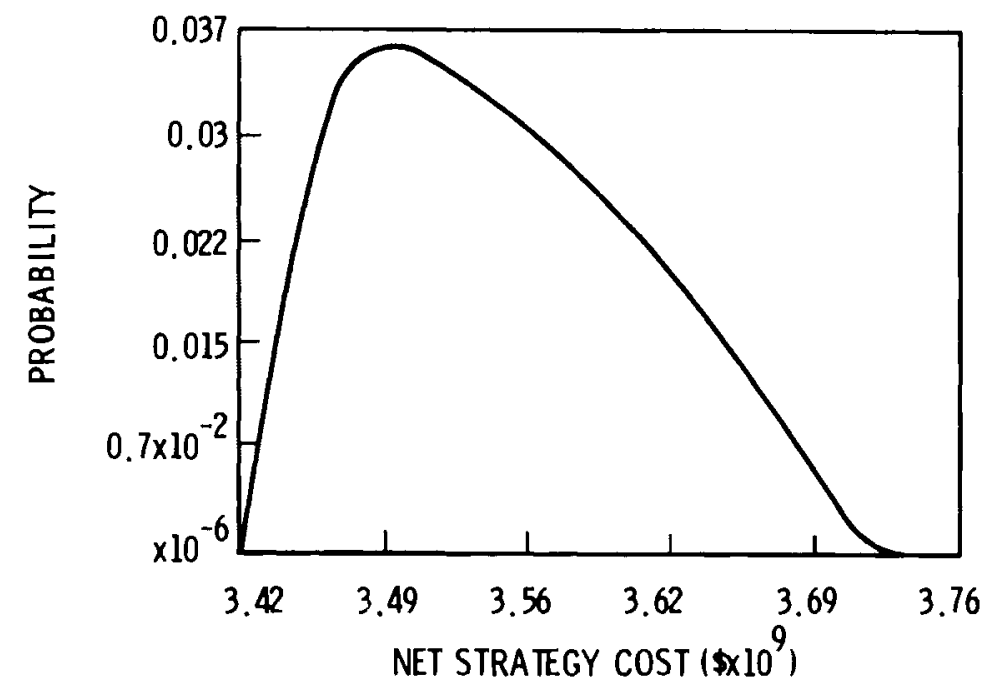

FIGURE 4.13. Discounted Capital Cost Probability Distribution for Component. Testing Strategy (E) 


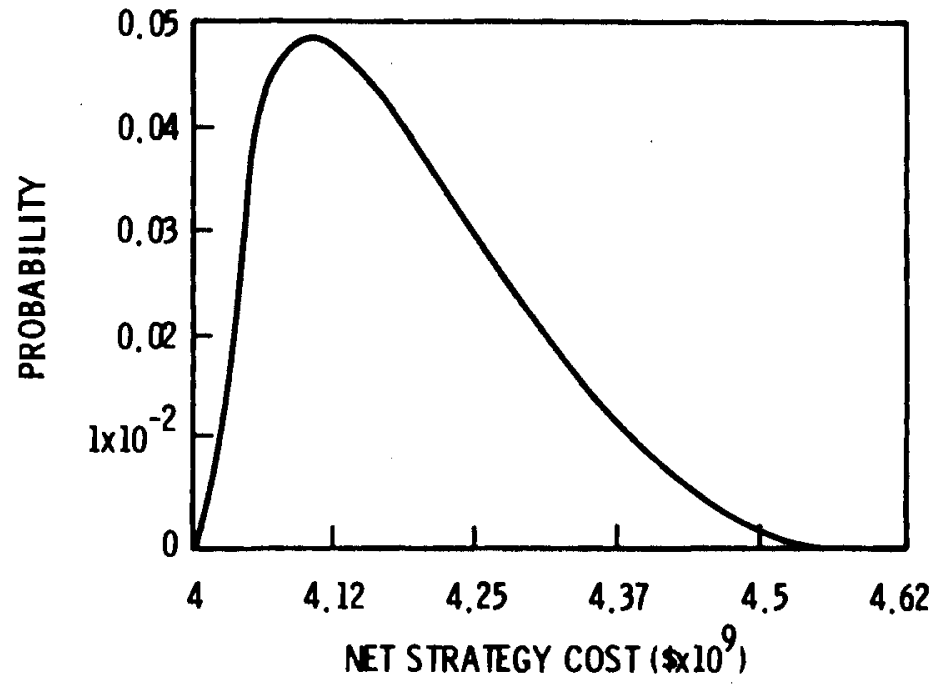

FIGURE 4.14. Discounted Capital Cost Probability Distribution for Direct Prototype Compressed Strategy (F)

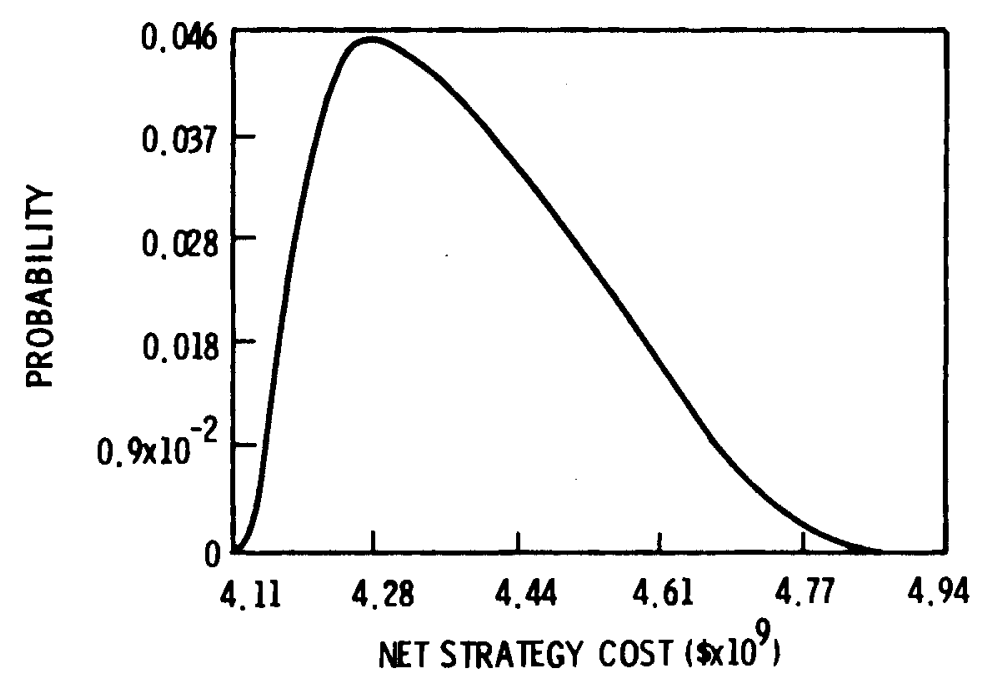

FIGURE 4.15. Discounted Capital Cost Probability Distribution for Direct Replicate Strategy (G) 
One effect of discounting is to alter the apparent uncertainties associated with strategy cost. As indicated in Chapter 3 and later in Chapter 5 , the uncertainties associated with cost and time are greater for the delayed strategies. However, the discounted distributions show an apparent decrease in the capital cost uncertainties. This is because the front-end strategy capital costs have less of an impact on total strategy cost in the delayed cases because of discounting. This effect is graphically illustrated in Figures 4.8, 4.9, 4.10, and 4.11. The discounted capital cost uncertainties for the Component Testing Strategy (Strategy E) also decreased as a result of delaying construction of the prototype for 10 vears. Discounting did not significantly alter the capital cost uncertainties in Strategies $F$ and $G$. 


\subsection{SCHEDULE TIME METHODOLOGY}

There are many uncertainties in the construction time for a commercial size FBR. For instance, the time from submittal of the Preliminary Safety Analysis Report (PSAR) to the awarding of the construction permit is uncertain. The process of having once submitted a PSAR to NRC for review will reduce the uncertainty about being able to submit the required documentation for subsequent plants. However, until the full licensing process, including all public hearings, has been completed, there will be considerable uncertainty associated with the time to receive a construction permit. FBR licensing procedures have not yet been firmly established. Furthermore, for any large scale construction project, there is a high probability for schedule slippage due to design problems, delays in shipment of components, etc. A probabilistic approach to developing strategy completion times was selected for this analysis to represent these many uncertainties.

Since a commercial size FBR has never been built in the United States, empirical data for plant completion times are non-existent. The FBR schedule time distributions used by this analysis were developed from interviews with participants in the prototype LMFBR studies, the Fast Flux Test Facility (FFTF) project, the Clinch River Breeder Reactor (CRBR) project, the LMFBR Conceptual Design Study (CDS) and industry representatives familiar with the French Phoenix projects. Their comments on the evolution of a mature industry and the relative importance of retention of skilled personnel, industrial growth, economies of scale, design standardization, and operation and construction experience form the basis of the time distributions assigned to each project activity in each strategy.

To probabilistically quantify the uncertainties associated with strategy completion times, the schedules for FBRs comprising each strategy are described in terms of their major milestones. These major milestones comprise a single generic project schedule that is used to represent the project schedules for a 11 FBRs. The generic schedules for each FBR are then combined and linked together to form a strategy. Associated with each milestone for any given FBR is a time probability distribution. This probability distribution 
characterizes the uncertainties associated with the time to complete each milestone. The computation of the strategy completion time probability distribution from the discrete milestone distributions was done with the aid of the network model QGERT. This program uses the Monte Carlo random path selection technique to develop the completion distribution for each strategy. A total of 1000 random selections are made among the individual milestone time probability distributions. A number of convergence tests were performed with the result that 1000 random selections yielded an acceptable variance in the estimate of the mean value for the completion time of each milestone. The strategy completion time probability distribution then is the combination of these 1000 selections and their relative frequency of occurrence. Before entering into the strategy completion time discussion, the following is a description of the generic FBR project schedule and its associated major milestones.

\subsection{GENERIC SCHEDULE}

The analysis of the various strategies utilizes a single project schedule network to represent each power plant project. This network is shown in Figure 5.1. Each activity or family of activities is discussed below.

1. Select Site and Award NSSS. Each project formally starts with the site selection and NSSS award, which typically occur in about the same time frame. Some prior activities such as preliminary site evaluations, evaluation of local public opinions, economic studies of delivered power cost tradeoffs relative to location, engineering site evaluations, and availability of construction labor, will have been completed. Depending on the planning horizon and state and local regulatory requirements, this may represent 3 to 5 years of application, review, hearings, and even litigation to obtain site approva 1 .

Federal projects follow a different process of nominally the same duration that involves a request for proposal, initial proposal and award and conduct a conceptual design. This process is followed by congressional authorization of the project. Some projects also do a 


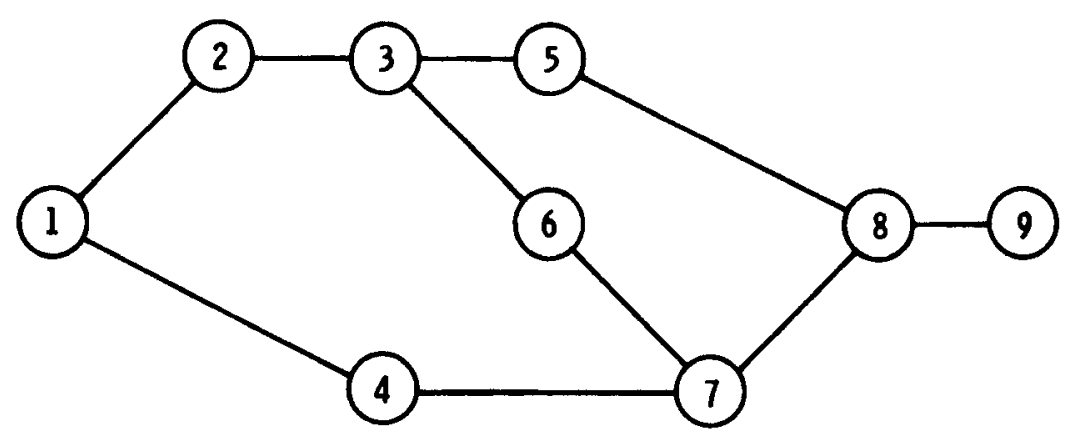

1. SIIE SELECTION/CONGRESSIONAL AUTHORIZATION

2. SUBMIT PSAR

3. ISSUE CONSTRUCTION PERMIT/CONSTRUCTION AUTHORIZATION

4. COMPLETE COMPONENT TESTING

5. COMPLETE CONSTRUCTION

6. SUBMIT FSAR

7. ISSUE OPERATING LICENSE/AUTHORIZE FUEL LOADING

8. LOAD FUEL/INITIAL CRITICALITY

9. COMMERCIAL/FULL POWER OPERATION

\section{FIGURE 5.1. Generic Project Schedule}

reference conceptual design prior to authorization. No money is spent on final design or procurement until authorization is received. This procedure is the equivalent of site selection and NSSS award for a commercial project. The federal project has this 2- to 4-year lead time while the project is evaluated prior to requesting congress to authorize the specific project at a specific site using specific contractors. The remainder of the schedule is similar enough that each activity or family of activities is representative of both federal and commercial projects.

2. Submit Preliminary Safety Analys is Report (PSAR). This represents the state of engineering design, completion of the environmental impact statement (EIS) and a 11 of the site characterizations. The engineering is 10 to $15 \%$ complete. 
3. Issue Construction Permit. This indicates that the project is far enough along to permit nonreversable work to commence. Construction force mobilization has been planned and civil structural design has reached the point where this work can commence with minimal potential for change. The regulatory review of the site and power plant design has been completed and the NRC is satisfied that both meet. safety criteria.

4. Complete Component Testing. This indicates that all of the capital equipment and safety related components scheduled for testing have been validated for use in the plant for a federal project. This also indicates that the base technology component testing in support of that project has verified the performance of the components planned for testing.

5. Complete Construction. All major construction prerequisite to beneficial use of the facility is completed. Some continuation of construction related activities is to be expected. This cleanup may include final site grading, completion of office building, completion of onsite spent fuel storage and construction punch list completion.

6. Submit Final Safety Analysis Report (FSAR). This activity signifies that all of the design work needed to complete the safety analysis has been completed. Any later design changes are generally initiated by the construction field engineers and are necessitated by construction or installation requirements. This is also the end of Title 2 engineering in federal terminology.

7. Issue Operating License. This is typically the last constraint on loading fuel in the power plant. All regulatory requirements have been satisfied and the plant has NRC authorization to load fuel, go critical, and operate at power. This, together with construction completion, signifies that the power plant is ready for commercial or full power operation. 
8. Load Nuclear Fuel and Initial Criticality. The construction is complete and the operating license is issued. The power plant is now capable of generating the heat to make steam and become a net power producer. All regulatory and technical restraints have been put behind. The power plant testing is essentially complete and following the core validation physics testing the ascent to full power provides the opportunity to perform the manufacturer's 100 hour warranty demonstration; the plant is then declared to be in "commercial operation."

9. Complete 1 Year Full Power Operation. This indicates that the plant has demonstrated its capability to generate electricity on the grid and has also completed its first refueling cycle to show that all plant design concepts have been validated. Initial plant capacity, availability, reliability and maintainability performance data have been accumulated.

\subsection{STRATEGY ANALYSIS}

As mentioned in Chapter 3, the factors that affect the uncertainty associated with strategy completion times are:

- scale-up

- operating experience

- personnel retention

- licensing

- component testing

- data transfer

- utility/industry commitment.

There are two principal effects on the strategy specific completion time distributions as a result of the above factors:

- a change in the scheduled duration for an individual activity from plant to plant

- a change in the uncertainty of the scheduled duration for an individual activity. 
These two effects are strategy specific and are directly influenced by the amount of learning transferred between FBRs built in succession. The degree of learning transferred is a function of overlap between the FBRs comprising a specific strategy.

Since the strategy completion times are quantified as probability distributions, there are two significant attributes of uncertainty associated with these distributions that will be illustrated in the following discussion.

1. The range of completion times

2. the relative likelihood of completion within the range.

The relative likelihood of completion refers to an interval of completion times within the completion distribution where there is a $90 \%$ probability of occurrence.

The following discussion utilizes these two attributes to compare the completion times and their associated uncertainties for each strategy. Time probability density functions, which are the result of the QGERT analysis, are presented for each strategy. It is interesting to compare the planned strategy completion times with the completion times predicted by the probability density functions. As shown in Figures 5.3, 5.7, 5.9, 5.11, 5.13, and 5.15 there is little or no probability that a strategy will be completed as planned. The planned or scheduled completion times contain no contingencies for slippage and assume the minimum time for completion of each major milestone. For large-scale construction projects, this is usually not the case as there frequently are situations that cause schedule delays. As mentioned earlier, these uncertainties are accounted for in the completion time probability distributions.

\section{Strategy A: Sequential}

A simplified version of the detailed network found in Appendix $B$ is shown in Figure 5.2 which graphically depicts the primary FBR linkages. As shown, the prototype receives congressional authorization to proceed when the developmental plant has operated for 1 full year. Likewise, the NSSS for replicate 1 


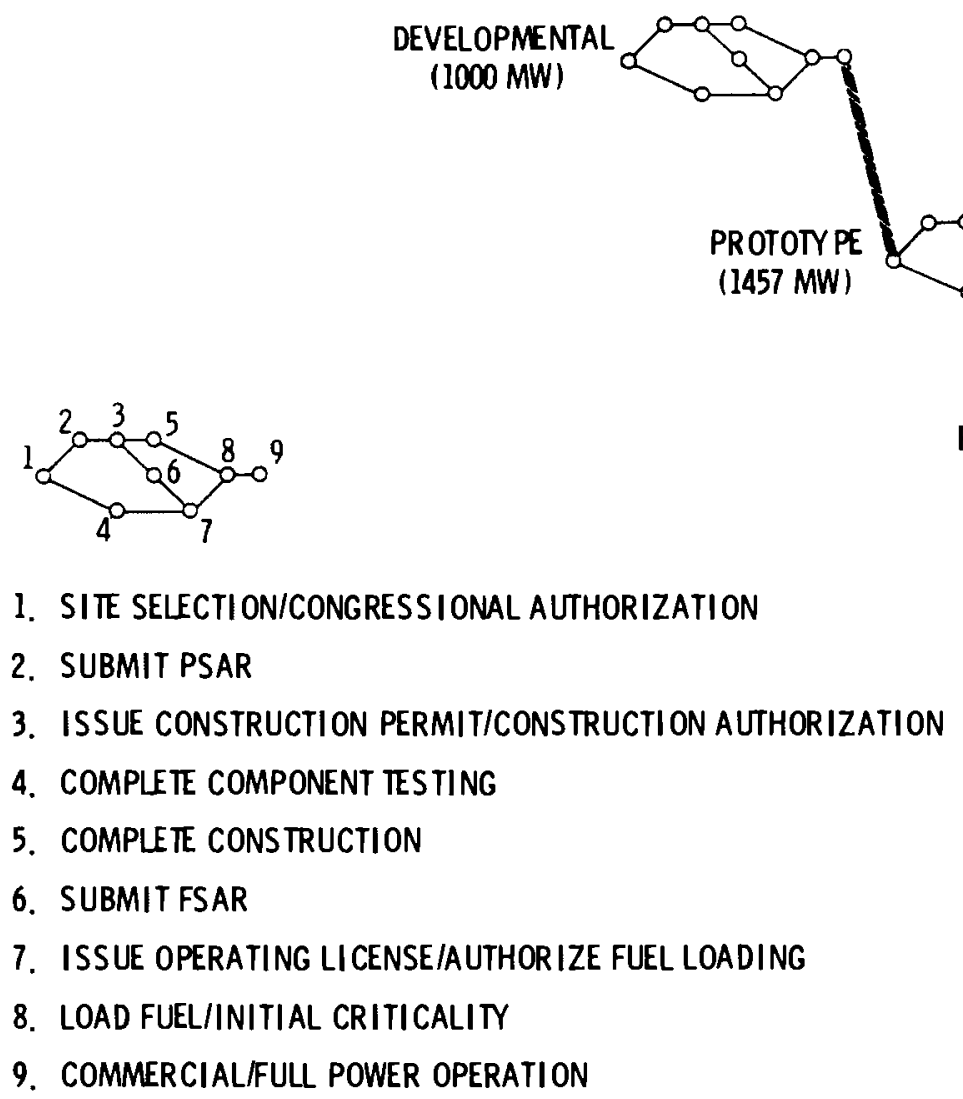

FIGURE 5.2. Primary Plant Linkage for Sequential Strategy $A$

is awarded when the prototype has operated for 1 full year. The replicate plants 2 and 3 and CBR-1 are scheduled to start at 1 year intervals following the start of replicate 1 .

The principal impact with this type of facility linkage is the relative increase in uncertainty associated with the overall strategy completion time. This may be somewhat counterintuitive since this strategy accumulates a large amount of operating experience, which would tend to reduce many of the technical uncertainties associated with development of commercial FBRs. However the attrition of skilled personnel is estimated to have a larger influence on the uncertainty associated with strategy completion. The large delay between the developmental and prototype plants and the prototype and replicate 1 plants would cause a demobilization of skilled licensing, design, and managerial 
personnel. The need to train new personnel for the design and licensing of each follow-on plant not only increases the uncertainties in plant completion times but also in the overall strategy completion time.

Figure 5.3 shows the completion time probability distribution which was calculated for the Sequential Strategy. The expected time of completion is 45 years with a minimum of 40.8 years and a maximum of 50.3 years. The imp? $i-$ cation is that there is some finite probability that commercializaton of FBRs in the Sequential Strategy will occur sometime over a period of about 10 years. Also, as shown in Figure 5.3, the 90\% probability interval of completion tines is about 7 years, which is another reflection of the uncertainty associated with the overall strategy completion time. For the remainder of this discussion, the other 6 strategies will be compared to the Sequential Strategy to point out relative differences.

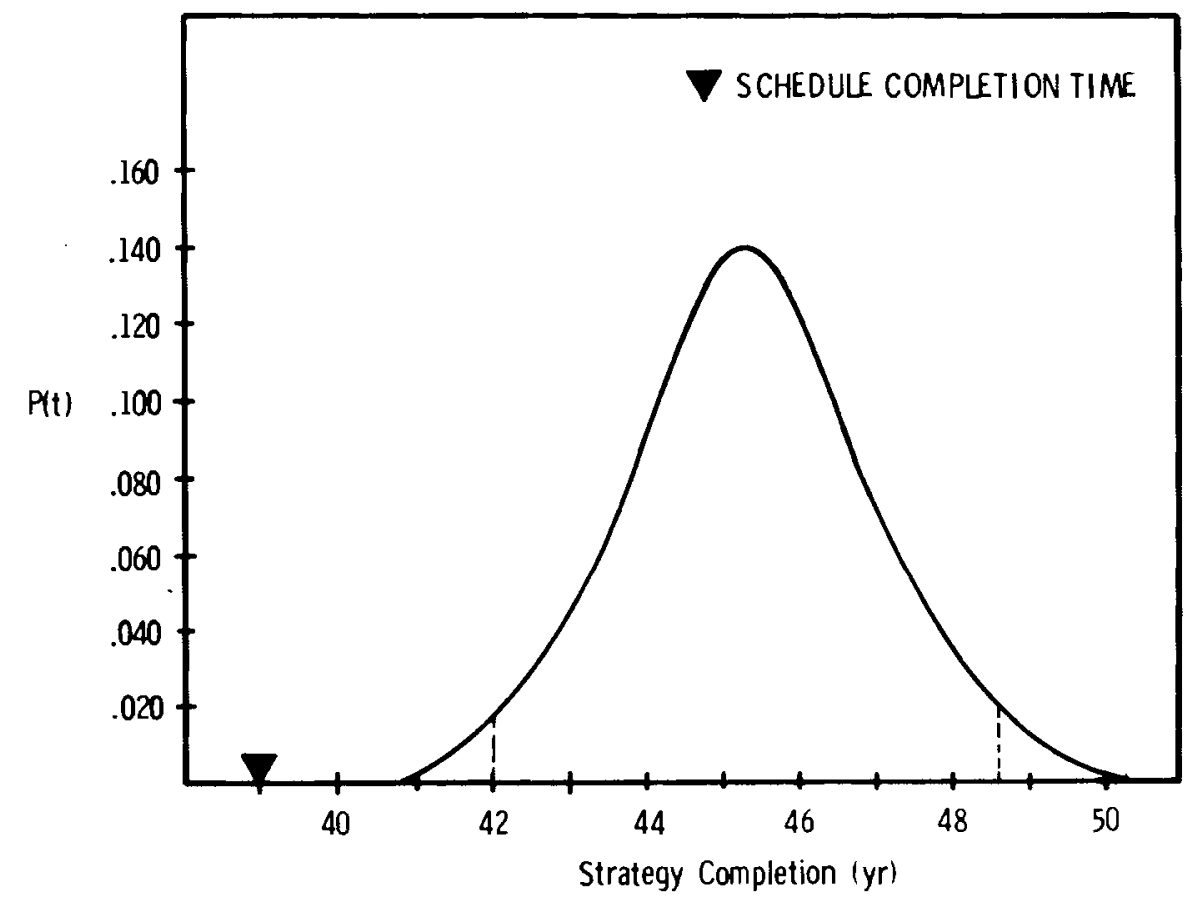

FIGURE 5.3. Completion Time Probability Distribution for Sequential Strategy A 


\section{Strategy B: Delayed Sequential}

The facility linkages for the Delayed Sequential and the Sequential Strategy are the same except that the decision to start Strategy $B$ is delayed 5 years as shown in Figure 5.4. The primary impact of this delay would be the loss of some skilled personnel who are now actively involved in the design and development of breeders. As a result the engineering and licensing activities for the developmental plant (CDS) are slightly greater than in the Sequential Strategy as well as their associated uncertainties. Beyond that, this strategy is similar to the Sequential Strategy with respect to the uncertainty associated with the time of completion as shown in Figure 5.5. The expected time of completion is 50 years with a minimum of 45.8 and a maximum of 55.4 years. As with the Sequential Strategy, the range of probable completion times is about 10 years and the $90 \%$ interval of completion times is about 7 years.

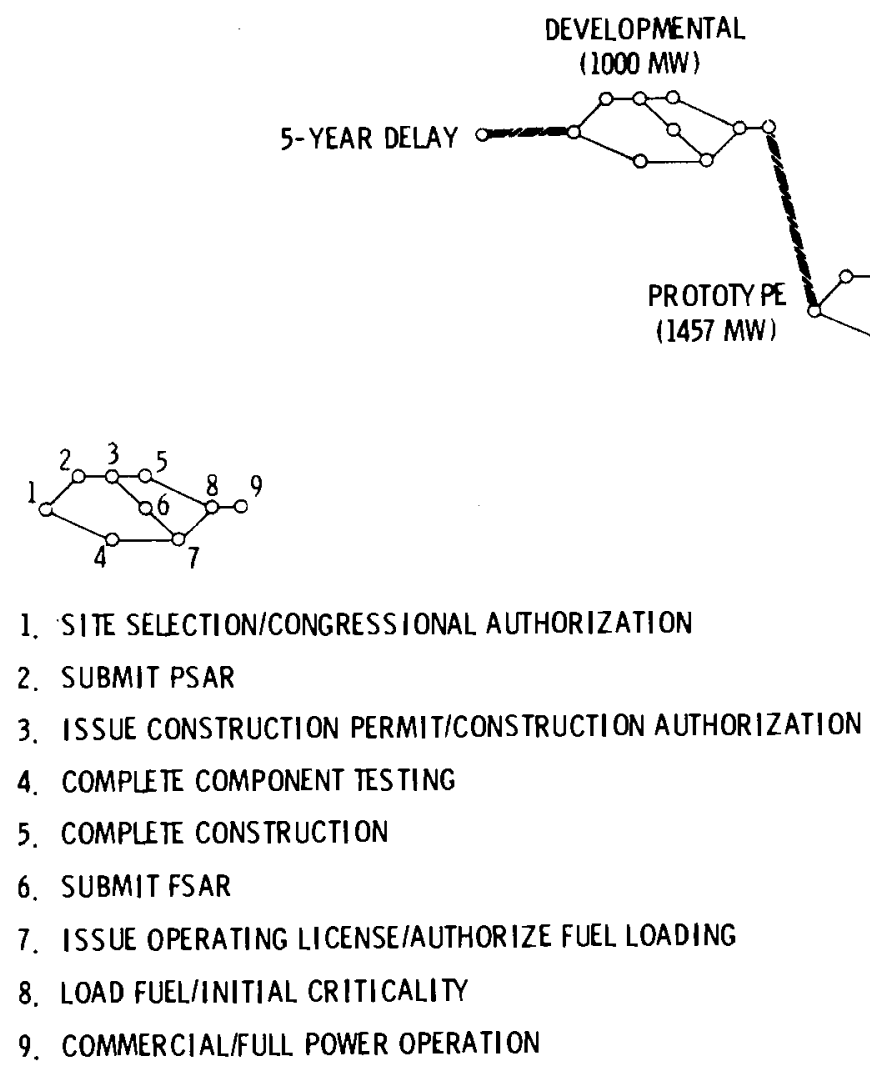

FIGURE 5.4. Primary Plant Linkage for Delayed Sequential Strategy B 


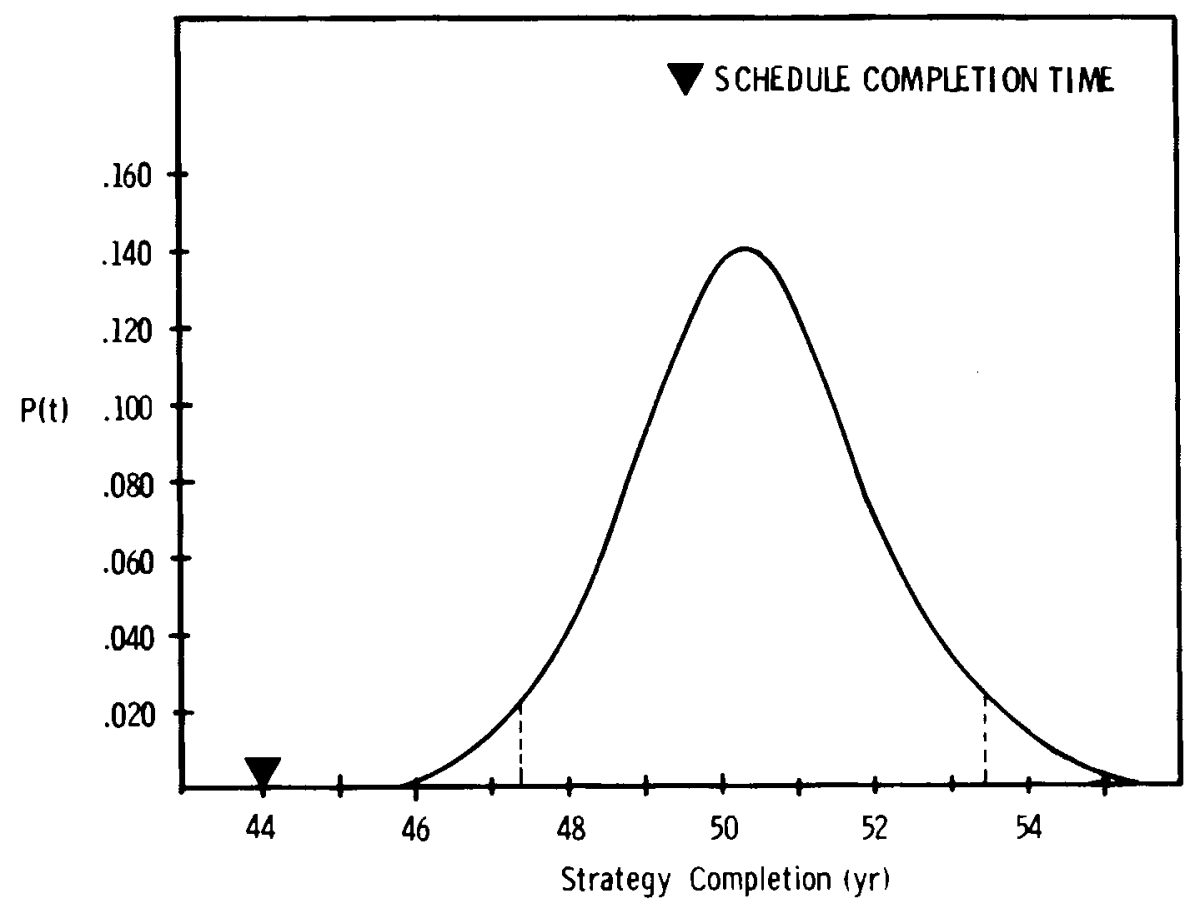

FIGURE 5.5. Completion Time Probability Distribution for Delayed Sequential Strategy B

\section{Strategy C: Compressed}

As shown in Figure 5.5, congressional authorization for the prototype plant will be coincident with completion of the component testing program for the Development Plant. The NSSS for replicate 1 will be awarded when the prototype receives an operating license. This is a more accelerated approach to commercial development of FBRs than the Sequential Strategy. With this degree of overlap between FBRs, the transition from the development phase to a mature, commercial industry is more rapid. The overall result is a reduction in the uncertainty associated with strategy completion compared to the Sequential Strategy. The expected completion time is 33 years with a minimum of 30 and a maximum of 37.8 years. As shown in Figure 5.7 , the range of strategy completion times is 7.8 years, which is about 2 years less than the Sequential Strategy and the $90 \%$ probability interval of completion times is about 5 years. 


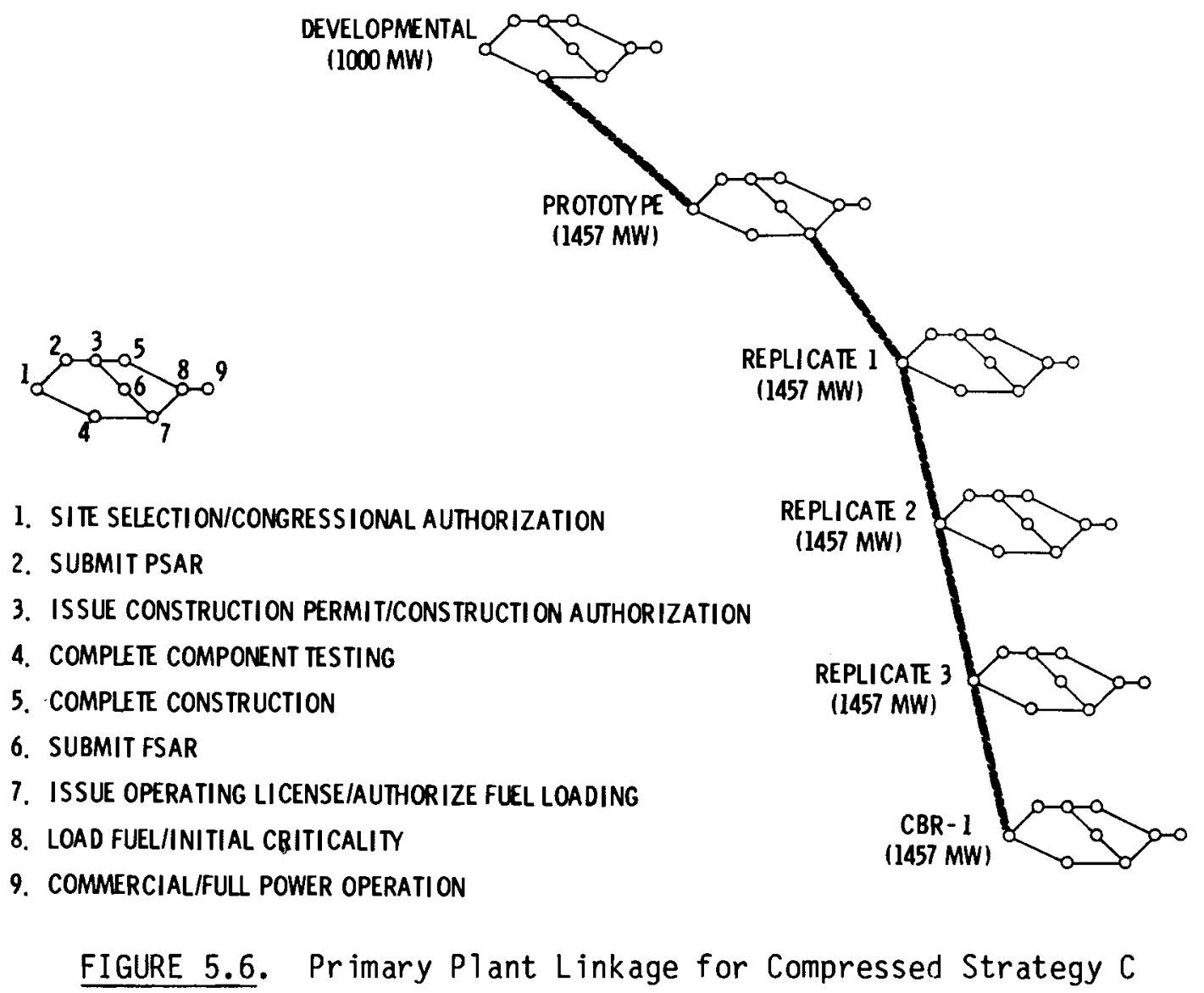

Strategy D: Delayed Compressed

This strategy is identical to the Compressed Strategy with the exception of a 5-year delay in obtaining congressional authorization for the developmental plant shown in Figure 5.8. The impact of this delay would be to increase the uncertainty of completing the component testing for the developmental plant. Due to the rapid development of FBRs with this strategy, this delay, as shown in Figure 5.9, has more of an impact on the strategy completion time uncertainty than in the case of the Delayed Sequential Strategy. The range of completion times is about 8.8 years, 1 year more than the Compressed Strategy and the $90 \%$ probability interval of completion times is about 5 years. Relative to the Compressed Strategy, the 5-year delay translates to a 12 month increase in the uncertainty on the total range of completion times, which have a minimum and maximum of 34 and 42.8 years, respectively, and an expected time for completion of 38 years. 


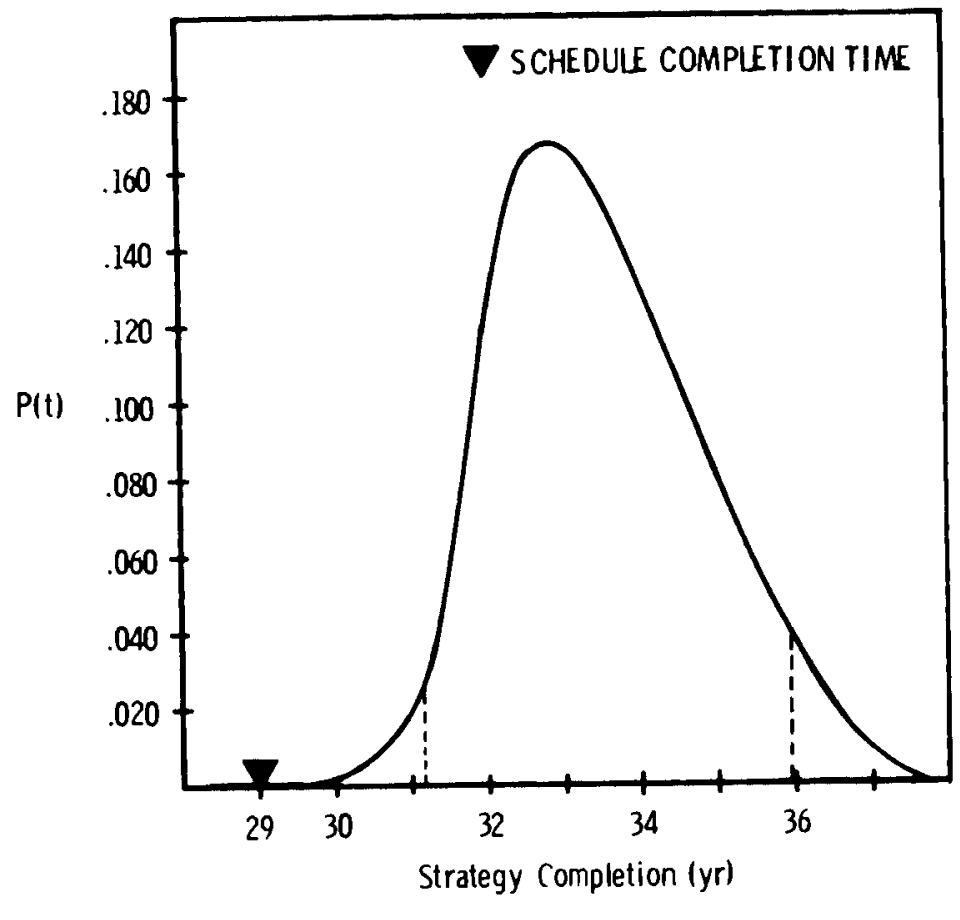

FIGURE 5.7. Completion Time Probability Distribution for Compressed Strategy C

\section{Strategy $\mathrm{E}:$ Component Testing}

This strategy assumes that a 10 year component testing program is followed by congressional authorization for a prototype plant as shown in Figure 5.10. The design and construction for replicate 1 is scheduled to start when the prototype plant receives an operating license. There is a considerable reduction of the technical uncertainties associated with large sodium components with this type of strategy, which tends to reduce the uncertainty associated with completion and operation of the prototype plant. Since there is no scale-up associated with the following plants the experience accumulated during the 10-year component testing program, as well as the components themselves, can be applied to each preceding plant. This will tend to reduce the uncertainty in the time to license replicate 1 , which in turn reduces the uncertainty associated with strategy completion. As a result, the range for 


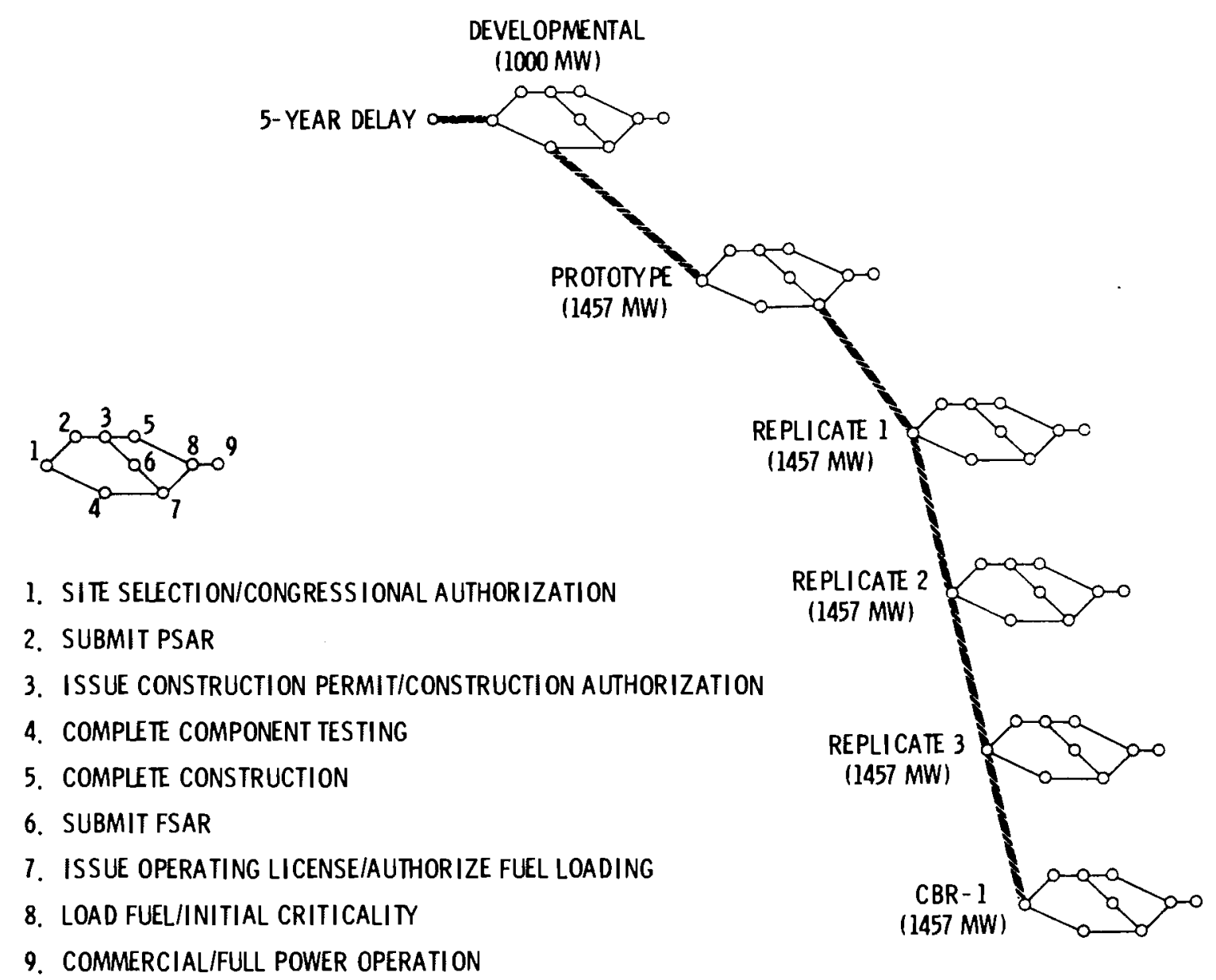

FIGURE 5.8. Primary Plant Linkage for Delayed Compressed Strategy D

strategy completion as shown in Figure 5.11 is 8 years. The expected completion time is 37 years with a minimum and maximum of 34 and 42 years, respectively. The most significant result is that the $90 \%$ probability interval for completion is about 4 years. This represents a reduction in completion uncertainty of 3 years relative to the Sequential Strategy.

Strategy F: Direct Prototype

This strategy proceeds with the design and construction of a prototype plant that is to be fully licensed and designed to meet utility requirements. Replicate 1 is scheduled to begin when the prototype has received an operating license as shown in Figure 5.12. Without any commercial size FBR operating 


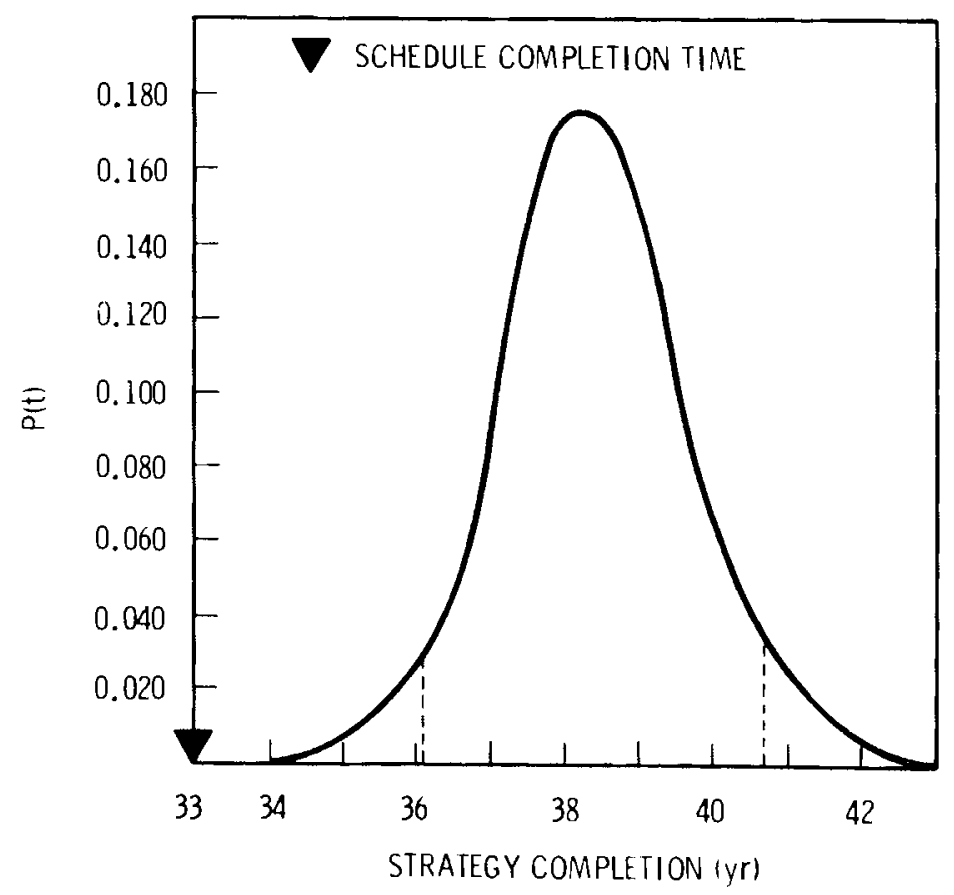

FIGURE 5.9. Completion Time Probability Distribution for Delayed Compressed Strategy D

experience available the principal uncertainty associated with strategy completion time is the licensing of the prototype plant. However, as a result, the uncertainty associated with the time to license replicate 1 is significantly reduced. Relative to the Sequential Strategy, the overall strategy completion time is less as is the uncertainty associated with the completion time. This can be seen in Figure 5.13. The range for strategy completion is about 8 years but the $90 \%$ probability interval for completion is 4 to 5 years. The expected time for strategy completion is 28 years with a minimum of 24 years and a maximum of 32 years.

Strategy G: Direct Replicate

Like Strategy $A$, this strategy begins with the design of the developmental plant (CDS) as shown in Figure 5.14. After operating for 1 full year, the developmental plant is followed by replicate 1 with subsequent FBRs coming at 1-year intervals. The principal uncertainty associated with strategy completion time is the attrition of skilled personnel resulting from the significant 


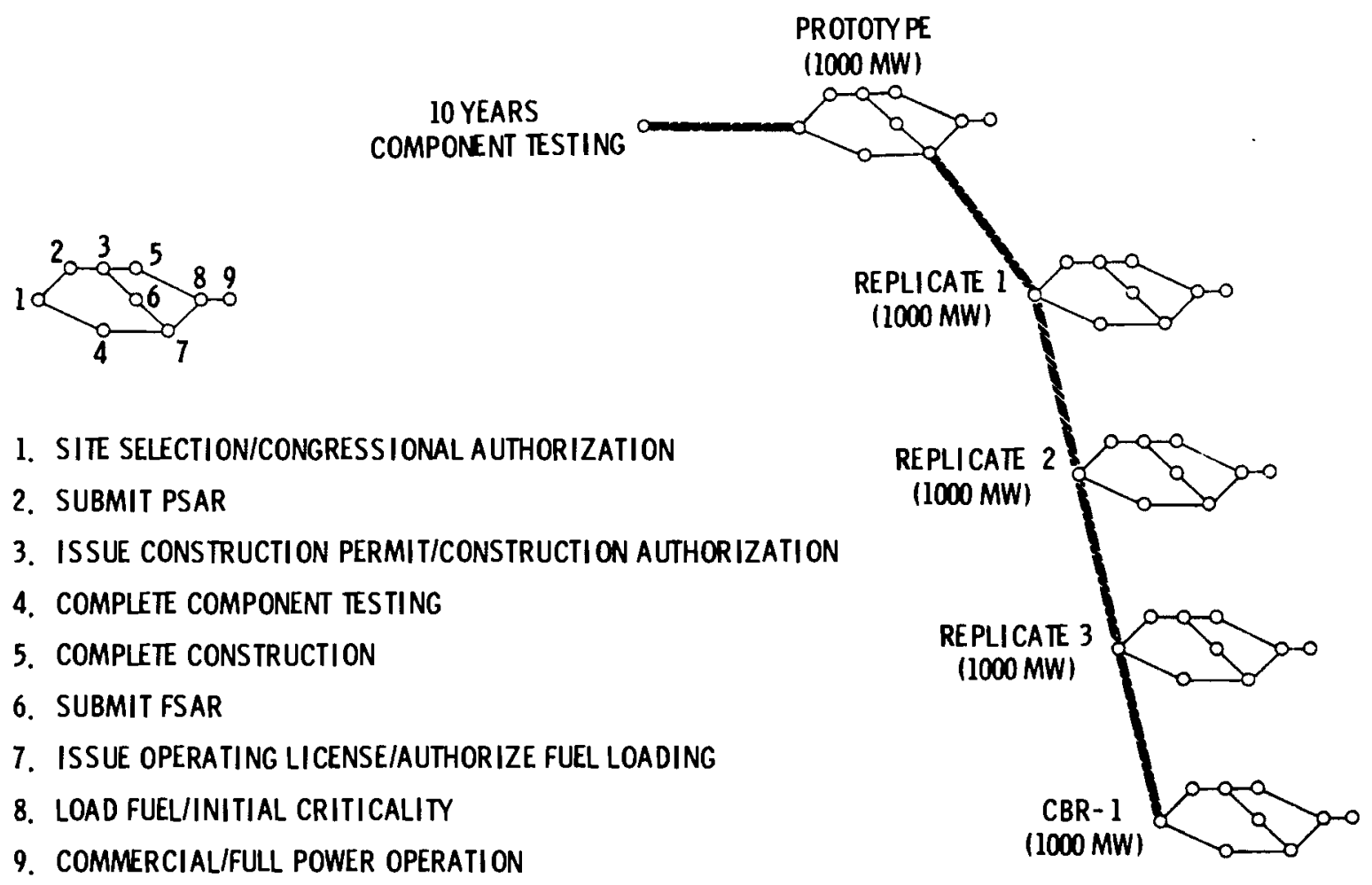

FIGURE 5.10. Primary Plant Linkage for Component Testing Strategy E

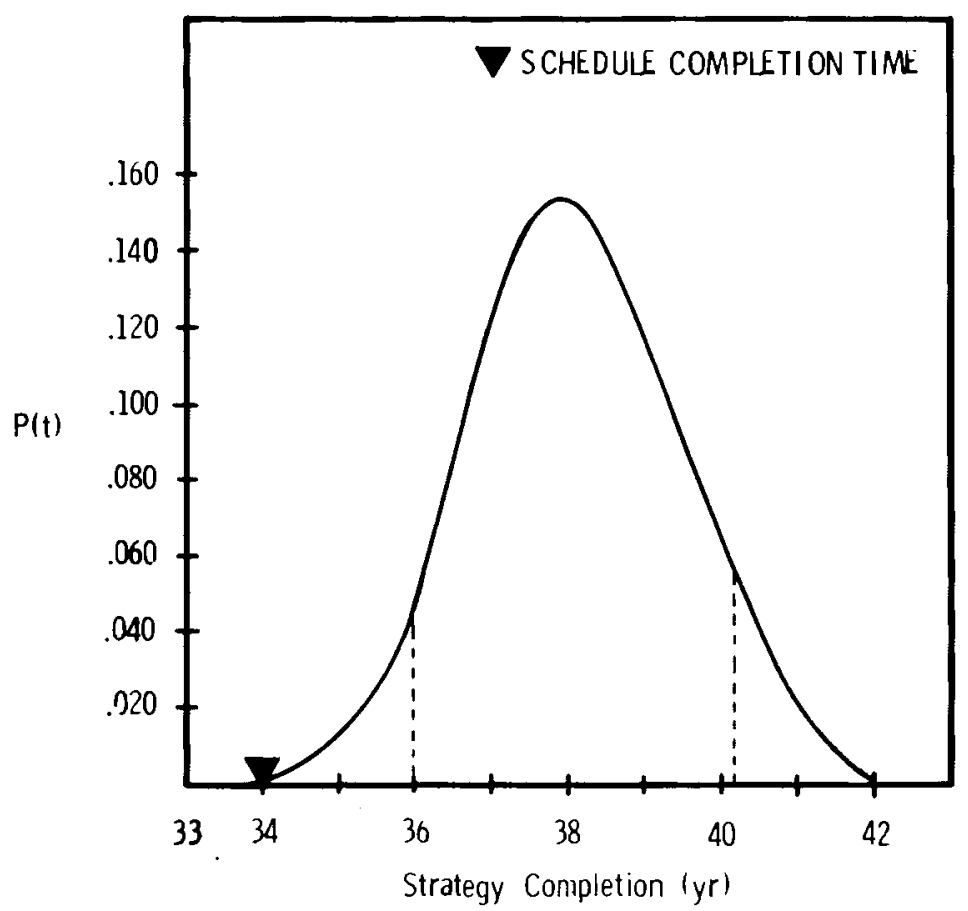

FIGURE 5.11. Completion Time Probability Distribution for Component Testing Strategy E 


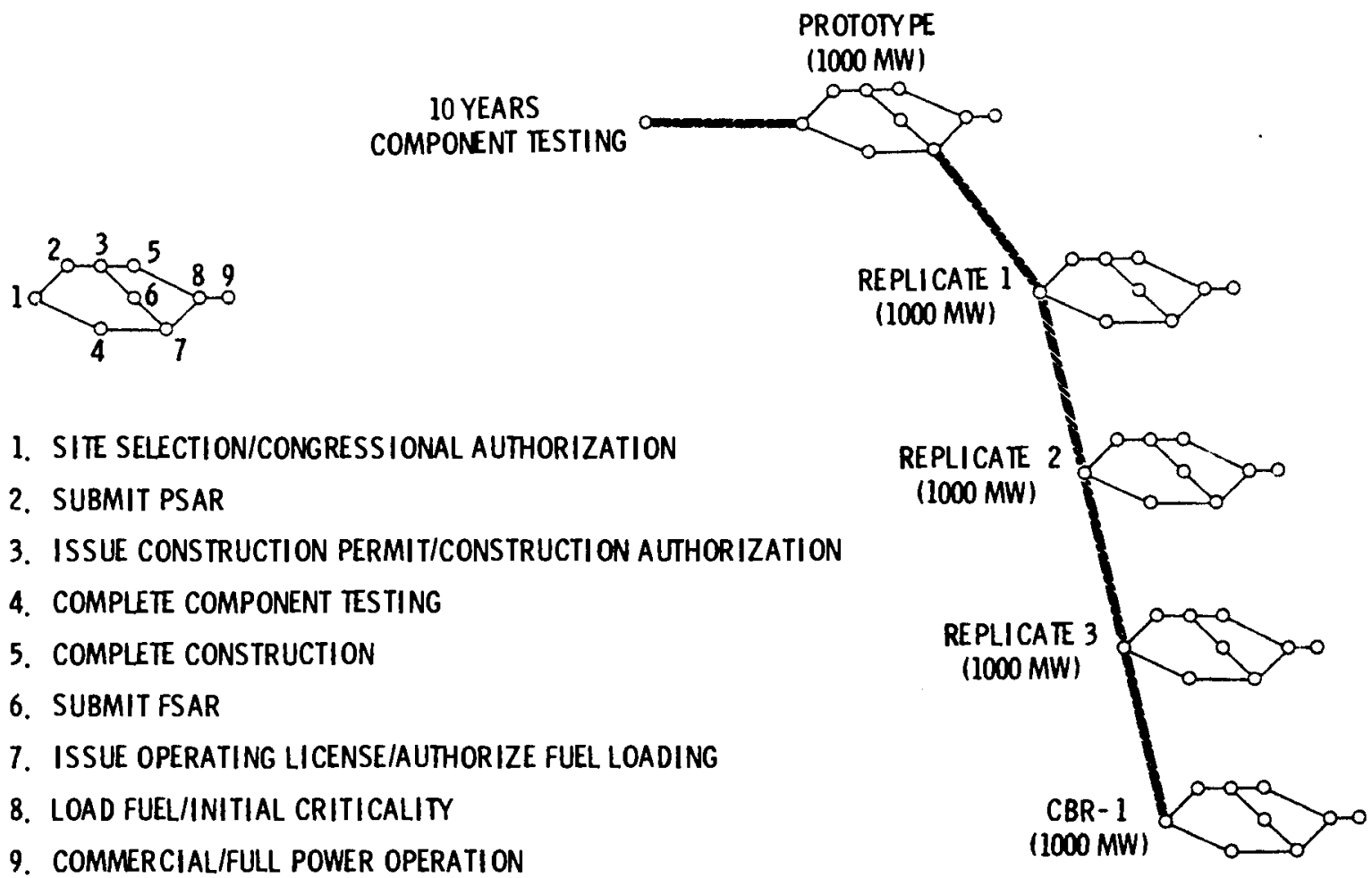

FIGURE 5.10. Primary Plant Linkage for Component Testing Strategy E

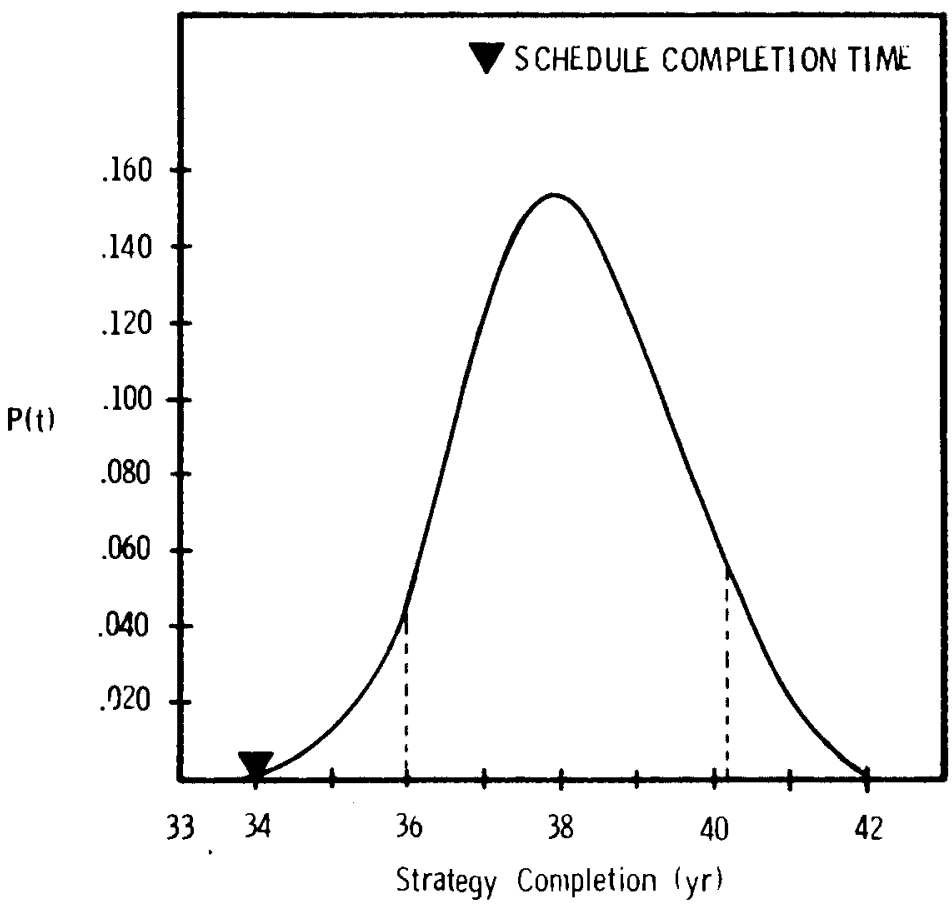

FIGURE 5.11. Completion Time Probability Distribution for Component Testing Strategy $E$ 


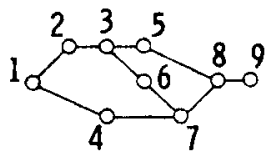

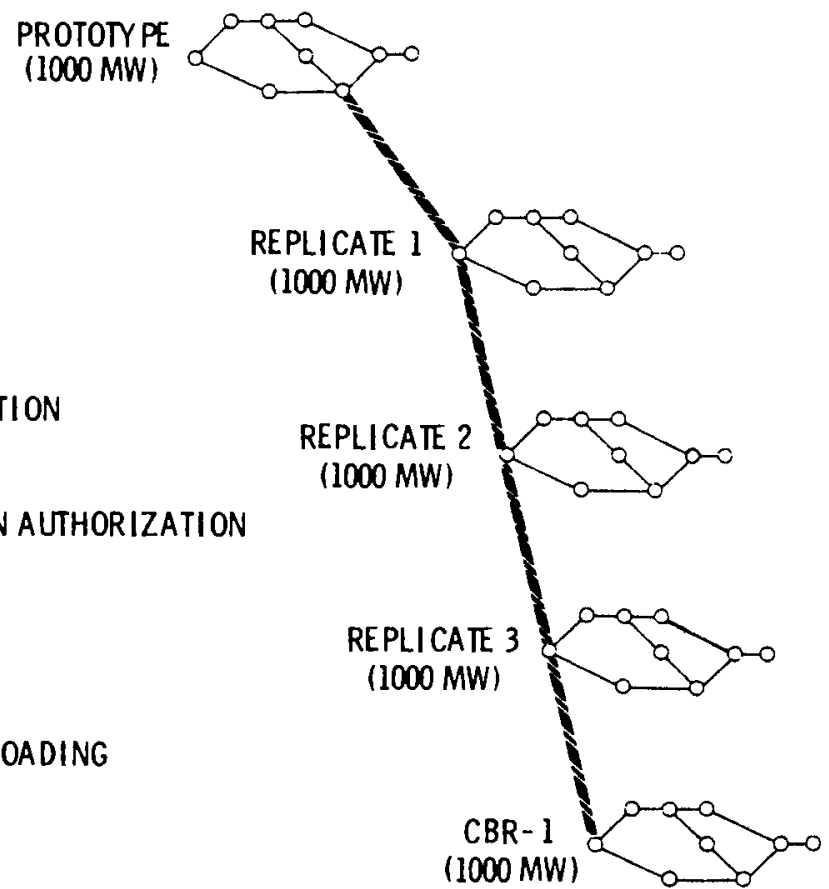

1. SIIE SELECTION/CONGRESSIONAL AUTHORIZATION

2. SUBMIT PSAR

3. ISSUE CONSTRUCTION PERMIT/CONSTRUCTION AUTHORIZATION

4. COMPLETE COMPONENT TESTING

5. COMPLETE CONSTRUCTION

6. SUBMIT FSAR

7. ISSUE OPERATING LICENSE/AUTHORIZE FUEL LOADING

8. LOAD FUEL/INITIAL CRITICALITY

9. COMMERCIAL/FULL POWER OPERATION

FIGURE 5.12. Primary Plant Linkage for Direct Prototype Strategy F

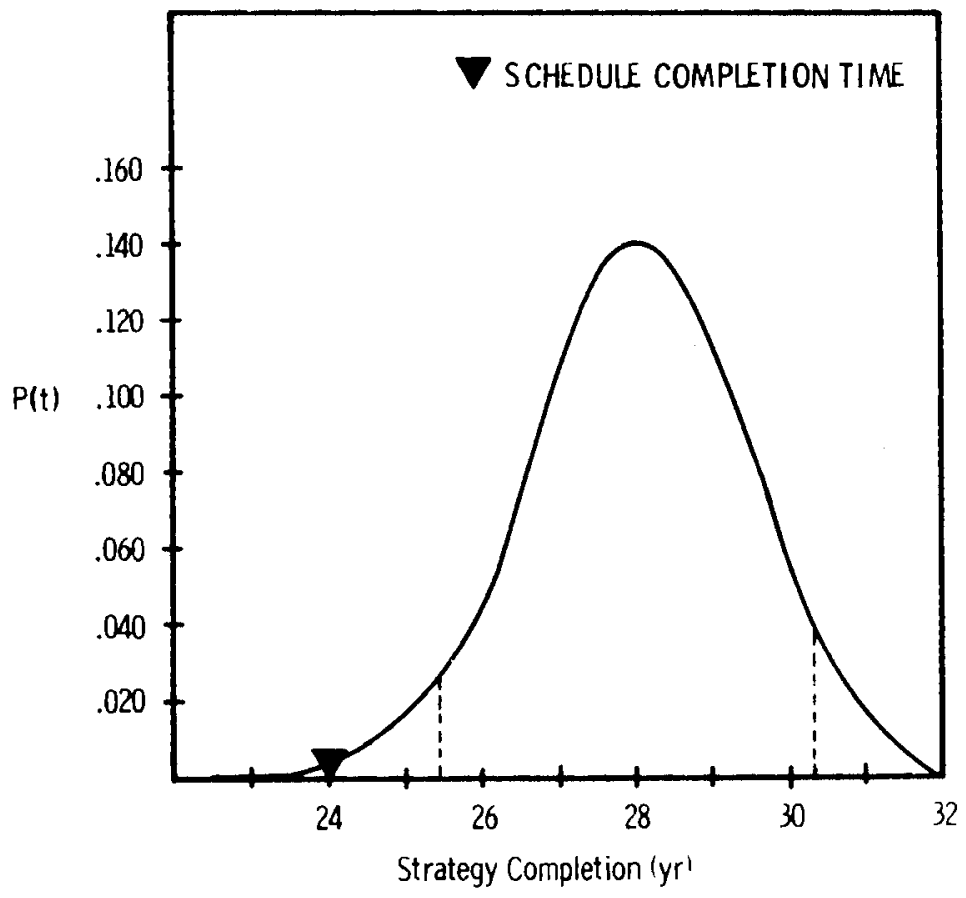

FIGURE 5.13. Completion Time Probability Distribution for Direct Prototype Strategy F 
delay between the developmental and replicate plants. However, unlike the Sequential Strategy, this occurs only once since there is no prototype following the developmental plant and the build up of a commercial industry is immediate with the start of replicate 1. Relative to the Sequential Strategy, then, the uncertainty associated with strategy completion is reduced as shown in Figure 5.15. The range of completion times is about 8 years and the $90 \%$ probability interval for completion time is 4 to 5 years. The expected time for completion is 29 years with a minimum and maximum of 25.3 and 33.2 years, respectively.

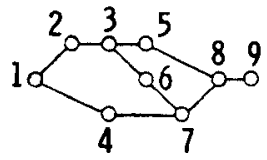

\section{DEVELOPMENTAL} (1000 MW)

1. SIIE SELECTION/CONGRESSIONAL AUTHORIZATION

2. SUBMIT PSAR

3. ISSUE CONSTRUCTION PERMIT/CONSTRUCTION AUTHORIZATION

4. COMPLETE COMPONENT TESTING

5. COMPLETE CONSTRUCTION

6. SUBMIT FSAR

7. ISSUE OPERATING LICENSE/AUTHORIZE FUEL LOADING

8. LOAD FUELIINITIAL CRITICALITY

9. COMMERCIAL/FULL POWER OPERATION

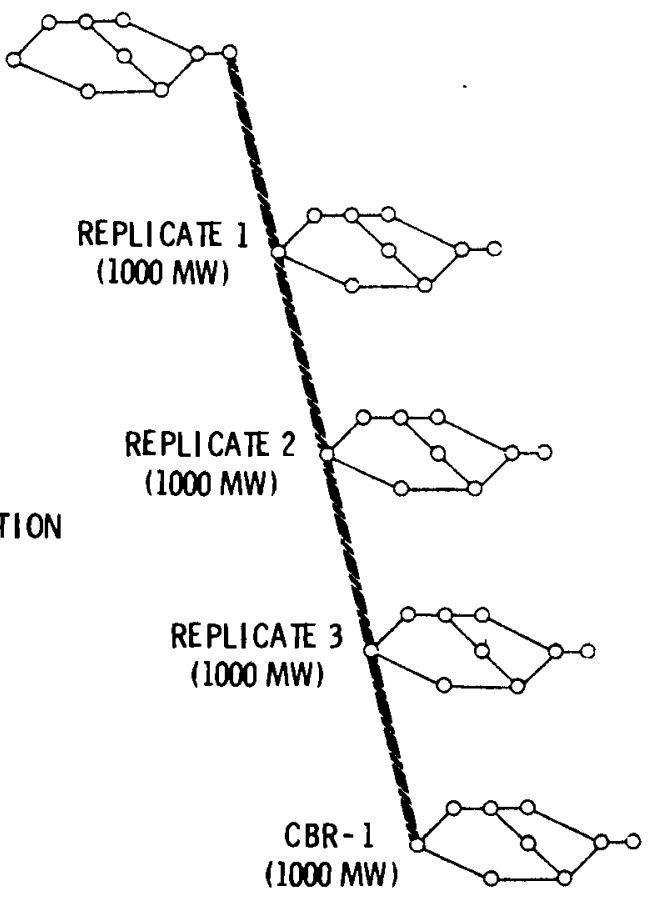

FIGURE 5.14. Primary Plant Linkage for Direct Replicate Strategy G 


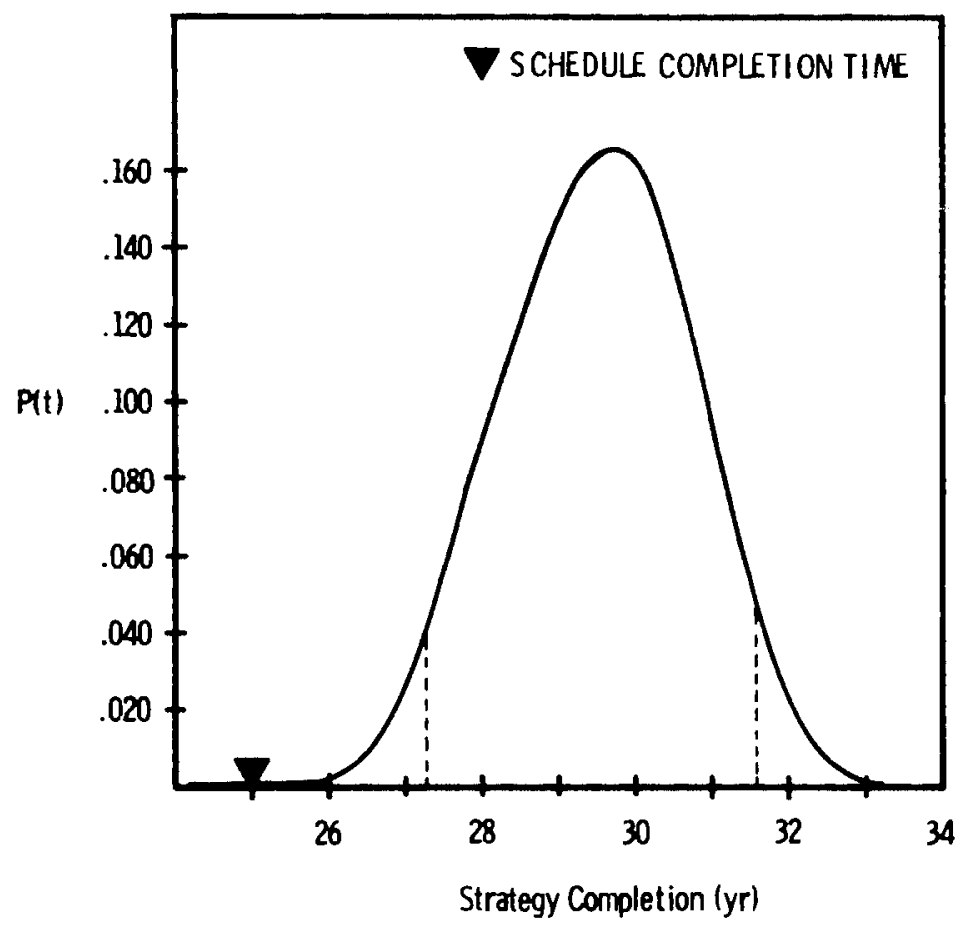

FIGURE 5.15. Completion Time Probability Distribution for Direct Replicate Strategy $G$ 


\subsection{CONCLUSIONS}

Commercial FBR development can proceed using any one of a number of alternative strategies. Regardless of the development path selected, there are tradeoffs that influence the strategy costs and completion times as well as their respective uncertainties. The general trend identified by this analysis is that the uncertainty associated with strategy completion time is reduced with the accelerated strategies while the uncertainty associated with strategy cost increased with these strategies. As might be expected, the inclusion of uncertainties into the time analysis results in markedly longer expected times for development strategies than does simple addition of schedule times. In view of historical project development data, it seems that the network analysis used here provides a realistic estimate of development times. 


\section{REFERENCES}

Abramowitz, J., and I. A. Stegun, eds. 1964. Handbook of Mathematical Functions. Applied Mathematics Series 55, National Bureau of Standards, U.S. Government Printing Office, Washington, D.C.

Budwani, Ramesh. May 1980. "Power Plant Capital Cost Analysis." Power Engineering.

Burnham. J. B., A. J. Boege 1, D. W. Fraley, and M. K. White. 1981. Analysis of Alternative FBR Development Strategies. PNL-3600, Pacific Northwest Laboratory, Richland, Washington

Executive Office of the President, Energy Policy and Planning. 1977. The National Energy Plan. p. ix. U.S. Government Printing Office, Washington, D.C.

Fraley, D. W. 1981. A Method for Selecting Fast Breeder Reactor Development Strategies in the Presence of Uncertainties. PNL-3598, Pacific Northwest Laboratory, Richland, Washington.

Hahn, G. J., and S. S. Shapiro. 1967, Statistical Models in Engineering. John Wiley \& Sons, Inc., New York.

Nanda, R., and G. L. Adler, eds. 1977. Learning Curves Theory and Application. Monograph Series No. 6, Amercian Institute of Industrial Engineers, Atlanta, Georgia.

NUS Corporation. 1969. Guide for Economic Evaluaton of Nuclear Reactor Plant Designs. NUS-531, prepared for U.S. Atomic Energy Commission and Oak Ridge National Laboratory by NUS Corporation, Rockville, Maryland.

Piepe1, G. F., et al. 1981. Probabilistic Estimates of U.S. Uranium Supply. PNL-3595, Pacific Northwest Laboratory, Richland, Washington.

Pritsker, A. A. B. 1977. Modeling and Analysis Using Q-GERT Networks. Halsted Press, John Wiley \& Sons, Inc., New York.

United Engineers \& Constructors (UE\&C). 1979. Energy Economic Data Base (EEDB) Program Phase I. Vols 1, 2, and 3. UE\&C-DOE-790930, prepared for U.S. Department of Energy by United Engineers \& Constructors, Inc., Philadelphia, Pennsylvania.

U.S. GAO. 1975. The Liquid Metal Fast Breeder Reactor Program - Past, Present, and Future. RED-75-352. U.S. Government Printing Office, Washington, D.C.

White, M.K., and E.T. Merrill. 1981. Evaluation of the Commercial FBR Introduction Date. PNL-3597, Pacific Northwest Laboratory, Richland, Washington. 

APPENDIX A

\section{DERIVATION OF CAPITAL COST DISTRIBUTIONS}

As mentioned in Chapter 4 , the tota 1 net cost to the government for the implementation of a particular strategy is the sum of the various plant capital costs, base technology costs, fuel cycle and 0\&M costs, and power credits. This appendix will explain the derivation of these components.

\section{A.1. PLANT CAPITAL COSTS}

The following is a sample of the calculational procedure used to determine the beta distribution for the developmental plant in the Sequential Strategy. The capital cost estimate for this plant as provided by DOE in 1980 do 11 ars was:

$\frac{\text { Minimum }}{\$ 2680 \times 10^{6}} \frac{\text { Expected }}{\$ 2920 \times 10^{6}} \frac{\text { Maximum }}{\$ 3500 \times 10^{6}}$

Since confidence levels of $10 \%$ and $90 \%$ were requested for the minimum and maximum estimates respectively, the points of zero probability had to be estimated in an iterative fashion. The results of these iterations yielded the new range of absolute minimum and maximum values:

$$
\frac{\text { Min imum }}{\$ 2600 \times 10^{6}} \quad \frac{\text { Expected }}{\$ 2920 \times 10^{6}} \quad \frac{\text { Maximum }}{\$ 3560 \times 10^{6}}
$$

These values then, were transformed to an interval defined by $0 \leq x \leq 1$, by the following equation:

$$
x=\frac{\text { Capital Cost }-\$ 2600 \times 10^{6}}{\$ 960 \times 10^{6}}
$$


Thus, the above estimates were reduced to:

$\frac{\text { Minimum }}{0} \quad \frac{\text { Expected }}{0.334} \frac{\text { Maximum }}{1.0}$

The next step is to iteratively estimate the mode of the distribution. This was found to be $\$ 2750 \times 10^{6}$, which transforms to $x=0.156$. With a beta distribution, the expected value is defined by:

$$
\text { expected value }=\frac{\gamma}{\gamma+\eta}
$$

With the expected value known, $n$ can be defined in terms of $\gamma$ :

$$
\begin{aligned}
0.334 & =\frac{\gamma}{\gamma+\eta} \\
\eta & =1.995 \gamma
\end{aligned}
$$

It is also characteristic of beta distributions that the mode can be defined in terms of $\gamma$ and $\eta$ :

$$
\begin{aligned}
\gamma-1 & =\operatorname{mode}(\gamma+n-2) \\
& =0.156(\gamma+n-2)
\end{aligned}
$$

Substituting equation A.4 into A.5 yields a value for $Y$ of 1.29. Using equation $A .4 n$ is found to be 2.58. The general form of the beta distribution is:

$$
f(x)=B(\gamma, n)(x)^{\gamma-1}(1-x)^{n-1}
$$

The term $B(\gamma, \eta)$ is the beta function: 


$$
B(\gamma, n)=\frac{\Gamma(\gamma+n)}{\Gamma(\gamma) \Gamma(n)}
$$

Using published tabular values for the gamma function, equation A.7 yields:

$$
B(\gamma, n)=2.47
$$

When the argument in the gamma function is $\geq 2$ the following relationship is used:

$$
\Gamma(n)=(n-1) \Gamma(n-1)
$$

where

$$
n \geq 2
$$

The other three distributions for the developmental plant were calculated in a similar fashion. The results are found in Table A.1.

TABLE A.1. Analytical Cost Distributions for the Developmental Plant Strategy Probability Function Cost Transformation

$$
\begin{aligned}
& A, C, G \quad f(x)=2.47(x)^{\gamma-1}(1-x)^{n-1} \\
& \begin{array}{l}
r=1.29 \\
n=2.58
\end{array} \text { Cost }\left(\$ \times 10^{6}\right)=960(x)+2.600 \\
& B, D \quad f(x)=4.66(x)^{\gamma-1}(1-x)^{n-1} \\
& \begin{array}{l}
\gamma=1.32 \\
\eta=2.80
\end{array} \text { Cost }\left(\$ \times 10^{6}\right)=1000(x)+2700 \\
& E \quad f(x)=1.99(x)^{\gamma-1}(1-x)^{n-1} \\
& \gamma=1.13 \\
& \eta=1.68 \\
& \operatorname{Cost}\left(\$ \times 10^{6}\right)=620(x)+2500 \\
& F \quad f(x)=8.5(x)^{\gamma-1}(1-x)^{\Gamma_{1}-1} \\
& \gamma=1.54 \\
& \operatorname{Cost}\left(\$ \times 10^{6}\right)=780(x)+2380
\end{aligned}
$$

Chapter 4 indicated that several estimates were received for the mature 1000- and 1457-MW FBRs. Each estimate was fit to a Weibull distribution in the following manner. The density function for the Weibull distribution is defined by: 


$$
f(x)=\frac{c}{\alpha}\left(\frac{x-\xi}{\alpha}\right)^{C-1} \exp \left[-\left(\frac{x-\xi}{\alpha}\right)^{C}\right] \quad x>\xi
$$

The cumulative distribution is:

$$
\begin{aligned}
f(x) & =\int_{\xi}^{x} f(t) d t \\
& =1-\exp \left[-\left(\frac{x-\xi}{\alpha}\right)^{C}\right]
\end{aligned}
$$

The expected value for a Weibull distribution is calculated by:

$$
\text { Expected Value }=\xi+\alpha \Gamma\left(\frac{1}{\mathrm{C}}+1\right)
$$

With $10 \%$ and $90 \%$ confidence levels on the minimum and maximum values, respectively, the term $\xi$ represents the absolute minimum. Therefore, from equation $A .12$ we know that:

$$
\begin{aligned}
& 0.1=1-\exp \left[-\left(\frac{x_{1}-\xi}{\alpha}\right)^{C}\right] \\
& 0.9=1-\exp \left[-\left(\frac{x_{3}-\xi}{\alpha}\right)^{C}\right]
\end{aligned}
$$

where

$$
\begin{aligned}
& x_{1}=\text { minimum estimate } \\
& x_{3}=\text { maximum estimate }
\end{aligned}
$$


Equation A.14 reduces to:

$$
\begin{aligned}
& \left(\frac{x_{1}-\xi}{\alpha}\right)^{C}=-\ln 0.1 \\
& \left(\frac{x_{3}-\xi}{\alpha}\right)^{C}=-\ln 0.9
\end{aligned}
$$

By eliminating in both equations an expression for the calculation of $C$ can be found. Combining A.16 and A.17, yields:

$$
\left(\frac{x_{1}-\xi}{x_{3}-\xi}\right)^{C}=\frac{\ln 0.9}{\ln 0.1}
$$

Solving for C:

$$
C=\frac{\left.\ln \frac{(\ln 0.9}{\ln 0.1}\right)}{\ln \left(\frac{x_{1}-\xi}{x_{3}-\xi}\right)}
$$

Additionally, the term $\alpha$ for a Weibull distribution is found by:

$$
\alpha=\frac{x_{3}-\xi}{(-\ln 0.1)^{1 / C}}
$$

The first step is to estimate the term $\xi$, followed by the determination of $C$ and $\alpha$. This process is iterated until the expected value, as predicted by equation A.13, is equivalent to the estimate of the expected value provider by DOE. The results are shown in Tables A.2 and A.3. In all cases, these iterations yielded expected values that were within $6 \%$ of the expected values provided by DOE. 
TABLE A.2. Capital Cost Distribution Parameters for Mature 1000-MW FBR

\begin{tabular}{|c|c|c|c|}
\hline \multirow[b]{2}{*}{ Estimate } & $\exp$ & & $x>\xi$ \\
\hline & $\xi$ & $C$ & $\alpha$ \\
\hline$A$ & 1660 & 1.06 & 336.17 \\
\hline B & 1215 & 1.01 & 418 \\
\hline C & 1280 & 1.08 & 120.89 \\
\hline D & 1400 & 2.65 & 606 \\
\hline$E$ & 1650 & 1.04 & 350.7 \\
\hline $\mathrm{F}$ & 1715 & 1.01 & 322.6 \\
\hline
\end{tabular}

TABLE A.3. Capital Cost Distribution Parameters for Mature 1457-MW FBR

\begin{tabular}{|c|c|c|c|}
\hline \multirow[b]{2}{*}{ Estimate } & \multicolumn{2}{|c|}{ Paramete } & $x>\xi$ \\
\hline & $\xi$ & C & $\alpha$ \\
\hline A & 1400 & 1.15 & 284.9 \\
\hline B & 910 & 1.05 & 325 \\
\hline C & 1040 & 1.01 & 92.2 \\
\hline D & 1000 & 3.25 & 758.5 \\
\hline$E$ & 1370 & 1.13 & 295.4 \\
\hline
\end{tabular}

These distributions were then summed to yield a single distribution probabilistically defining the range of costs for each respective plant in the following manner: 


$$
\begin{aligned}
& 1000 \mathrm{MW} \mathrm{f}^{\prime}(x)=\frac{1}{6} \sum_{1}^{6} f(x)_{j} \\
& 1457 \mathrm{MW} \mathrm{f}^{\prime}(x)=\frac{1}{5} \sum_{j}^{5} f(x)
\end{aligned}
$$

The locus of points defined by these two equations was then fit to a beta distribution. The following two beta distributions then, represent the entire range of industrial estimates in a probabilistic fashion for each plant respectively as seen in Figure A.1.

$$
f(x)_{1000}=17.85(x)^{\gamma-1}(1-x)^{n-1}
$$

where the shape parameters

$$
\begin{aligned}
& \gamma=2.03 \\
& \eta=3.68
\end{aligned}
$$

and

$$
\begin{aligned}
x & =\frac{\text { Capital Cost }(\$ / \mathrm{kW})-1000 \$ / \mathrm{kW}}{1636 \$ / \mathrm{kW}} \\
f(x)_{1457} & =5.707(x)^{\gamma-1}(1-x)^{n-1}
\end{aligned}
$$

where

$$
\begin{aligned}
& \gamma=1.61 \\
& \eta=2.47
\end{aligned}
$$

and 


$$
x=\frac{\text { Capital } \operatorname{Cost}(\$ / \mathrm{kW})-820 \$ / \mathrm{kW}}{1180 \$ / \mathrm{kW}}
$$

Included is the probability distribution for the LWR capital costs. This distribution is defined by:

$$
f(x)=\frac{1}{\sigma \sqrt{2 \pi}} e^{-\left[(x-u)^{2} / 2 \sigma^{2}\right]}
$$

where

$$
\begin{aligned}
& u=\text { mean value } \\
& \sigma=\text { one standard deviation } \\
& x=\text { Capital Cost } \$ / k w
\end{aligned}
$$

This probability distribution is based on historical information presented in "Power Plant Capital Cost Analysis," R. Budwani, Power Engineering May 1980.

\section{A.2. STRATEGY COST}

FBR alternative strategy costs consist of the following components;

- plant capital costs

- fuel cycle costs

- operation and maintenance costs

- base technology program costs

- credit for the sale of power generated by a government facility.

- cost of support for R-1, R-2, and R-3.

\section{Plant Capital Cost}

Derivation of plant capital cost distributions was discussed in the previous section.

\section{Fuel Cycle Costs}

The following assumptions were made to determine FBR fuel cycle costs:

1. There are $9.7 \mathrm{~kg}$ Pu/MT spent LWR fuel.

2. This plutonium is $73 \%$ fissile. 


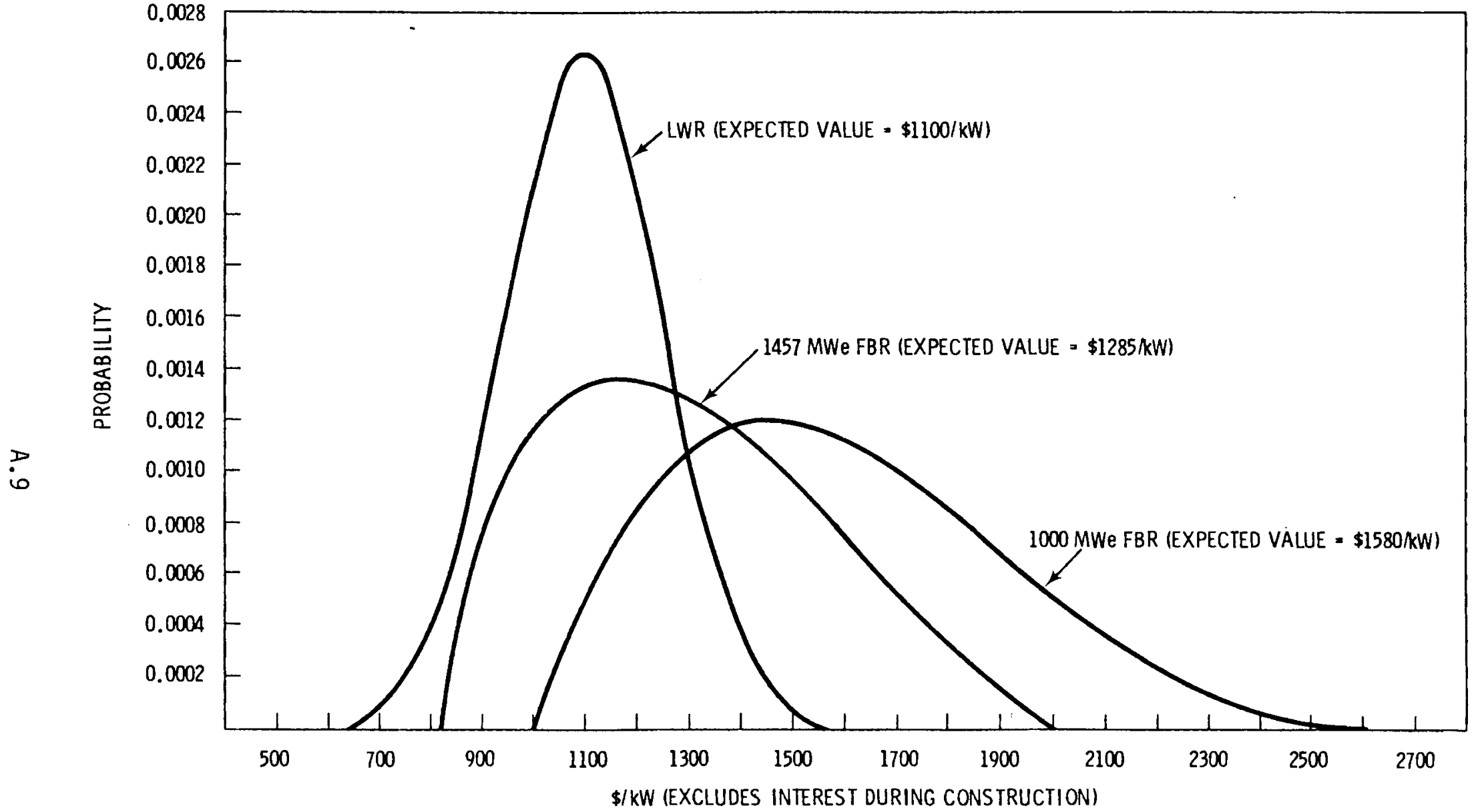

FIGURE A.1. Comparison of LWR and FBR Capital Cost Distributions 
3. First core, 1 st and 2 nd reload Pu requirements are satisfied by the recovery of the $\mathrm{Pu}$ in LWR spent fuel.

4. Equilibrium reload requirements are supplied by FBRs.

5. For a $1000-\mathrm{MW}$ facility $5300 \mathrm{~kg} \mathrm{Pu}$ are required for the first core and $2650 \mathrm{~kg} \mathrm{Pu}$ are required for each reload.

6. For a 1457-MW facility, $7700 \mathrm{~kg} \mathrm{Pu}$ are required for the first core and $3850 \mathrm{~kg} \mathrm{Pu}$ are required for each reload.

7. Half-core, annual refueling schedule.

8. Purchase of first core occurs two years prior to fuel loading.

9. Average residence time of blanket material is 3 years.

The LWR spent fuel requirements are determined in the following manner for the 1000-MW facility:

$$
\frac{(5300 \mathrm{~kg} \mathrm{Pu})}{(9.7 \mathrm{~kg} / \mathrm{MT})}=546.4 \mathrm{MT}
$$

To account for reprocessing and fabrication material losses totaling roughly $1 \%$, the amount of LWR spent fuel required for the first core becomes 552 MT. Based on this, the reload requirement is 276 MT LWR spent fuel. The plutonium requirements for the $1457-\mathrm{MW}$ facility were determined in a similar manner.

Table A.4 lists the fuel cycle unit costs used in this analysis. For the calculation of the fuel cycle costs, the LWR and FBR transportation costs were added to their respective reprocessing costs. Likewise, the waste management costs for LWR and FBR fuel were added to the respective reprocessing costs. The transportation cost of $(\mathrm{U}, \mathrm{PU}) \mathrm{O}_{2}$ is added to the FBR core and axial blanket fabrication unit cost. Mass flows used for the 1000- and 1457-MW FBRs can be seen in Table A.5.

First core purchase is assumed to occur 2 years before fue 1 loading. The plutonium requirements for the first core and first and second reloads are assumed to be satisfied with spent fuel from LWRs. Since this material is to 
TABLE A.4 Fuel Cycle Unit Costs $(\$ / \mathrm{kg})$

$\begin{array}{lr}\text { Reprocessing (FBR) } & \\ \text { Core and Axial Blanket } & 295 \\ \text { Radial Blanket } & 295 \\ \text { Reprocessing (LWR) } & 242 \\ \text { Fabrication } & \\ \text { Core and Axial Blanket } & 599 \\ \text { Radial Blanket } & \\ \text { Transportation } & \\ \text { LWR Spent Fuel } & 26 \\ \text { FBR Spent Fuel } & 95 \\ \text { (U,Pu) 0 2 } & 21 \\ \text { Waste Management } & \\ \text { LWR Fue l } & 45 \\ \text { FBR Fuel } & 83\end{array}$

be used for research and development by the government, it was assumed that there are no additional expenses other than the operational and production costs for its recovery. These costs are normally allocated to the R\&D budget, and therefore, this analysis did not assign an explicit value for this plutonium. Once the developmental and prototype plants achieve equilibrium, they will supply their own plutonium requirements. Since these facilities will be government owned and operated it was further assumed that there is no explicit value associated with this plutonium. A more detailed discussion of the explicit value of plutonium as a function of uranium and separative work values can be found in PNL-3597 (White and Merrill 1981).

For calculation of fuel cycle costs, the LWR reprocessing unit cost is used for the first core material and first and second reloads. FBR reprocessing unit costs are used for equilibrium reloads. On the average, LWR fuel at discharge contains $9.7 \mathrm{~kg}$ Pu/MT, which is $73 \%$ fissile. This was the basis for calculation of LWR spent fuel requirements seen in Table A.5. 
TABLE A.5. FBR Mass Flows ( $80 \%$ capacity factor)

$1000 \mathrm{MW}$

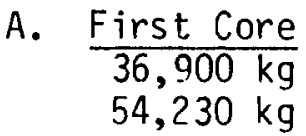
Core and Axial Blanket
Radial Blanket
B. Reload
$18,450 \mathrm{~kg} \quad$ Core and Axial Blanket
$19,040 \mathrm{~kg} \quad$ Radial Blanket
C. $\mathrm{Pu}$ Required $5,300 \mathrm{~kg}$
First Core
Reload ?, $650 \mathrm{~kg}$
D. Amount of LWR Spent Fuel Required
$552,000 \mathrm{~kg} \quad$ First Core
$276,000 \mathrm{~kg} \quad$ Reload

$1457 \mathrm{MW}$
A. First Core
$79,013 \mathrm{~kg}$
Core and Axial
Radial Blanket
B. Reload
$26,882 \mathrm{~kg} \quad$ Core and Axial
$27,741 \mathrm{~kg} \quad$ Radial blanket
C. Pu Required
$7,400 \mathrm{~kg}$
$3,700 \mathrm{~kg}$
First Core
Reload
D. Amount of LWR Spent Fuel Required $800,000 \mathrm{~kg} \quad$ First Core $400,000 \mathrm{~kg} \quad$ Reload

Average residence time for FBR core material was assumed to be 2 years, which results in an annual half-core refueling schedule. The average residence time for radial blanket material was assumed to be 3 years.

Since mass flow requirements are a function of the plant capacity factor, the mass flows shown in Table $A .5$ are adjusted to the annual capacity factor (CF) in Table A.6 by the capacity factor ratio (CF/.8). As demand requires, both plants could be used as intermediate load units in the later half of their operational lifetimes. 
TABLE A.6. Plant Capacity Factors

Year of

Operation

Developmental

Prototype

$\begin{array}{rrr}1 & .55 & .55 \\ 2 & .65 & .65 \\ 3-40 & .75 & .75\end{array}$

Operation and Maintenance Cost

The source for the operation and maintenance costs for this analys is was DOE's Energy Economic Data Base. A detailed breakdown of these costs is shown in Table A.7. The following assumptions apply to 0\&M costs;

1. O\&M costs will be independent of plant size between 700 to $1500 \mathrm{MW}$.

2. Base 0\&M costs are in $1 / 1 / 78$ dollars and are converted to $\$ 1980$ by this analysis using a discount rate of $10 \%$.

3. Base 0\&M costs are relative to a single unit.

\section{Base Technology Program Costs}

These costs are assumed to be the same for each strategy totalling $\$ 6 x$ $10^{9}$.

Credit for Sale of Power

As mentioned in Chapter 4 , it is beyond the scope of this analys is to assess what the regionally dependent highest incremental cost of power would be. Therefore, for this calculation, the price of the power generated by the government owned FBRs was taken as $48 \mathrm{mills} / \mathrm{Kwh}$, as reported in the conceptual design study. The following relationship was used for the calculation of the credit component of strategy cost.

Revenue from sale of power $=($ Size $)(C F)(8760 \mathrm{hr} / \mathrm{yr})(1000 \mathrm{~kW} / \mathrm{MW})(\mathrm{m} / \mathrm{kWh})$ $(\$ / 1000 \mathrm{mills})$ 
TABLE A.7. Annual Operation and Maintenance Costs (a)

Staff

Maintenance Material

Fixed

Variable

Supplies and Expenses

Fixed

Variable

Insurance and Fees

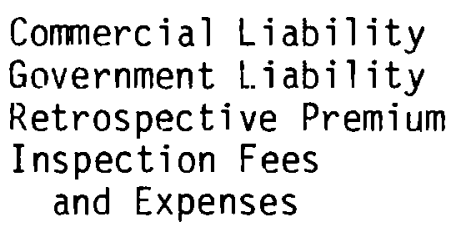

Administration and General

Total annual 0\&M costs

Adjusted to $\$ 1980$
$\$ 5265 \times 10^{3}$

$\$ 4316 \times 10^{3} \$ 4,316 \times 10^{3}$

0

$\$ 5000 \times 10^{3} \quad \$ 5,426 \times 10^{3}$ $\$ 426 \times 10^{3}$

$\$ 284 \times 10^{3} \$ 408 \times 10^{3}$

$\$ 13 \times 10^{3}$

$\$ 6 \times 10^{3}$

$\$ 100 \times 10^{3}$

$\$ 2,187 \times 10^{3}$

$\$ 17,602 \times 1.0^{3}$

$\$ 21.3 \times 10^{6}$

(a) Energy Economic Data Base, Phase 1, UE\&C-DOE-790930, September 1979.

Since this term is assigned as a credit, it is subtracted from the fuel cycle and $0 \& M$ costs, to obtain a net cost to the government for that particular year.

The following is a sample calculation for each cost item discussed above for the 1000-MW developmental plant. For illustration, the year of the fourth reload was selected, which has an associated capacity factor (CF) of 0.75 .

a. Reprocessing (core and axial blanket)

$$
(18,450 \mathrm{~kg} \mathrm{HM})(\$ 473 / \mathrm{kg})\left(\frac{C F}{0.8}\right)=\$ 8.2 \times 10^{6}
$$

Since all mass flows are relative to a plant capacity factor of $80 \%$, a ratio of the capacity factors is taken to simulate the amount of material that experienced burnup. 
b. Reprocessing (b lanket)

$$
(19,040 \mathrm{~kg} \mathrm{HM})(\$ 473 / \mathrm{kg})\left(\frac{\mathrm{CF}}{0.8}\right)=\$ 8.4 \times 10^{6}
$$

c. Fabrication (core and axial blanket)

$$
(18,450 \mathrm{~kg} \mathrm{HM})(\$ 620 / \mathrm{kg})\left(\frac{\mathrm{CF}}{0.8}\right)=\$ 10.7 \times 10^{6}
$$

d. Fabrication (blanket)

$$
(19,040 \mathrm{~kg} \mathrm{HM})(\$ 145 / \mathrm{kg})\left(\frac{\mathrm{CF}}{0.8}\right)=\$ 2.6 \times 10^{6}
$$

e. Operation and Maintenance

$$
0 \& M=\$ 21.3 \times 10^{6}
$$

f. Power Credit

$(1000 \mathrm{MW})(1000 \mathrm{~kW} / \mathrm{MW})(8760 \mathrm{hr} / \mathrm{yr})(\mathrm{CF})(48 \mathrm{mills} / \mathrm{kWh})(\$ / 1000 \mathrm{mi} 11 \mathrm{~s})$

$$
=\$ 315.4 \times 10^{6}
$$

Therefore
a. Reprocessing (core and axial)
$\$ 8.2 \times 10^{6}$
b. Reprocessing (blanket)
$\$ 8.4 \times 10^{6}$
c. Fabrication (core and axial
$\$ 10.7 \times 10^{6}$
d. Fabrication (blanket)
$\$ 2.6 \times 10^{6}$
e. O\&M
$\$ 21.3 \times 10^{6}$
f. Power Credit
$-\$ 315.4 \times 10^{6}$
Total $=-\$ 264.2 \times 10^{6}$ 
The negative sign in the above example indicates that the government realizes a net gain for these cost items.

g. Subsidy for Replicates $1,2,3$

To illustrate the subsidy calculation assume that the capital costs for Replicates $1,2,3$ and CBR-1 are as follows.

$$
\begin{aligned}
& \text { Replicate } 1=\$ 2127 \times 10^{6} \\
& \text { Replicate 2 }=\$ 2045 \times 10^{6} \\
& \text { Replicate 3 }=\$ 1935 \times 10^{6} \\
& \text { CBR-1 }
\end{aligned}
$$

The capital cost for CBR-1 is then subtracted from each replicate plant yielding a subsidy to be provided by the government for replicate 1, 2, and 3 respectively.

$$
\begin{aligned}
& \text { Replicate } 1=\$ 257 \times 10^{6} \\
& \text { Replicate } 2=\$ 175 \times 10^{6} \\
& \text { Replicate } 3=\$ 65 \times 10^{6} \\
& \text { Total }
\end{aligned}
$$

Table A.9 summarizes the total net undiscounted annual cash flows for each strategy. 
TABLE A.9. Summary of Total Net Undiscounted Cash Flows for Each Strategy (\$1980 millions)

\begin{tabular}{|c|c|c|c|c|c|c|c|}
\hline & $\begin{array}{l}\text { Sequential } \\
\text { Strategy }\end{array}$ & $\begin{array}{c}\text { Delayed } \\
\text { Sequential } \\
\text { Strategy } \\
\end{array}$ & $\begin{array}{l}\text { Compressed } \\
\text { Strategy }\end{array}$ & $\begin{array}{c}\text { Delayed } \\
\text { Compressed } \\
\text { Strategy } \\
\end{array}$ & $\begin{array}{c}\text { Component } \\
\text { Testing } \\
\text { Strategy } \\
\end{array}$ & $\begin{array}{l}\text { Direct } \\
\text { Prototype } \\
\text { Strategy } \\
\end{array}$ & $\begin{array}{l}\text { Direct } \\
\text { Replicate } \\
\text { Strategy } \\
\end{array}$ \\
\hline Strategy & A & B & $C$ & $D$ & $E$ & $F$ & G \\
\hline 1981 & 214.3 & 166.7 & 336.5 & 250.0 & 250.0 & 447.2 & 420.7 \\
\hline 1982 & 231.3 & 166.7 & 353.5 & 250.0 & 250.0 & 462.4 & 437.7 \\
\hline 1983 & 237.4 & 166.7 & 359.6 & 250.0 & 250.0 & 467.9 & 443.8 \\
\hline 1984 & 295.8 & 166.7 & 418.0 & 250.0 & 250.0 & 520.3 & 502.2 \\
\hline 1985 & 339.6 & 166.7 & 478.0 & 250.0 & 250.0 & 559.6 & 546.0 \\
\hline 1986 & 368.8 & 188.1 & 520.8 & 271.4 & 250.0 & 585.8 & 575.2 \\
\hline 1987 & 573.2 & 205.1 & 729.3 & 289.0 & 250.0 & 769.2 & 779.6 \\
\hline 1988 & 602.4 & 212.0 & 807.0 & 295.3 & 250.0 & 795.4 & 808.8 \\
\hline 1989 & 660.8 & 272.4 & 896.9 & 355.7 & 250.0 & 847.8 & 867.2 \\
\hline 1990 & 573.2 & 317.7 & 836.0 & 417.2 & 250.0 & 769.2 & 779.6 \\
\hline 1991 & 544.0 & 347.9 & 969.2 & 461.0 & 269.5 & 743.0 & 750.4 \\
\hline 1992 & 601.5 & 559.3 & 1053.4 & 676.5 & 285.5 & 815.5 & 807.9 \\
\hline 1993 & 310.4 & 589.5 & 808.3 & 755.2 & 291.2 & 533.4 & 516.8 \\
\hline 1994 & 281.2 & 649.9 & 704.0 & 847.1 & 346.2 & 507.2 & 487.6 \\
\hline 1995 & 52.8 & 559.3 & 448.9 & 783.2 & 387.5 & -140.8 & 259.2 \\
\hline 1996 & 40.5 & 529.1 & 303.1 & 915.4 & 415.0 & -170.3 & -170.3 \\
\hline 1997 & 25.4 & 581.6 & 509.5 & 994.6 & 607.5 & -199.8 & -199.8 \\
\hline 1998 & -34.6 & 287.5 & 148.6 & 746.5 & 635.0 & -264.1 & -264.1 \\
\hline 1999 & 16.7 & 257.3 & 124.4 & 641.2 & 690.0 & -264.1 & -264.1 \\
\hline 2000 & 50.0 & 25.9 & -479.0 & 383.1 & 607.5 & -264.1 & -264.1 \\
\hline 2001 & 78.2 & 13.6 & -522.0 & 237.3 & 580.0 & -264.1 & -264.1 \\
\hline 2002 & 250.0 & -1.5 & -564.9 & 443.7 & 646.0 & -264.1 & -264.1 \\
\hline 2003 & 278.2 & -61.5 & -658.7 & 82.8 & 360.0 & -264.1 & -264.1 \\
\hline 2004 & 326.9 & -10.2 & -658.7 & 58.6 & 332.5 & -264.1 & -264.1 \\
\hline 2005 & 247.4 & 23.1 & -658.7 & -479.0 & -140.8 & -264.1 & -264.1 \\
\hline 2006 & 219.2 & 51.3 & -658.7 & -522.0 & -170.3 & -264.1 & -264.1 \\
\hline 2007 & 96.1 & 223.1 & -658.7 & -564.9 & 63.2 & -264.1 & -264.1 \\
\hline
\end{tabular}


TABLE A.9. (Continued)

\begin{tabular}{|c|c|c|c|c|c|c|c|}
\hline Strategy & $\mathrm{A}$ & $B$ & $C$ & $D$ & $E$ & $\mathrm{~F}$ & G \\
\hline 2008 & 328.6 & 251.3 & -658.7 & -658.7 & -264.1 & -1.1 & -264.1 \\
\hline 2009 & 32.0 & 300.0 & -658.7 & -658.7 & -264.1 & -264.1 & -264.1 \\
\hline 2010 & 6.4 & 220.5 & -658.7 & -658.7 & -264.1 & -264.1 & -391.9 \\
\hline 2011 & -285.4 & 192.3 & -658.7 & -658.7 & -264.1 & -264.1 & -264.1 \\
\hline 2012 & -522.0 & 69.2 & -658.7 & -658.7 & -264.1 & -264.1 & -264.1 \\
\hline 2013 & -564.9 & 301.7 & -318.7 & -658.7 & -264.1 & -264.1 & -264.1 \\
\hline 2014 & -658.7 & 5.1 & -658.7 & -658.7 & -264.1 & -264.1 & -264.1 \\
\hline 2015 & -658.7 & -20.5 & -658.7 & -658.7 & -264.1 & -264.1 & -264.1 \\
\hline 2016 & -658.7 & -312.3 & -658.7 & -658.7 & -264.1 & -264.1 & -264.1 \\
\hline 2017 & -658.7 & -522.0 & -658.7 & -658.7 & -262.1 & -264.1 & -264.1 \\
\hline 2018 & -658.7 & -564.9 & -658.7 & -318.7 & -264.1 & -264.1 & -264.1 \\
\hline 2019 & -658.7 & -658.7 & -658.7 & -658.7 & -264.1 & -264.1 & -264.1 \\
\hline 2020 & -658.7 & -658.7 & -658.7 & -658.7 & -264.1 & -264.1 & -264.1 \\
\hline 2021 & -658.7 & -658.7 & -658.7 & -658.7 & -264.1 & -264.1 & -264.1 \\
\hline 2022 & -658.7 & -658.7 & -658.7 & -658.7 & -264.1 & -264.1 & -264.1 \\
\hline 2023 & -658.7 & -658.7 & -658.7 & -658.7 & -264.1 & -264.1 & -264.1 \\
\hline 2024 & -658.7 & -658.7 & -658.7 & -658.7 & -264.1 & -264.1 & -264.1 \\
\hline 2025 & -161.7 & -658.7 & -658.7 & -658.7 & -264.1 & -264.1 & -264.1 \\
\hline 2026 & -658.7 & -658.7 & -658.7 & -658.7 & -264.1 & -264.1 & -264.1 \\
\hline 2027 & -658.7 & -658.7 & -658.7 & -658.7 & -264.1 & -264.1 & -264.1 \\
\hline 2028 & -658.7 & -658.7 & -658.7 & -658.7 & -264.1 & -264.1 & -264.1 \\
\hline 2029 & -658.7 & -658.7 & -658.7 & -658.7 & -264.1 & -264.1 & -264.1 \\
\hline 2030 & -658.7 & -658.7 & -658.7 & -658.7 & -264.1 & -264.1 & -264.1 \\
\hline 2031 & -658.7 & -161.7 & -658.7 & -658.7 & -264.1 & -264.1 & -264.1 \\
\hline 2032 & -658.7 & -658.7 & -658.7 & -658.7 & -264.1 & -264.1 & -264.1 \\
\hline 2033 & -658.7 & -658.7 & -658.7 & -658.7 & -264.1 & -264.1 & -264.1 \\
\hline 2034 & -658.7 & -658.7 & -658.7 & -658.7 & -264.1 & -264.1 & -264.1 \\
\hline 2035 & -394.6 & -658.7 & -394.6 & -658.7 & -264.1 & & \\
\hline 2036 & -394.6 & -658.7 & -394.6 & -658.7 & -264.1 & & \\
\hline 2037 & -394.6 & -658.7 & -394.6 & -658.7 & -264.1 & & \\
\hline
\end{tabular}


TABLE A.g. (Cont inued)

\begin{tabular}{|c|c|c|c|c|c|c|c|}
\hline Strategy & A & B & 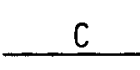 & $D$ & $E$ & $\mathrm{~F}$ & G \\
\hline 2038 & -394.6 & -658.7 & -394.6 & -658.7 & -264.1 & & \\
\hline 2039 & -394.6 & -658.7 & -394.6 & -658.7 & -264.1 & & \\
\hline 2040 & -394.6 & -394.6 & & -394.6 & -264.1 & & \\
\hline 2041 & -394.6 & -394.6 & & -394.6 & -264.1 & & \\
\hline 2042 & -394.6 & -394.6 & & -394.6 & -264.1 & & \\
\hline 2043 & -394.6 & -394.6 & & -394.6 & -264.1 & & \\
\hline 2044 & -394.6 & -394.6 & & -394.6 & -264.1 & & \\
\hline 2045 & -394.6 & -394.6 & & & & & \\
\hline 2046 & -394.6 & -394.6 & & & & & \\
\hline 2047 & -394.6 & -394.6 & & & & & \\
\hline 2048 & -394.6 & -394.6 & & & & & \\
\hline 2049 & -394.6 & -394.6 & & & & & \\
\hline 2050 & -394.6 & -394.6 & & & & & \\
\hline 2051 & & -394.6 & & & & & \\
\hline 2052 & & -394.6 & & & & & \\
\hline 2053 & & -394.6 & & & & & \\
\hline 2054 & & -394.6 & & & & & \\
\hline 2055 & & -394.6 & & & & & \\
\hline
\end{tabular}


APPENDIX B

\section{DEVELOPMENT OF STRATEGY TIME DISTRIBUTIONS}

The rationale and assumptions used to develop the plant specific time distributions are discussed below. Figures B.1 through B.7 represent the detailed strategy network diagrams used for the QGERT analysis. Next to each network diagram Tables B.1 through B.7 indicate the time values for each activity. These were developed by this analysis with the aid of schedulina specialists in the nuclear industry. These times represent the probable durations between any two nodes within the diagrams.

\section{B.1 STRATEGY A: SEQUENTIAL.}

The Sequential Strategy starts with the conceptual design study (CDS) 1000-MWe 4-1 oop LMFBR as shown in Figure B.1. The second plant is a prototype, a 1457-MWe scaled-up version of the CDS. Some conceptual work for the prototype will be started about the time the construction is completed on the CDS. Congressional authorization for the prototype will be sought to coincide with the completion of 1 year of full power operation of the CDS. Replicate 1 (R-1) will have its site selection and NSSS award coincide with completion of one year of full power operation of the prototype plant. The site selection of replicate $2(R-2)$ is 1 year after site selection of $R-1$. Site selection of replicate $3(R-3)$ will be 1 year after site selection of $R-2$. The site selection of the commercial breeder reactor (CBR) will be 1 year after the site selection of R-3. Replicates 1, 2, and 3, and the CBR will have the same design as the prototype. Only changes necessitated by the lessons learned in building and operation of the prototype and CDS plant would be incorporated into the design of the replicates.

\section{Deve lopmental Plant}

This schedule is designed to reflect a success-oriented project and very little probability exists that activities will be completed earlier than scheduled. However, significant probabilities exist that some of the activities may 



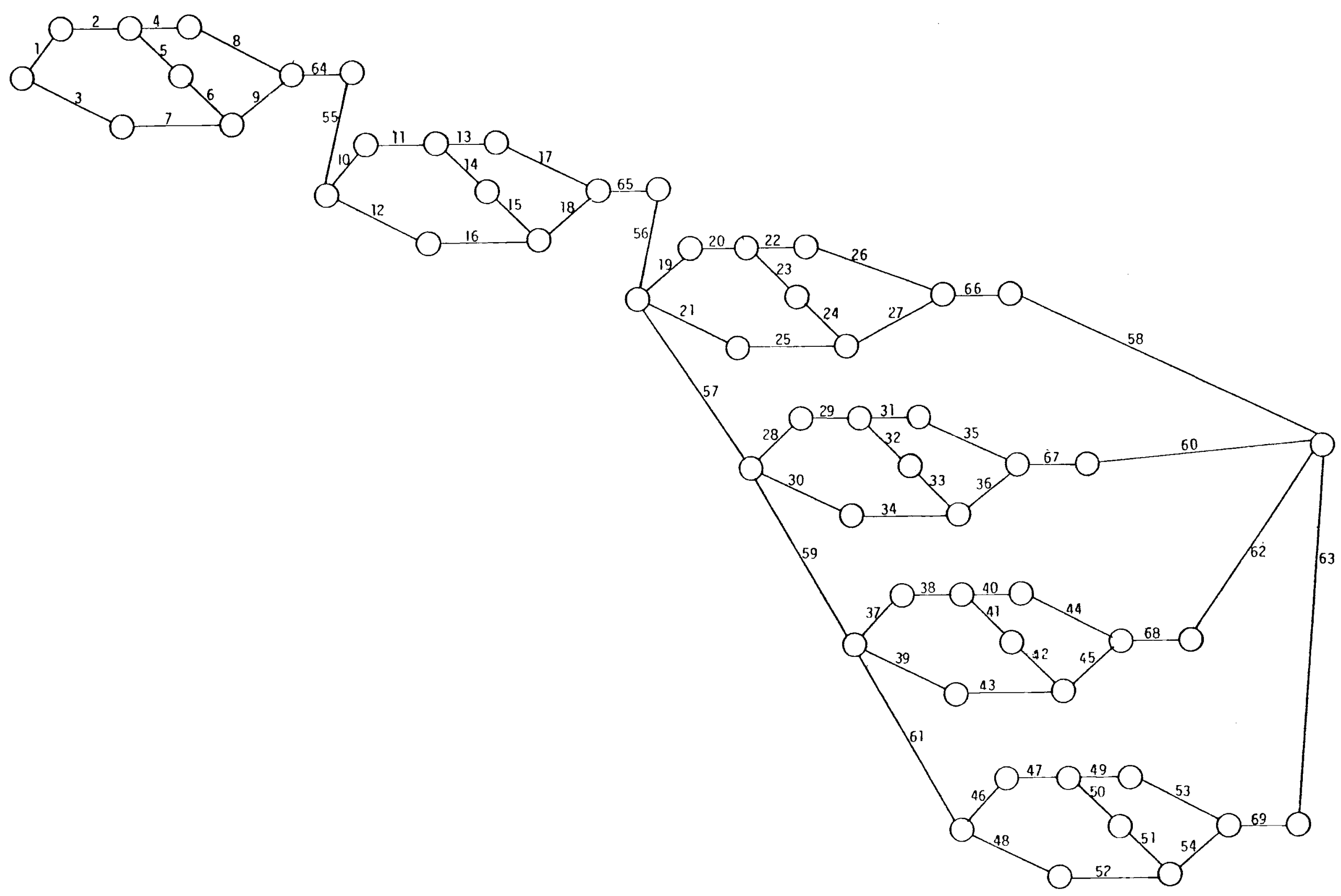

FIGURE B.1. Detailed Activity Network - Sequential Strategy "A"

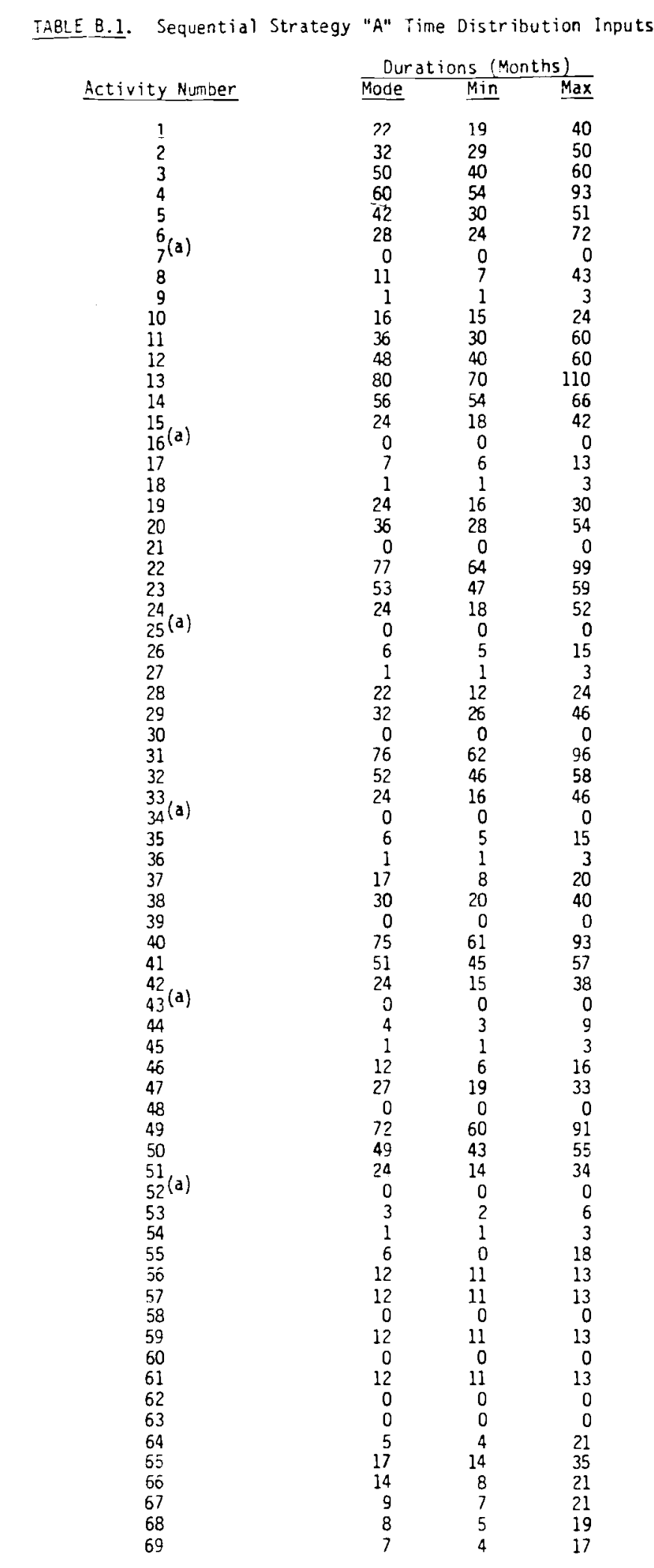

(a) No further constraint on licensing after completion of component testing. 
be completed later than scheduled. Because the CDS is envisioned as a licensable but not licensed plant, the procedures for licensing a nuclear power plant on a government reservation will be followed. The plant does not need an actual construction permit nor an NRC operating license. There will be a full NRC review of the safety analysis reports but no public hearings will be conducted. The permits required will be limited to those required for a federal project on a federal reservation. The CDS will also be supported by a component development and testing program that will seek to evaluate and reduce the uncertainties associated with the feasibility of fabricating and operating commercial size sodium components.

The duration of the activities scheduled between congressional authorization of the CDS and submittal of the PSAR is about 22 months. This submittal could be as much as three months earlier, with a real probability that it could be more than 2 years in preparation.

A finite probability also exists that Congress may not authorize the project intially. Projects of this size need backing from both the Congress and the incumbent administration for successful legislative action to result. The Congress must also approve the license exemption, which may be controversial, and could cause 1 or 2 years delay. A maximum duration of 40 months is assumed for this activity.

The next step is the issue of a construction permit (CP) which is scheduled to take about 32 months from submittal of the PSAR. This is an optimistic schedule and definitely reflects the license exemption that the DOE plans to request from Congress in the authorization bill. It now takes more than 32 months to obtain a CP for a commercial LWR. A delay in the authorization could be used to do a reference conceptual design and put together an especially comprehensive PSAR. This extra effort might result in DOE issuing a letter of compliance and starting construction as early as 2-1/4 years after PSAR submittal. It is more likely that the CP will be issued after a comprehensive review by the NRC, including time to train the NRC reviewers in LMFBR technology. Close interaction between the many participants of the CDS team and the technical integrator will be needed. This activity could take as long as $4-1 / 3$ years. 
Completion of component testing is scheduled for about 4 years after congressional authorization with an earliest expected completion at about 40 months and a maximum of about 5 years. This activity actually starts during the preauthorization period with the selection of the components to be tested, preparation of the design specifications, bidding, awarding fabrications contracts and on through the complete test program.

Completion of construction will demonstrate that a larger FBR can be designed and constructed. Much of the initial plant system precritical testing will be complete and no other construction is specifically required to be prepared to operate the power plant. The duration from issue of the $C P$ to construction completion is scheduled to be 5 years. If the $C P$ is late then the design may be more mature and more construction planning may be completed prior to the start of construction. If this were coupled with a trouble free construction period the plant might be completed in 4-1/2 years. However, this plant will be the first of a kind and size to be built with continually tightening, regulatory, and quality assurance requirements. It is entirely possible that the construction could take as long as 8 years after $C P$ issue. Many factors contribute to the possibility of delay; labor availability, contracts, federal funding bills, jurisdictional disputes, design changes, new regulations, etc.

FSAR submission for NRC review is an indication that plant design and analysis are complete enough to proceed with the operating license (OL) application. The actual submission is keyed closely to the expected license need and the anticipated time to process the application, review it, and issue the license. The NRC requires that the plant be within 2 years of completion before submittal of the FSAR. An early submission has several advantages. The NRC may be flexible about the 2 year requirement in order to maintain continuity in the review team; this requires less training and facilitates efficient review. A nominal 2-year window exists and the schedule places it at just under 4 years after $C P$ issue, although it could be as little as 3 years or as much as 5-1/2 years after issue of the $C P$ depending on the status of the project.

The CDS project schedule allows 2-1/4 years to obtain an OL after the FSAR submittal. This is approximately 1 year less than recent LWR experience, 
but it can take up to 5 years to obtain the $0 \mathrm{~L}$. Best efforts, considering that public hearings will not be required, may let them finish the licensing process in 2 years. The whole question of licensing is uncertain and difficult to define. A trend has developed toward tougher, slower LWR licensing due to more stringent licensing requirements.

Initial criticality could come about 1 month after the $\mathrm{OL}$ has been issued with some probability that it could occur 3 months after issue of the $\mathrm{OL}$.

The CDS schedule allows about 5 months to complete the test program for commercial operation, including escalation to full power. This must be predicated upon a very successful, comprehensive acceptance test program prior to receipt of an operating authorization and construction completion. Nine months is normally the minimum to complete a nuclear test and power ascension program. On a first-of-a-kind and size power plant project such as this, it could take almost 2 years. No economic pressure will exist to get a federal plant into commercial operation. There are many very interesting tests to perform at low power and the availability of a slightly radioactive environment provides some useful opportunities that will not be available after commencing full power operation.

Prototype Plant

The second power plant in this strategy is a 1457-MWe scaled-up version of the CDS plant. This project would be timed to receive congressional authorization when the CDS has completed 1 year of full power operaton. This is a federal project, like the CDS, and will have a couple of years of proposal, conceptual design, and similar activities prior to seeking congressional authorization. As a prototype it will serve as the model for the first generation of commercial LMFBRs and will be fully licensed. There will be no utility financial participation in this project. The schedule for a project of this size is 14 years from congressional authorization to full power operation. An additional 2 years of preauthorization work makes the overall schedule 16 years long. There will be a component testing program for any component whose size or rating increases (due to scaling). Additional component testing may also be required to satisfy NRC safety concerns. 
This project will have to recognize and deal with all the issues and requirements that face a utility in selecting a power plant for commercial application. Some of the design requirements facing a typical government project must be assessed from the perspective of a utility such as high availability and reliability.

The duration of the first activity on the schedule, preparation to submit the PSAR, will take about 3-1/2 years from the project's start and nominally 1-1/2 years from congressional authorization. The minimum time to accomplish this work will be 1 year from authorization and a maximum time could be almost 3 years, depending on the continuity of the teams involved in LMFBR work, especially licensing. Shorter times could result from strong industry support and a real commitment to keep the experienced engineering staff on the job. Since this is a one-plant-at-a-time strategy there is considerable uncertainty these personnel will be available for the follow on plants.

The issue of the construction permit (CP) normally takes 3 years from the PSAR submittal. The basic NRC criteria for licensing an FBR should have been defined in the work on the CDS plant. Additionally the CDS will have been operating for about 4 years so there will be some confidence in the design, provided that it is operating as expected. Since this is the first project where public hearings will be conducted, the project has little or no probability of receiving a CP in less than 2-1/2 years and could take 5 years because the design is not identical to the CDS plant.

The component testing for the prototype will be less exhaustive than it may have to be for the CDS project due to the confidence gained in the CDS operations. The testing will be scheduled to take about 4 years following congressional authorization with a minimum of 40 months and a maximum of about 5 years, which is similar to the CDS component testing.

Prototype construction is estimated to take 6-2/3 years. This project will be the first fully licensed LMFBR to be built and the first FBR of any size to be started in about 14 years. Architects engineers/constructors assert that building a nuclear power plant is no different than building any other heavy construction project; however, they do acknowledge that the addition of a nuclear quality assurance program imparts a significant scheduling penalty. 
Six and one half years is close to the time required to build an 1100 MWe LWR with about 6 years as the minimum and $8-1 / 2$ years the maximum.

To comply with the NRC requirements of being within 2 years of completion, the prototype's FSAR should be submitted about 56 months after the CP issue. If the construction and engineering can support it, the time could be minimized to a submittal of 4-1/2 years after $C P$ issue. Under any circumstances the FSAR should not be submitted later than 5-1/2 years after the $C P$ issue.

Once the FSAR has been submitted the complete licensing review and a complete set of public hearings is scheduled to take 2 years, which is similar to 1 arge LWR licensing times. The review will take at least $1-1 / 2$ years on this first fully licensed LMFBR and could take as long as 3-1/2 years to obtain the operating license.

Initial criticality on the prototype is most likely to be about $1 / 2$ year after construction is complete. This will be about 1-2 months after receipt of the operating license.

Start of full power operation for the prototype is estimated to take two years after both construction completion and $\mathrm{OL}$ issue. The test program following fuel loading will be exhaustive and little probability exists that it can be completed in less than 1 year with some probability that it could take $2-1 / 2$ years.

\section{Replicate Power Plants}

For the Sequential Strategy the first replicate $(R-1)$ will not have its site selection/NSSS award until a nominal 28 to 30 years after the decision to authorize the CDS plant. Since R-1 would be the third plant in almost 30 years it would still be difficult to characterize this as a growth industry. Very few of the individual contributors to the CDS plant would be available for R-1. However, at the time of site selection/NSSS award there will be approximately 16 reactor years of 1 arge FBR operating experience.

Replicate-1 is the first complete replication of the prototype and the first in a series to be built to what will effectively be a standard design. This should be perceived as the start of a growth industry. These plants are all built under common design, free exchange of information, maximum technology 
transfer between projects, and with maximum efforts to optimize the path toward a mature industry. It is assumed that the federal government will provide some form of subsidy, warranty, or tax incentive to make the replicates completely competitive compared with available LWRs. It is important to note that this will be the start of utility financial involvement in the strategy since both the CDS plant and the prototype plant will have been federal projects, most likely built on federal reservations. Not to be excluded is the possibility that the replicate and CBR plants (any or all) may be sited on a government reservation. Precedents exist for this eventuality. The R-1 site selection NSSS award is timed to happen when the prototype plant has completed 1 year of full power operation.

Replicate-1 will then take about 2 years to prepare and submit its PSAR, EIS, and other permits, although it could be done in about $1-1 / 2$ years or may take nearly 3 years. The utility will assume the responsibility to complete these tasks on schedule. Also, the procedures that utilities may have to follow vary from state to state. The mature plant and stable licensing environment supporting the standardized design leads to an activity duration of about 1 year with a 6 month minimum and a 16 month maximum for CBR-1. A component test program does not need to be scheduled unless there are any unresolved safety concerns.

Construction permit issue is estimated to take 3 years. The CP could be issued in 2-1/3 years or it could take 4-1/2 years, depending on the effectiveness of the whole licensing team. CBR-1 should receive a CP in approximately 2-1/4 years with a 19 month minimum and a 2-3/4 year maximum. The benefits of standard design, complementary vendor, AE, utility, and NRC efforts will all contribute to this shortening of time and narrowing of uncertainty. The reactor operating experience from the CDS and prototype will also add to the reduction in uncertainty. Since the design has been licensed before and the analysis has all been reviewed for the generic design then basically the only needs to be satisfied are the additional site specific requirements.

The submittal of the FSAR for $R-1$ should occur about 4-1/2 years after the construction permit is issued. The job may be done in 4 years or may take nearly 5 years. CBR-1 will require less effort to prepare the FSAR due to 
standard features and previous licensing activities but the work at the NRC will probably be scheduled for 49 months +6 months due to the license application load. This will still allow $\mathrm{OL}$ issue in time to support the project schedule.

Construction completion for $R-1$ will be about $6-1 / 2$ years after $C P$ issue. The relatively long delay between the prototype and $R-1$ contributes to a longer completion time. A utility will need 5-1/3 years minimum and up to 8-1/4 years to get through this first project. Construction of this kind of facility will always be a challenge and the many factors discussed in the CDS plant and prototype plant are still pertinent. CBR-1 will have a construction duration of 6 years with a minimum of 5 years and a maximum of nearly 8 years, still due to the complexity and quality assurance requirements for this type of plant.

Initial criticality for R-1 will most likely take place about 6 months after construction is complete and about 1 month after the $0 L$ is issued. Criticality is not likely to be achieved in less than a month but should be done in no more than 3 months. For CBR-1 the initial criticality should take 3 months from construction completion and about one month after $\mathrm{OL}$ issue.

Commercial operation for R-1 will be achieved in about 9 months with a minimum of 8 months and a maximum of 18 months. The pressures of being a commercial venture will necessitate that the operator plan the test program to support the earliest prudent escalation to full power and a full power demonstration to get the plant into the rate base and onto the depreciation schedule. Since the prototype will have been in operation developing an experience base for some 12 years, few problems should hinder the ascent to power. The CBR ascent to power will be an 8 month activity with a minimum of 1 month and a maximum of something like 14 months reflecting increasing confidence, learning and certainty about completion.

The R-1 project schedule has a total duration of about $12-1 / 2$ years with a range from 10 years to 20 years, which is the uncertainty that reflects the slow continous approach. The CBR schedule is expected to be 10 years with a range from about $7-1 / 2$ years to $12-1 / 2$ years, which is based on the learning, supportive regulatory environment and a high growth industry. 


\section{B.2 STRATEGY B: DELAYED SEQUENTIAL}

This strategy starts after a 5 year delay, as shown in Figure B.2. The only change in the schedule time distributions shown in the Sequential Strategy would be to extend the times to complete each of the engineering and licensing activities by a couple of months each to reflect losses in the vendor staff commitiments. Since the Sequential Strategy already reflects some of this type of impact no other adjustments have been made in the CDS or subsequent plant time distributions.

\section{B.3 STRATEGY C: COMPRESSED}

The Compressed Strategy, shown in Figure B.3, utilizes the same series of components as does the Sequential Strategy.

The strategy starts with the conceptual design study (CDS) 1000-MWe 4-loop FBR. The second $p l a n t$ is a prototype, a 1457-MWe scaled-up version of the CDS. Some conceptual work for the prototype will be started about the time the PSAR is submitted on the CDS. Congressional authorization for the prototype will be sought to coincide with the completion of the component test program for the CDS. Site selection of replicate-l (R-1) will coincide with the $O L$ issue on the prototype. Site selection of replicate $2(R-2)$ is 1 year after site selection of $R-1$. Site selection of replicate $3(R-3)$ will be 1 year after site selection of $R-2$. Site selection of the commercial breeder reactor (CBR) will be 1 year after the site selection of $R-3$. Replicates 1 , 2, and 3 and the CBR will have the same design as the prototype. Only changes necessitated by the lessons learned in building and operation of the prototype and CDS plant would be incorporated into the design of the replicates.

Developmental Plant

The discussion of this plant is the same in all respects as that found in the previous Sequential Strategy discussion. The reader is directed to that section for reference. 
IABLE B.2. Delayed Sequential Strategy " 8 " Time Distribution Inputs
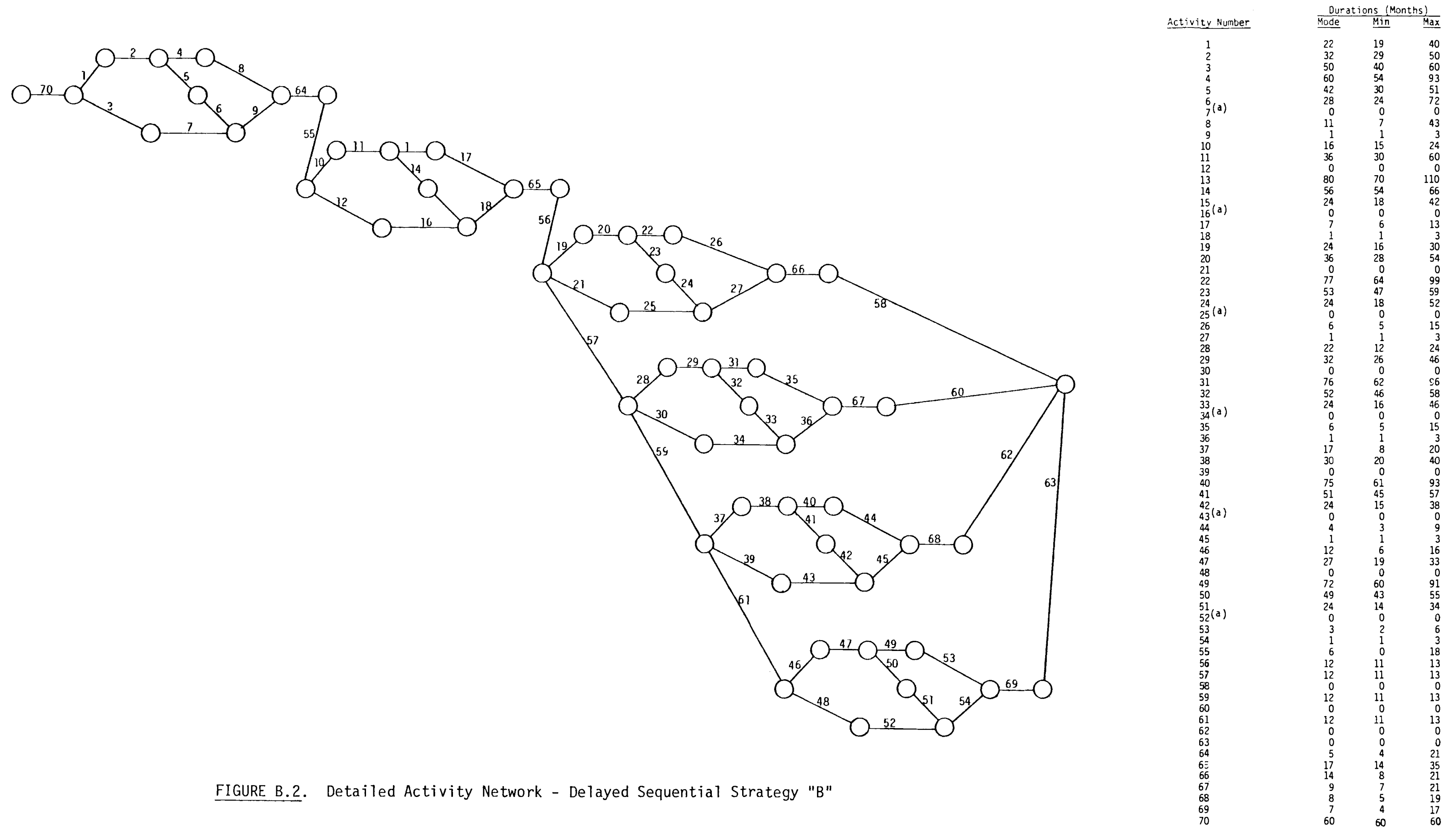

FIGURE B.2. Detailed Activity Network - Delayed Sequential Strategy "B"

(a) No further constraint on licensing after completion of component testing. 


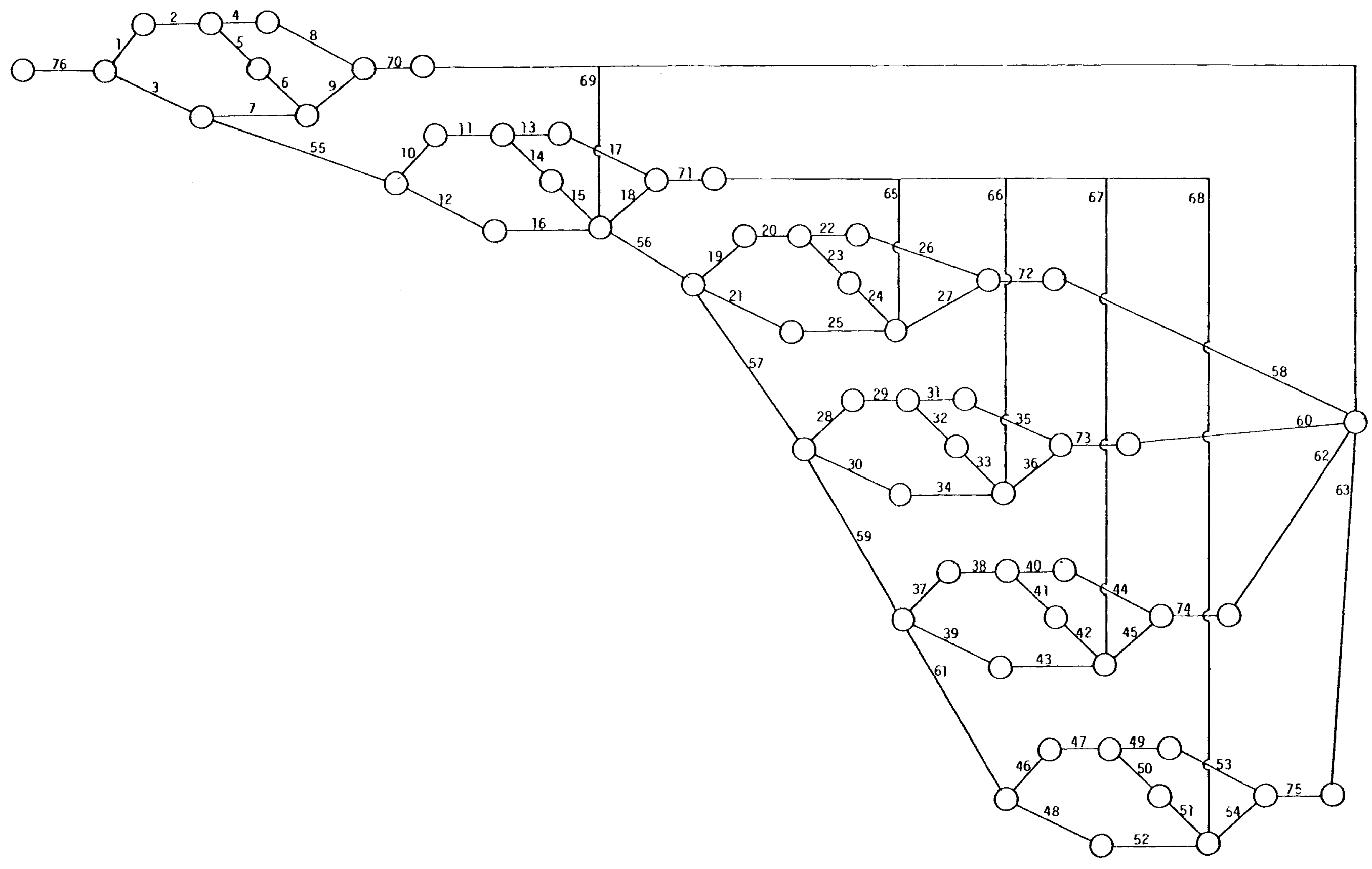

IAB.E B.3. Compressed Strategy "C" Time Distribution Inputs

\begin{tabular}{|c|c|c|c|}
\hline Activity Number & $\frac{\text { Dur }}{\text { Mode }}$ & ins $\frac{\text { in }}{\text { Min }}$ & $\frac{1}{\text { Max }}$ \\
\hline$\frac{1}{2}$ & $\begin{array}{l}22 \\
32\end{array}$ & 19 & $\begin{array}{l}40 \\
50\end{array}$ \\
\hline $\begin{array}{l}2 \\
3 \\
4\end{array}$ & $\begin{array}{l}52 \\
50 \\
60\end{array}$ & $\begin{array}{l}29 \\
40 \\
54\end{array}$ & $\begin{array}{l}60 \\
60 \\
93\end{array}$ \\
\hline $\begin{array}{l}5 \\
{ }_{7}^{6}(\mathrm{a})\end{array}$ & $\begin{array}{l}42 \\
28 \\
0\end{array}$ & $\begin{array}{l}30 \\
24 \\
0 \\
0\end{array}$ & $\begin{array}{c}51 \\
72 \\
0\end{array}$ \\
\hline $\begin{array}{l}8 \\
9\end{array}$ & ${ }_{1}^{11}$ & 7 & ${ }_{3}^{43}$ \\
\hline $\begin{array}{l}10 \\
11\end{array}$ & $\begin{array}{l}12 \\
36\end{array}$ & $\begin{array}{l}11 \\
30\end{array}$ & $\begin{array}{l}24 \\
600\end{array}$ \\
\hline $\begin{array}{l}12 \\
13 \\
14\end{array}$ & $\begin{array}{l}78 \\
78 \\
60\end{array}$ & $\begin{array}{l}40 \\
60 \\
54\end{array}$ & $\begin{array}{r}120 \\
120 \\
66\end{array}$ \\
\hline $\begin{array}{l}15 \\
16 \\
17\end{array}$ & $\begin{array}{r}24 \\
0 \\
7\end{array}$ & $\begin{array}{r}19 \\
0 \\
5\end{array}$ & $\begin{array}{c}60 \\
0 \\
10\end{array}$ \\
\hline $\begin{array}{l}18 \\
19 \\
19\end{array}$ & $\frac{1}{24}$ & $\frac{1}{18}$ & 30 \\
\hline $\begin{array}{l}19 \\
20 \\
21\end{array}$ & 34 & $\begin{array}{r}10 \\
28 \\
0\end{array}$ & $\begin{array}{r}54 \\
54\end{array}$ \\
\hline $\begin{array}{l}22 \\
23\end{array}$ & $\begin{array}{l}75 \\
51\end{array}$ & $\begin{array}{l}60 \\
48\end{array}$ & $\begin{array}{l}100 \\
60\end{array}$ \\
\hline 25 (a) & $\begin{array}{c}24 \\
0 \\
0\end{array}$ & $\begin{array}{l}19 \\
0\end{array}$ & $\begin{array}{l}30 \\
n \\
\eta 7\end{array}$ \\
\hline $\begin{array}{l}26 \\
27\end{array}$ & 1 & 1 & 3 \\
\hline 29 & $\begin{array}{l}18 \\
32\end{array}$ & 26 & $\begin{array}{l}24 \\
48\end{array}$ \\
\hline $\begin{array}{l}30 \\
31 \\
32\end{array}$ & $\begin{array}{r}74 \\
51\end{array}$ & $\begin{array}{l}50 \\
50\end{array}$ & $\begin{array}{l}99 \\
99 \\
59\end{array}$ \\
\hline $\begin{array}{l}33 \\
34(\mathrm{a})\end{array}$ & $\begin{array}{r}24 \\
0 \\
6\end{array}$ & $\begin{array}{c}16 \\
0 \\
4\end{array}$ & $\begin{array}{l}51 \\
0 \\
20\end{array}$ \\
\hline $\begin{array}{l}36 \\
37\end{array}$ & $\begin{array}{c}0 \\
1 \\
14\end{array}$ & $\begin{array}{l}4 \\
1 \\
8\end{array}$ & $\begin{array}{l}3 \\
20\end{array}$ \\
\hline $\begin{array}{l}38 \\
39 \\
40 \\
40\end{array}$ & $\begin{array}{c}30 \\
0 \\
73\end{array}$ & $\begin{array}{l}22 \\
0 \\
60\end{array}$ & $\begin{array}{l}42 \\
0 \\
98\end{array}$ \\
\hline $\begin{array}{l}41 \\
42 \\
43(a) \\
44\end{array}$ & $\begin{array}{r}24 \\
24 \\
0 \\
4\end{array}$ & $\begin{array}{r}r_{0} \\
0 \\
2\end{array}$ & $\begin{array}{l}36 \\
45 \\
0 \\
13\end{array}$ \\
\hline $\begin{array}{l}45 \\
46 \\
47\end{array}$ & $\begin{array}{l}1 \\
12 \\
27\end{array}$ & $\begin{array}{r}1 \\
6 \\
10\end{array}$ & $\begin{array}{r}3 \\
18 \\
-36\end{array}$ \\
\hline $\begin{array}{l}48 \\
49 \\
49\end{array}$ & $\begin{array}{l}0 \\
72 \\
78\end{array}$ & $\begin{array}{l}0 \\
60 \\
60\end{array}$ & $\begin{array}{l}0 \\
98 \\
55\end{array}$ \\
\hline $\begin{array}{l}51 \\
52 \\
52\end{array}$ & $\begin{array}{c}24 \\
0 \\
0 \\
2\end{array}$ & $\begin{array}{r}12 \\
12 \\
1\end{array}$ & 0 \\
\hline $\begin{array}{l}54 \\
55\end{array}$ & $\frac{1}{3}$ & 0 & 6 \\
\hline $\begin{array}{l}56 \\
57\end{array}$ & $\begin{array}{l}12 \\
12 \\
0\end{array}$ & $\begin{array}{l}11 \\
11 \\
0\end{array}$ & $\begin{array}{c}13 \\
13 \\
0\end{array}$ \\
\hline $\begin{array}{l}58 \\
59 \\
60\end{array}$ & $\begin{array}{r}12 \\
0\end{array}$ & $\begin{array}{r}11 \\
0\end{array}$ & $\begin{array}{l}13 \\
0\end{array}$ \\
\hline $\begin{array}{l}60 \\
61 \\
62 \\
62\end{array}$ & $\begin{array}{r}12 \\
0\end{array}$ & $\begin{array}{r}11 \\
0\end{array}$ & $\begin{array}{r}13 \\
0\end{array}$ \\
\hline $\begin{array}{l}63 \\
64 \\
65\end{array}$ & $\begin{array}{l}0 \\
0 \\
0\end{array}$ & $\begin{array}{l}0 \\
0 \\
0\end{array}$ & 0 \\
\hline $\begin{array}{l}66 \\
67 \\
67\end{array}$ & $\begin{array}{l}0 \\
0\end{array}$ & $\begin{array}{c}0 \\
0 \\
0\end{array}$ & $\begin{array}{c}0 \\
0 \\
0\end{array}$ \\
\hline $\begin{array}{l}68 \\
69 \\
69\end{array}$ & $\begin{array}{l}0 \\
0\end{array}$ & $\begin{array}{l}0 \\
0\end{array}$ & $\begin{array}{l}0 \\
0\end{array}$ \\
\hline $\begin{array}{l}70 \\
71 \\
72\end{array}$ & $\begin{array}{r}5 \\
17 \\
9\end{array}$ & $\begin{array}{c}4 \\
14 \\
8\end{array}$ & 37 \\
\hline $\begin{array}{l}72 \\
73 \\
74\end{array}$ & $\begin{array}{l}9 \\
8 \\
7\end{array}$ & $\begin{array}{l}8 \\
7 \\
6 \\
\end{array}$ & \\
\hline 74 & 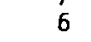 & & \\
\hline
\end{tabular}

FIGURE B.3. Detailed Activity Network - Compressed Strategy "C"

(a) No further constraint on licensing after completion of component testing. 

Prototype Plant

The second power plant in this strategy is a 1457 MWe scaled-up version of the CDS plant. This project would be timed to receive congressional authorization when the component testing program for the CDS project has been completed. This is a federal project like the CDS and will have a couple of years of proposal, conceptual design and simular activities prior to seeking congressional authorization. As a prototype it is to serve as the model for the first generation of commercial FBRs and will be fully licensed. There is no utility financial participation anticipated in this project. The optimistic schedule for a project of this size is 12-1/2 years from congressional authorization to full power operation. An additional two years of preauthorization work makes the overall schedule 14-1/2 years long.

This project will deal with all of the issues and requirements that face a utility in selecting a power plant design for commercial application. Some of the design requirements facing a typical government project must be assessed from the perspective of a utility to meet the high availability and reliability criteria expected for a commercial plant. The schedule has a minimum duration of almost 11 years and a maximum duration of 18-1/2 years.

The duration of the first activity on the schedule, preparation to submit the PSAR, will take about 3 years from the start of the project and nominally 1 year from the time the project is authorized by Congress. The minimum time to accomplish this work will be 12 months from authorization and it could take almost 2 years. This will depend on the availability of the teams which have been involved in FBR work, especially licensing.

The issue of the construction permit (CP) normally takes 3 years from the time the PSAR is submitted. The basic NRC criteria for licensing an FBR should have been defined with the CDS plant. Since this is the first project where public hearings will be conducted, there is little or no probability that the project can recieve a $C P$ in less than 2-1/2 years. Quite realistically it could take 5 years to get the $C P$.

The component testing for the prototype will be nearly as exhaustive as it may have to be for the CDS project due to the need to verify the components for a larger plant prior to gaining any operating experience on the CDS. It 
will be scheduled to take about 4 years following congressional authorization of the project with a minimum of 40 months and a maximum of about 5 years. This is simular to the component testing discussed for the CDS project.

The construction of the prototype is scheduled to take 6-1/2 years.

The FSAR for the prototype should be submitted about 5 years after the $C P$ issue. If the engineering in support of the $C P$ is mature and the project can support it the time could be minimized and submittal can perhaps he as early as 4-1/2 years after $C P$ issue. Under any circumstances the FSAR should not be submitted later than 5-1/2 years after the CP issue. The NRC will require that the plant be within two years of completion prior to docketing the application.

Once the FSAR has been submitted a complete licensing review and a complete set of public hearings will follow. This is scheduled to take 2 years which is similar to large LWR licensing times. It will take at least 1-1/2 years on this first fully licensed LMFBR and could take as long as 5 years to get the operating license issued.

Initial criticality on the prototype is most likely to be about $1 / 2$ year after construction is complete and about 1 to 2 months after receipt of the operating license.

Start of full power operation for the prototype is estimated to take $11 / 2$ years after both construction completion and operating license issue. The test program following fuel loading will be exhaustive and little probability exists that it can be completed in less than 14 months with some probability that it could take 3 years.

Replicate Plants and Commercial Breeder Reactor

For the Compressed Strategy the first replicate(R-1) will have its NSSS award/site selection a nominal 14-1/2 years after the decision to authorize the CDS plant. Since $R-1$ is the third plant in less than 15 years it would be characterized as a growth industry. Many of the individual contributors to the CDS plant would be available to contribute to R-1. However at the time of NSSS award/site selection there will only be about 4 reactor years of 1 arge LMFBR operating experience. 
As in previous strategies, $R-1$ is the first complete replication of the prototype and is the first in a program leading to a mature industry as exemplified by CBR-1. It will then take about 2 years to prepare and submit the PSAR, EIS, and other permits for R-1. This could be done in a little less than $1-1 / 2$ years or may take nearly $2-1 / 2$ years. The responsibility is charged to the utility to complete these tasks in a timely manner, and the procedures vary from state to state. The mature plant and stable licensing environment supporting the standardized design leads to a duration for this activity of about 1 year with a 6 month minimum and a 18 month maximum for CBR-1. There will be no need to schedule a component test program because components of this design are operating in the prototype.

The $C P$ issue for $R-1$ is scheduled to take 3 years, as it is on the prototype. This is due to the site specific licensing requirements and the introduction of a utility licensee. The NRC will have had a period of 3 years since the prototype operating license issue and the utility will be seeking $i$ ts first FBR license. The $C P$ could be issued in 2-1/3 years or it could take 4-1/2 years depending on the effectiveness of the whole licensing team. The CBR-1 should receive a CP in 2-1/4 years with a minimum of 19 months and a maximum of 36 months. The benefits of standard design, complementary vendor, AE, utility and NRC efforts will all contribute to this shortening of time and narrowing of uncertainty. The small reactor operating experience base from the CDS and Prototype will also add to the uncertainty. The submittal of the FSAR for R-1 should occur about 4-1/4 years or so after the construction permit is issued. Since the design has been licensed before and the analys is has all been reviewed for the generic design then all that needs to be satisfied are the additional site specific requirements for tornado, seismic, flond, and so forth. The job may be done in 5 years or may only take 4 years but the window is still about one year in support of the operating license need. For the CBR the effort required to prepare the FSAR will be less due to its standard features and previous licensing activities but the work at the NRC will probably schedule it for 4 years plus or minus 3 months due to the licence application load. This will still support the issue of the operating license in time to jupport the project schedule. 
Construction completion for $R-1$ will be $6-1 / 2$ years after $C P$ issue. It will take 5 years minimum and up to 8-1/4 years to get through this first project for a utility. Construction of this kind of a facility will always be a challenge and the many factors discussed in the CDS plant and prototype plant still come to bear here. The CBR-1 will have a construction duration of 6 years with a minimum of 5 years and a maximum of over 8 years. This is still due to complexity and quality requirements of this kind of a machine.

Commercial operation for R-1 will take about 9 months with a minimum of 8 months and a maximum of 2-1/4 years. The pressures of being a commercial venture will necessitate that the operator plan the test program to support the earliest prudent escalations to full power and a full power demonstration to get the plant into the rate base. For CBR-1 this will be a 6 month activity with a minimum of 5 months and a maximum of something like 19 months reflecting increasing confidence and learning.

The R-1 project schedule has a total duration of about 12 years with a range from $9-1 / 2$ to $18-1 / 2$ years, which reflects the serious development programs. The CBR schedule is expected to be 10 years with a range from $7-1 / 2$ to 13 years, which is based on the learning, supportive regulatory environment, and a high growth industry following a serious government development program.

\section{B.4 STRATEGY D: DELAYED COMPRESSED}

This strategy is identical to the Compressed Strategy with the exception of a 5-year delay in obtaining congressional authorization for the project (Figure B.4). This delay would allow completion of more conceptual work and evaluation of some component designs. At the same time, the prospective vendors have no incentive to retain skilled or experienced personnel for this work. These effects introduce some changes in the time distributions for the developmental plant only. The remainder of the time distributions are the same as the Compressed Strategy.

\section{B.5 STRATEGY E: COMPONENT TESTING}

This strategy, shown in Figure B.5, incorporates a major program of selecting, fabricating, and testing designs to develop confidence in the equipment around which the plant will be designed and built. For analys is purposes the 


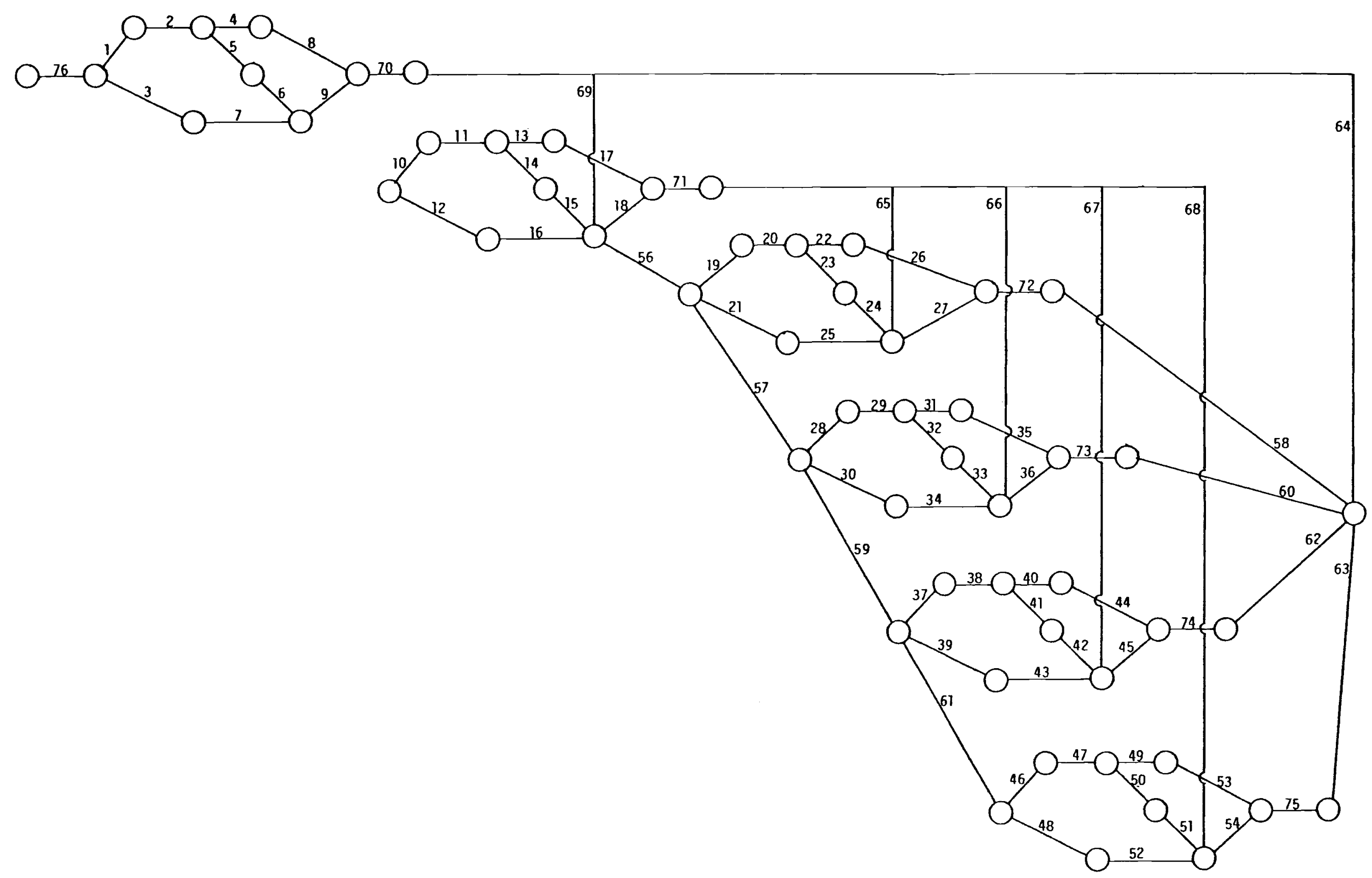

FIGURE B.4. Detailed Activity Network - Delayed Compressed Strategy "D"

TABLE B.4. Delayed Compressed Strategy "D" Time Distribution Inputs

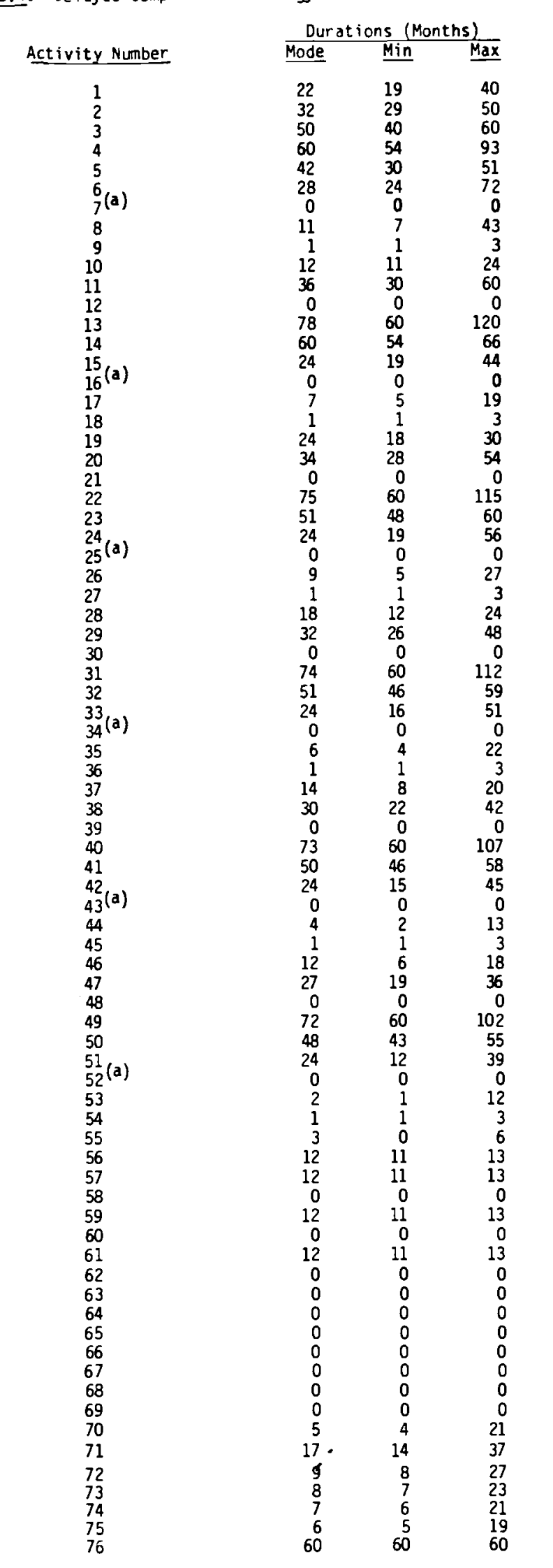

(a) No further constraint on licensing after completion of component testing. 


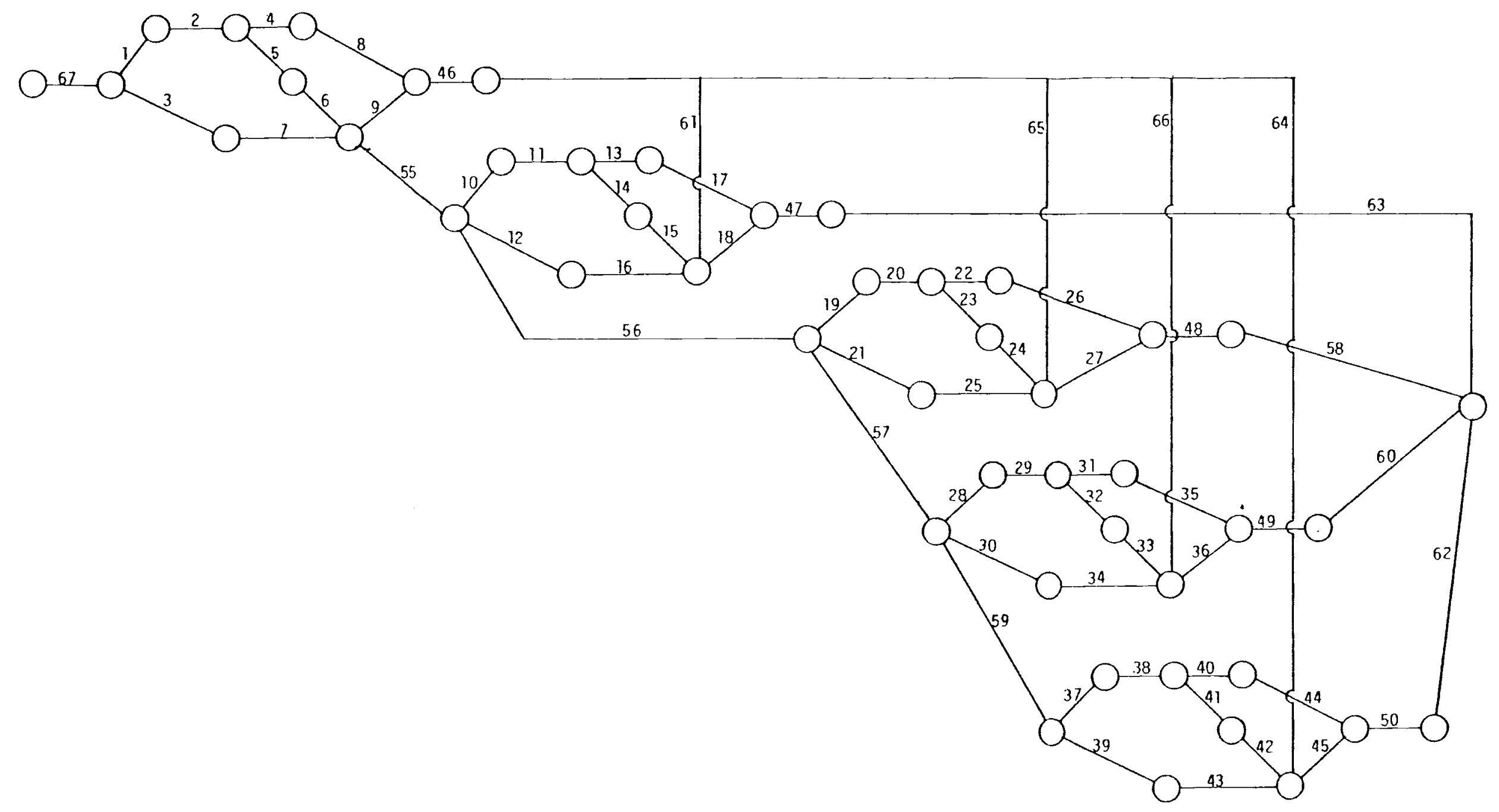

TABL.E B.5. Component Test ing Strategy "E" Time Distribution Inputs

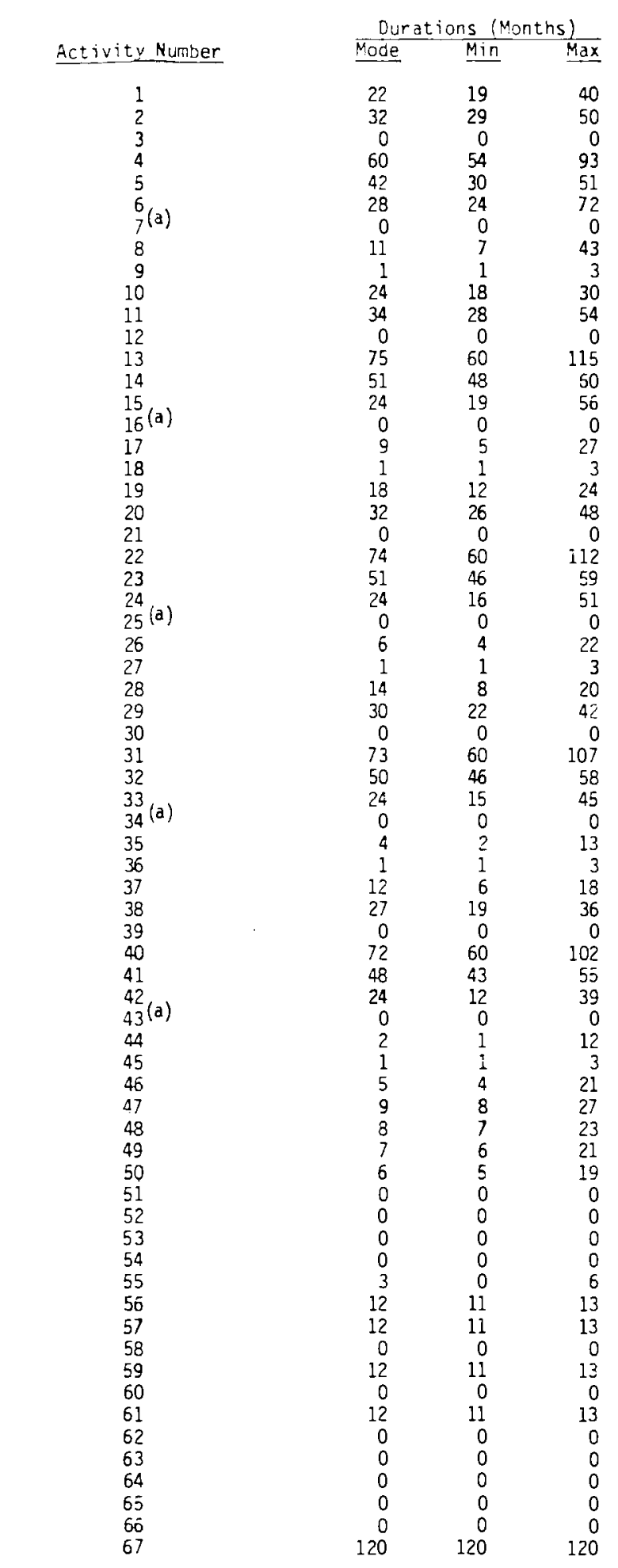

FIGURE B.5. Detailed Activity Network - Component Testing Strategy "E."

(a) No further constraint on licens inc after completion of component testing. 
component testing program is estimated to take 10 years. At that time congress will authorize a 1000-MWe FBR project. In this analysis the CDS schedule discussed in the Sequential Strategy (Section B.1) is used and all of the power plants are $1000 \mathrm{MWe}$. The schedules are the same as those used for the replicate plants and CBR-1 in the Compressed Strategy. The second plant will be started when the first plant receives its $\mathrm{OL}$. The demonstration of 1 year's power operation is a prerequisite to the issue of each of the following plant's 0L. After the second plant one plant will be started each year and since they are all essentially replicates of the first plant, the fifth plant is assumed to be the mature industry plant.

\section{B.6 STRATEGY F: DIRECT PROTOTYPE}

The Direct Prototype Strategy, Figure B.5, is one that proceeds with building an improved version of the CDS plant on the schedule for the prototype discussed in Section B.1. This plant is designed to meet the requirements of a utility. The plant is then replicated at 1000 MWe through to the fifth plant in the strategy as a mature industry plant. The second plant is started when the first receives its operating license and is followed by one plant each year for the next three years. The demonstration of one year of power operation in the COS Plant, which is fully licensed, is prerequisite to issue of the operating license of each of the following plants operating license issue. The scheduies used are those for the replicates in the Compressed Strategy since there is no scaling, and the approach to commercialization is rapid.

\section{B.7 STRATEGY G: DIRECT REPLICATE}

This strategy is made up of five 1000-MWe improved CDS plants shown in Figure B.7. The first plant is built as a licensable but not licensed plant. The second plant, which is committed by award of NSSS and site selection following a year of power operation of the CDS, will incorporate the lessons learned in the design, construction and operation of the CDS plant and will be fully licensed. The third, fourth, and fifth plants are committed one per year following Replicate-1. The time distributions were developed for these plants using the same set of assumptions that were discussed for the Sequential Strategy. 



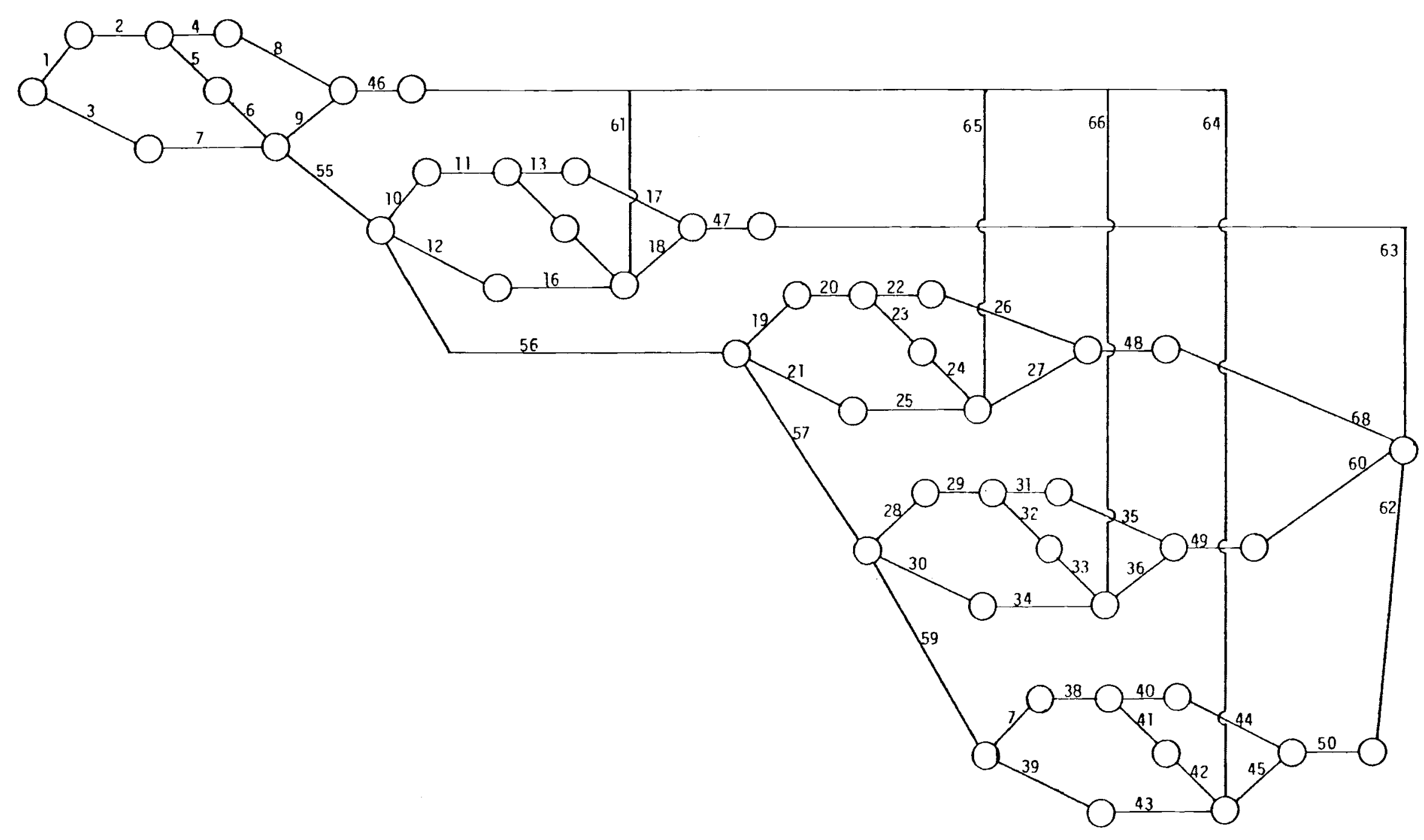

FIGURE B.6. Detailed Activity Network - Direct Prototype Strategy "F"

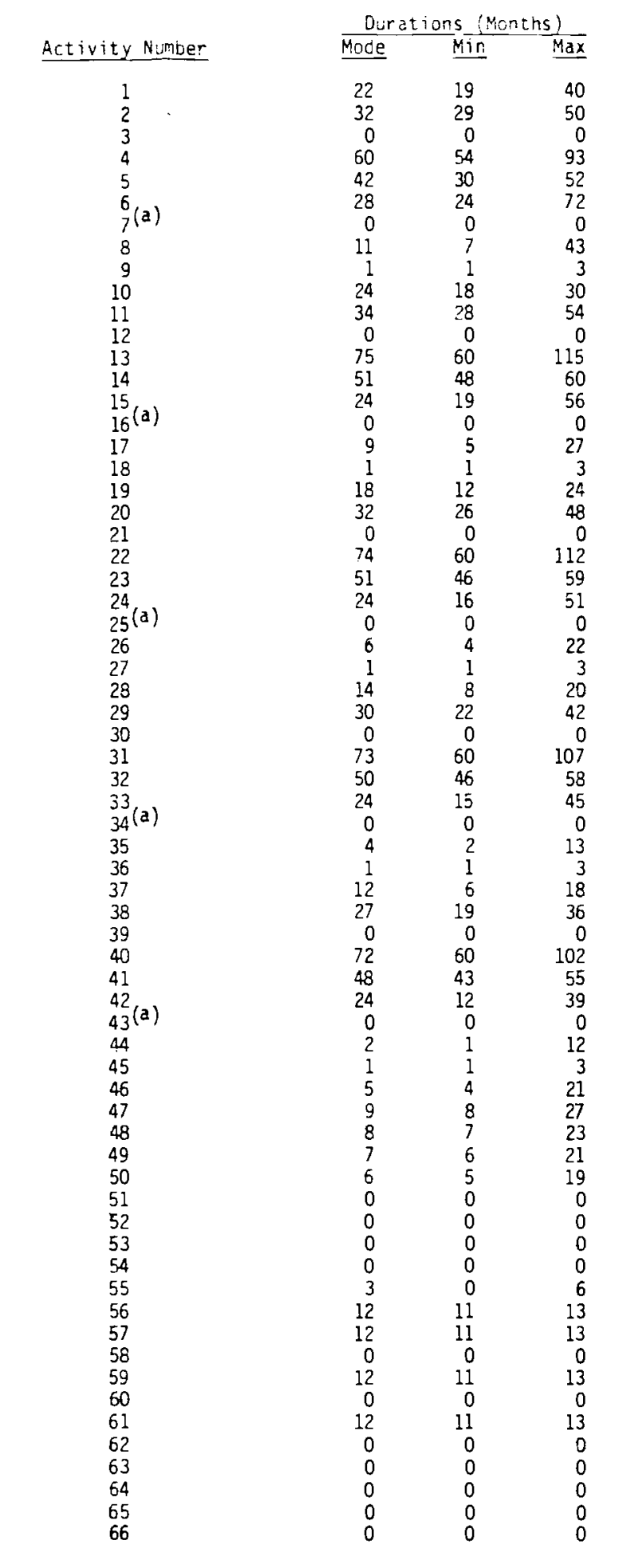

(a) No further constraint on licensing after completion of component testing. 


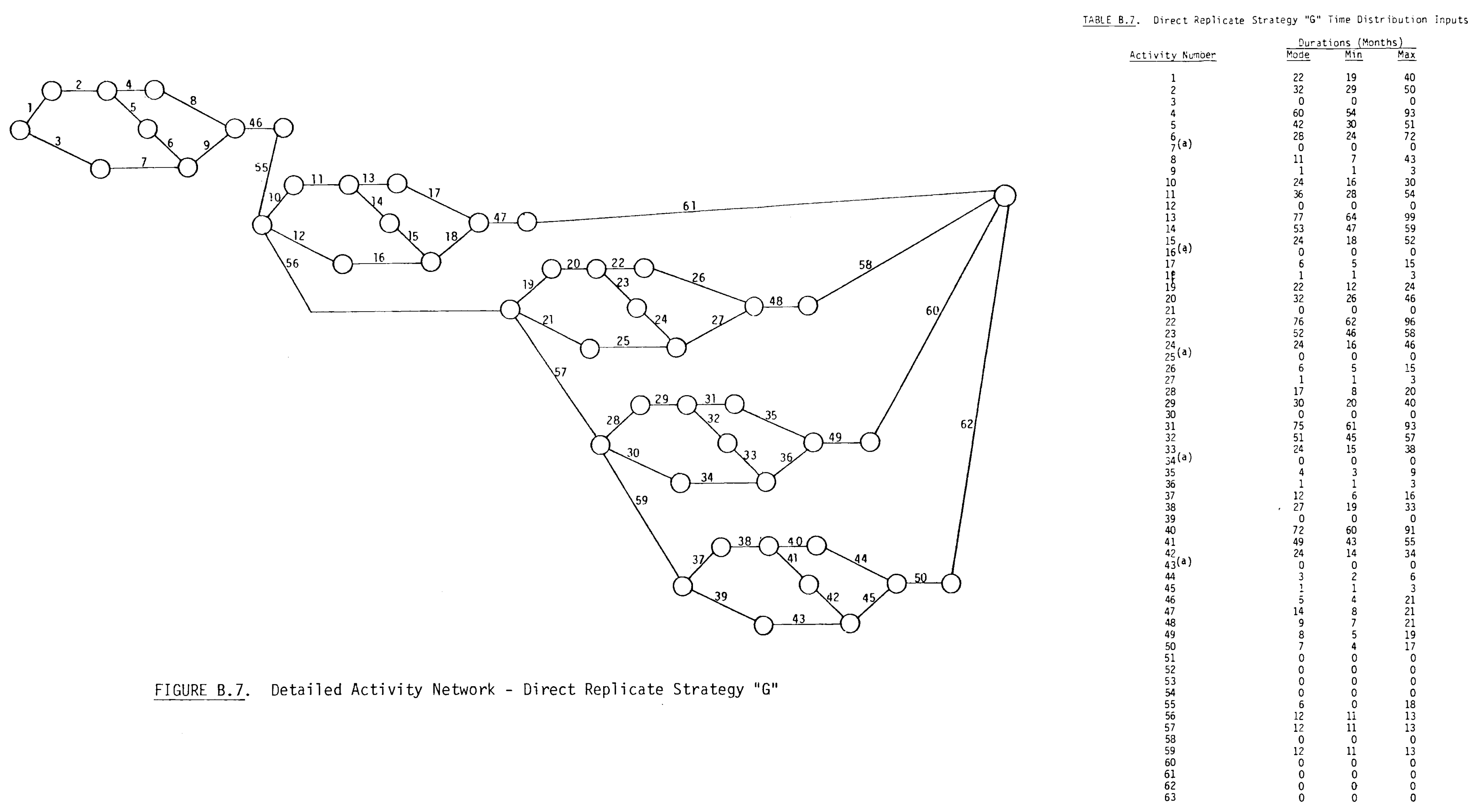

FIGURE B.7. Detailed Activity Network - Direct Replicate Strategy "G"

(a) No further constraint on licensing after completion of component testing. 


\section{DISTRIBUTION}

No. of

Copies

OFFSITE

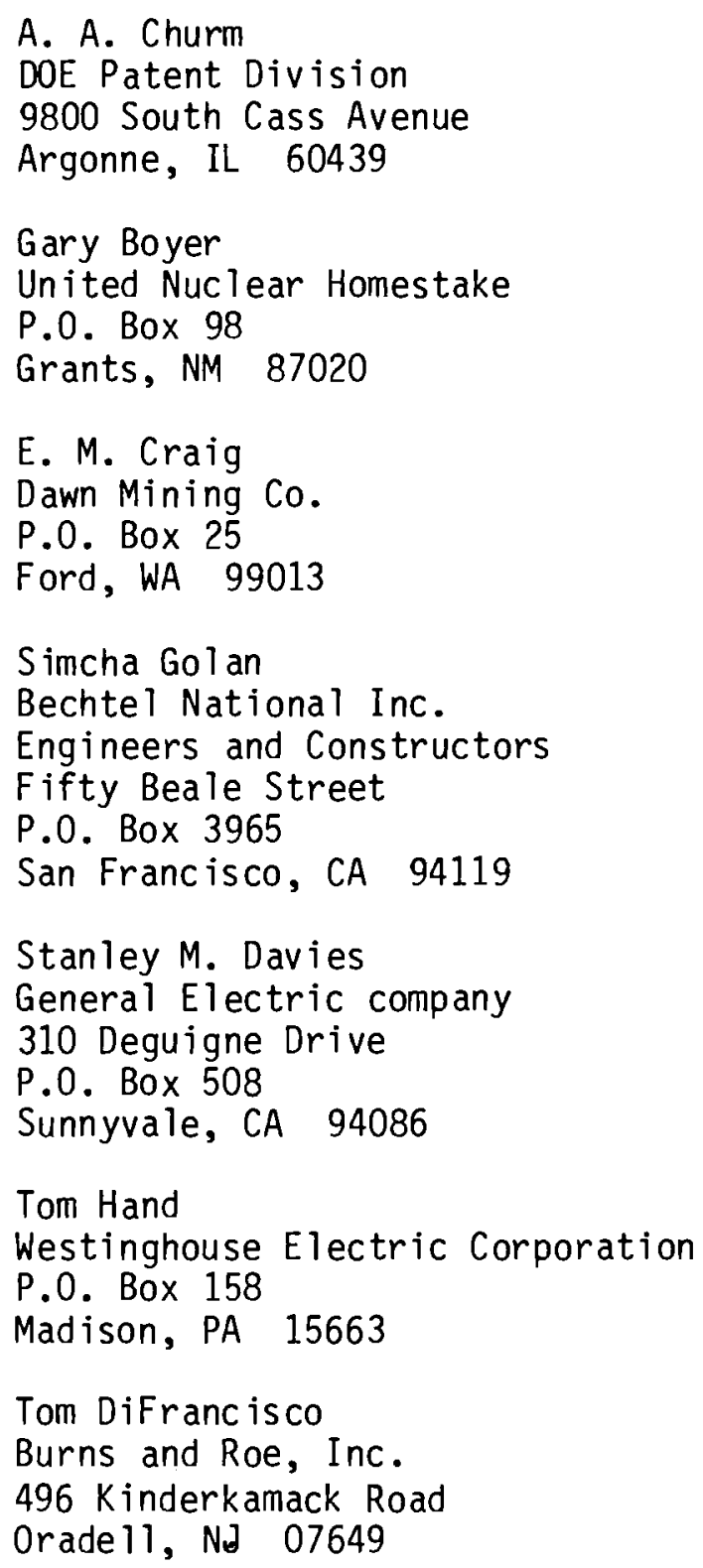

A. A. Churm

DOE Patent Division

9800 South Cass Avenue

Argonne, IL 60439

Gary Boyer

United Nuclear Homestake

P.0. Box 98

Grants, NM 87020

E. M. Craig

Dawn Mining Co.

P.0. Box 25

Ford, WA 99013

Simcha Golan

Bechtel National Inc.

Engineers and Constructors

Fifty Beale Street

P.0. Box 3965

San Francisco, CA 94119

Stanley M. Davies

General Electric company

310 Deguigne Drive

P.0. Box 508

Sunnyvale, CA 94086

Tom Hand

Westinghouse Electric Corporation

P.0. Box 158

Madison, PA 15663

Tom DiFrancisco

Burns and Roe, Inc.

496 Kinderkamack Road

Orade 11, Nd 07649

No. of

Copies

John H. Crowley

United Engineers and Constructors 300 South 17 Street

Philadelphia, PA 19101

George Garabedian

Stone and Webster Engineering Corp.

Power Division

245 Summer Street

Boston, MA 02107

Judy Grange

Science Applications, Inc.

40 Denver Tech Center West

7925 E. Prentice

Englewood, CO 80111

Bob Miller

United Nuclear

Drawer QQ

Gallup, NM 87301

Char les Stanley

Kerr McGee

Box 218

Grants, NM 87020

C. L. Storrs

C-E Power Systems

Combustion Engineering, Inc.

1000 Prospect Hill Rd.

Windsor, CT 06095

440

DOE Technical Information Service

P. 0. Box 62

Oak Ridge, TN 37830 
No. of

Copies

Noe 1 Gonzaga

S. M. Stoller Corporation 1250 Broadway

New York, NY 10001

10 J. P. Thereault

U.S. Department of Energy Washington D.C. 20545

W. W. Ballard

U.S. Department of Energy Washington D.C. 20545

S. T. Brewer

U.S. Department of Energy Washington D.C. 20545

Hugh Kendrick

U.S. Department of Energy Washington D.C. 20545

R. G. Staker

U.S. Department of Energy Washington D.C. 20545

J. R. Longenecker

U.S. Department of Energy Washington D.C. 20545

John Patterson

U.S. Department of Energy Washington D.C. 20545

Roger Gagne

U.S. Department of Energy Washington D.C. 20545

Tom Dillon

U.S. Department of Energy Washington D.C. 20545

Neal Goldberg

U.S. Department of Energy Washington D.C. 20545

Richie Williamson

U.S. Department of Energy Washington D.C. 20545
No. of

Copies

Dave Bodde

U.S. Department of Energy

Washington D.C. 20545

Bob Bown

U.S. Department of Energy

Washington D.C. 20545

Eli Goodman

U.S. Department of Energy

Washington D.C. 20545

A. J. Snyder

U.S. Department of Energy

Washington D.C. 20545

Ross Humphreys

U.S. Department of Energy

Washington D.C. 20545

Tom Werner

U.S. Department of Energy

Washington D.C. 20545

D. M. Blanchfield

Grand Junction Office

U.S. Department of Energy

P.0. Box 2567

Grand Junction, CO 81501

B. Boyer

Grand Junction office

U.S. Department of Energy

P.0. Box 2567

Grand Junction, CO 81501

M. E. Crew

Grand Junction office

U.S. Department of Energy

P.0. Box 2567

Grand Junction, CO 81501

D. L. Curry

Grand Junction Office

U.S. Department of Energy

P.0. Box 2567

Grand Junction, CO 81501 
No. of

Copies

J. Franco

Grand Junction Office

U.S. Department of Energy

P.0. Box 2567

Grand Junction, CO 81501

P. de Vergi

Grand Junction Office

U.S. Department of Energy

P.0. Box 2567

Grand Junction, CO 81501

D. L. Everhart

Grand Junction office

U.S. Department of Energy

P.0. Box 2567

Grand Junction, CO 81501

M. Hansen

Grand Junction Office

U.S. Department of Energy

P.0. Box 2567

Grand Junction, CO 81501

R. C. Malan

Grand Junction Office

U.S. Department of Energy

P.0. Box 2567

Grand Junction, CO 81501

L. Kovisars

MET Research

2403 Thomas Avenue

Dallas, TX 75201

R. A. MCLaren

Union Carbide Nuclear Division

P.0. Box P Mail Stop \#17

Oak Ridge, TN 37830

C. E. Ford

Union Carbide Nuclear Division

P.0. Box P Mail Stop \#17

Oak Ridge, TN 37830
No. of

Copies

P. Rogers

Bendix Field Engineering Corporation

Grand Junction Operations

P.0. Box 1569

Grand Junction, CO 81501

Lewis Perl

National Economic Research

As sociation

5 Wor ld Trade Center

New York, NY 10048

Martin Becker

Rensselaer Poly Tech

Nuclear Engineering Department

Troy, NY 12181

Prof. Deverle P. Harris

University of Arizona

Department of Mining and Geological Engineering

Tucson, AZ 85721

Prof. A. S. Manne

834 Esplanada Way

Stanford, Ca 94305

Prof. J. Daniel Khazzoom

380 Kensington Way

San Francisco, CA 94127

Prof. Wayne J. Davis

University of Illinois

Dept. of General Engineering

Urbana, IL 61801

Dr. Lawrence Droutman

Westinghouse Electric Corporation

P.0. Box 158

Madison, PA 15663

Randall L. Beatty

Science Applications, Inc.

800 Oak Ridge Turnpike

P.0. Box 843

Oak Ridge, TN 37830 
No. of

Copies

ONSITE

2 DOE Richland Operations Office

P. A. Craig

H. E. Ransom

79 Pacific Northwest Laboratory

R. L. Aaberg

C. H. Bloomster

A. J. Boege 1 (10)

J. B. Burnham (20)

L. L. Clark

M. J. Clausen

B. M. Cole

D. E. Deonigi

R. L. Enge 1

R. M. Fle ischman

D. W. Fraley

S. Goldsmith

D. L. Hall

C. R. Hann
No. of

Copies

J. N. Hart ley

H. Harty

A. J. Haverfield

C. M. Heeb

J. C. King

R. C. Liikala

J. W. Lithchfield

J. A. Mahaffey

R. P. Marshall

P. J. McGoey

R. W. Mckee

E. T. Merrill

D. F. Newman

R. E. Nightingale

D. E. Olesen

P. F. Piepel

R. J. Sorensen (10)

A. M. Sutey

M. K. White

0. J. Wick

L. D. Williams

Publishing Coordination (2)

Technical Information (5) KE 